\title{
UMA PROPOSTA DE CARREGAMENTO INCREMENTAL DE FLUXOS VEICULARES PARA ESTIMAÇÃO DE MATRIZ O-D SINTÉTICA
}

Dissertação apresentada à Escola de Engenharia de São Carlos da Universidade de São Paulo, como parte dos requisitos para obtenção do título de Mestre em Engenharia Civil: Planejamento e Operação de Sistemas de Transportes.

Orientador: Prof. Titular Eiji Kawamoto 
AUTORIZO A REPRODUÇÃO E DIVULGAÇÃO TOTAL OU PARCIAL DESTE TRABALHO, POR QUALQUER MEIO CONVENCIONAL OU ELETRÔNICO, PARA FINS DE ESTUDO E PESQUISA, DESDE QUE CITADA A FONTE.

Ficha catalográfica preparada pela Seção de Tratamento da Informação do Serviço de Biblioteca - EESC/USP

B547p Uertoncini, Bruno Vieira
Uma proposta de carregamento incremental de fluxos
veiculares para estimaça de matriz O-D sintética / Bruno
Vieira Bertoncini i orientador Eiji Kawamoto. -- São
Carlos, 2007.
Dissertação (Mestrado-Programa de Pós-Graduação em
Engenharia Civil. Área de Concentração: Planejamento e
Operação de Sistemas de Transportes) -- Escola de
Engenharia de São Carlos da Universidade de São Paulo,
2007.
1. Planejamento de transportes. 2. Estimação de
matrizes D. 3. Fluxos de veículos. 4. Carregamento
incremental. 5. Rede viária congestionada. 6. Rede viária
não-congestionada. I. Título.


Candidato: Engenheiro BRUNO VIEIRA BERTONCINI

Dissertação defendida e julgada em 08^®3-2007 perante a Comissão Julgadora:

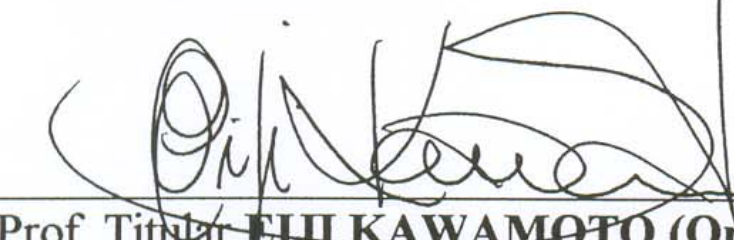

Prof. Tit Ar Fम KAWAMOTO (Orientador)

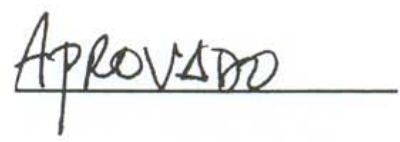

(Escola de Engenharia de São Carlos/USP)

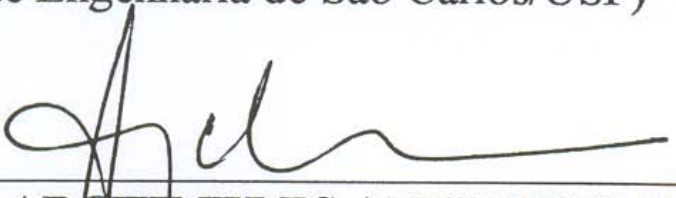

Prof. Dr. AROHIMEDES AZEVEDO RAIA JUNIOR

ARROUHAO

(Universidade Federal de São Carlos/UFSCar)

Pay $\rightarrow$ Fof. Dr. CARLOS FELIPE GRANGEIRO LOUREIRO

AProNAxO

(Universidade Federal do Ceará/UFC)

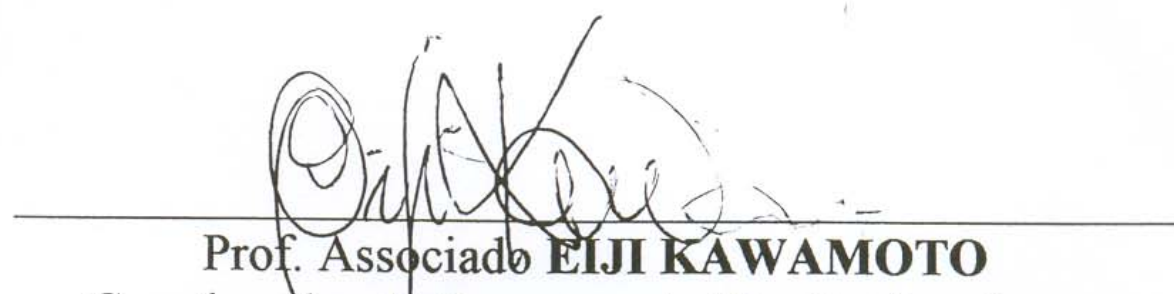

Coordenadord $\phi$ Programa de Pós-Graduação em em Engenharia de Transportes

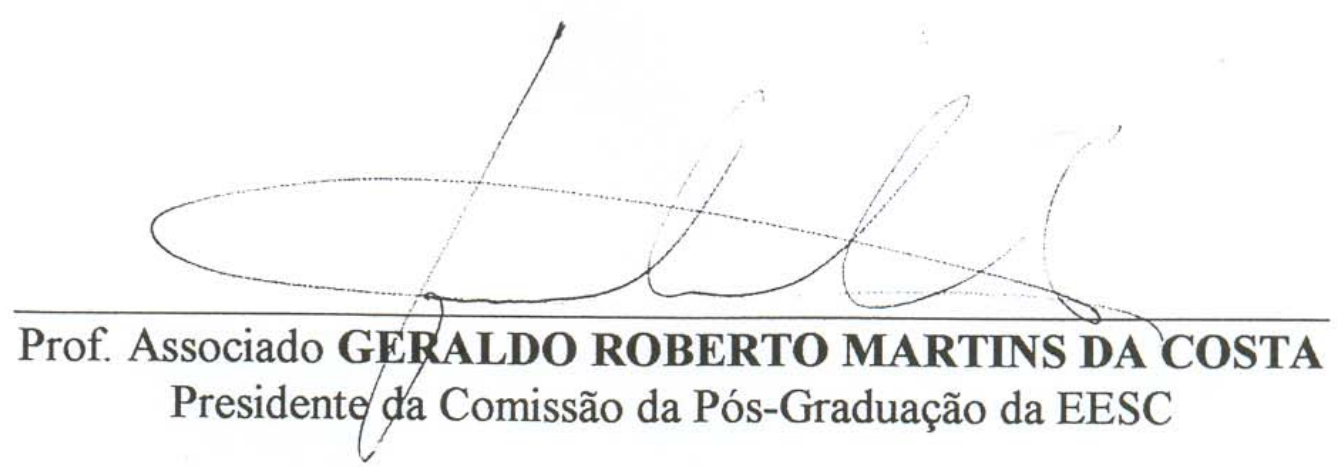


Aos meus pais e à minha irmã que sempre me apoiaram e me incentivaram durante todos estes anos. Eles mais do que ninguém merecem este reconhecimento.

Ao Professor Eiji Kawamoto por ter sempre me ajudado 
Durante esses dois anos de trabalho várias pessoas contribuíram de alguma maneira para que eu conseguisse concluir os objetivos aos quais me propus. Gostaria então de agradecer a estas pessoas e desde já peço desculpas àqueles que por um lapso de memória tenha esquecido de aqui manifestar minha gratidão.

Inicialmente gostaria de agradecer ao Professor Eiji, com quem tive o prazer e a honra de conviver durante estes dois anos de mestrado. Ele mostrou ser mais do que um orientador foi um excelente amigo, e como tal, sempre procurou com seus sábios conselhos me auxiliar no desenvolvimento do trabalho. Além disso, tenho que agradecer e muito a paciência que ele teve nos momentos finais da pesquisa.

Gostaria também de agradecer ao Professor Sergio Henrique Demarchi a quem devo muito, pois foi ele que em 2001 me convidou a fazer pesquisa e através da iniciação científica pude dar os primeiros passos nesta área. Sem a ajuda e incentivo dele provavelmente não teria tido esta oportunidade de prosseguir os estudos. Também gostaria de agradecer à Cláudia sua esposa que em várias oportunidades intercedeu por mim em momentos difíceis.

Uma outra felicidade que tive foi a oportunidade de trabalhar ao lado de três bons amigos, dois são da boa terra, Cira Souza Pitombo e Mateus Araújo e Silva e o terceiro com quem convivi por pouco tempo, mas que me ajudou bastante foi o Professor Marcus Seraphico. A estes meus amigos definitivamente não terei palavras para agradecer, pois sempre me ajudaram e muito no transcorrer desta pesquisa, não apenas esclarecendo algumas dúvidas, mas estando ao meu lado como companheiros que são nos momentos mais difíceis do trabalho.

Vários outros amigos me auxiliaram e possibilitaram que algumas dúvidas fossem sanadas assim farei um agradecimento coletivo aos amigos: Adalberto Faxina, Ana Paula Furlan, André Cunha, Andréa Júlia, Camilla Carrara, Daniel Anijar, Diogo Colella, Gustavo Manzato, Karênina Teixeira e Márcia Lika. Além de me ajudarem sempre se mostraram companheiros em vários momentos. 
Gostaria de agradecer aos funcionários do departamento: Alexandre, Beth, Heloisa, Magali, Sueli que sempre me auxiliaram na resolução das questões burocráticas. À dona Magali gostaria de agradecer ao auxílio prestado durante o período em que fui monitor de disciplinas e ao carinho que ela sempre dedicou durante este período de convívio. À Beth e à Heloisa gostaria de agradecer pela dedicação que tiveram nos trâmites para a realização da defesa. Ao Toco e ao Beto também gostaria de manifestar meus agradecimentos por sempre solucionarem os problemas técnicos apresentados pelo computador e pela impressora, que costumeiramente surgem nos momentos impróprios.

Não poderia deixar de fora o agradecimento aos amigos Gigante, Francis Kakuda, Jesner, João, Jorge Escalante, Leandro Piassi, Paulo Toyama e Weslley Novaes que nos momentos difíceis do trabalho me ajudaram mostrando que às vezes é importante pararmos e pensarmos em outras coisas para que os problemas possam ser resolvidos.

Este trabalho também teve a contribuição dos amigos Antonio Carlos Dinato e sua esposa Kika na correção gramatical do português e do amigo Michael Saunders que me auxiliou na correção ortográfica do Abstract.

Gostaria de agradecer a meu amigo Ed Pinheiro Lima, que sempre se mostrou companheiro e com seus questionamentos me ajudou a descobrir mais sobre o funcionamento do QUEENSOD e do INTEGRATION, além de me enviar artigos que eu não havia conseguido encontrar.

Agradeço também aos meus Professores do departamento de transportes aqui da EESC que me ajudaram e permitiram com que eu adquirisse mais conhecimento. Aos Professores José Leomar e Glauco que me supervisionaram na monitoria.

Também gostaria de agradecer aos Professores da Universidade Estadual de Maringá com quem tive a oportunidade de conviver e adquirir conhecimentos, em especial aos Professores Fernanda Antonio Simões e José Kiynha Yshiba.

Gostaria também de deixar meus agradecimentos aos Professores Carlos Felipe Grangeiro Loureiro e José Reynaldo Anselmo Setti que apresentaram muitas contribuições para o desenvolvimento deste trabalho.

Por fim, agradeço a Coordenadoria de Aperfeiçoamento de Pessoal de Nível Superior - CAPES pela bolsa de estudos concedida. 
"Feliz aquele que transfere o que sabe e aprende o que ensina."

(Cora Coralina). 
BERTONCINI, B. V. Uma proposta de carregamento incremental de fluxos veiculares para a estimação de matriz O-D sintética. 2007. 137 p. Dissertação (Mestrado) - Escola de Engenharia de São Carlos, Universidade de São Paulo, São Carlos, 2007.

Neste trabalho é proposto um método de carregamento incremental dos fluxos veiculares para a estimação de matriz O-D sintética. A principal motivação para o desenvolvimento deste trabalho está na complexidade dos métodos de estimação de matriz sintética pelo método iterativo, que tem conduzido a resultados não satisfatórios. O método de carregamento incremental, ora proposto neste trabalho, pode ser definido como o inverso do método de alocação incremental de viagens aos arcos de uma rede viária. A matriz O-D obtida com este método é o resultado da soma sucessiva das sub-matrizes estimadas através das parcelas dos fluxos observados nos arcos da rede. Este método pode ser aplicado em qualquer tipo de rede viária: congestionada ou não congestionada e com ou sem continuidade de fluxo. Para verificação do desempenho do método foram realizados testes experimentais, nos quais os resultados obtidos foram comparados com os valores observados. O desempenho do método incremental não se mostrou satisfatório. Assim, com o intuito de verificar a sua utilidade como um método alternativo os mesmos dados foram processados através de dois métodos iterativos. Os resultados mostraram que os erros são ainda maiores do que os obtidos pelo método proposto. A principal conclusão deste trabalho é que o método incremental pode ser usado como uma alternativa aos métodos iterativos.

Palavras-chave: Planejamento de Transportes; Estimação de Matrizes O-D; Fluxos de Veículos; Carregamento Incremental; Rede Viária Congestionada ; Rede Viária NãoCongestionada. 
BERTONCINI, B. V. A proposal for incremental loading in traffic flows for synthetic $\mathbf{O}$ D matrix estimation. 2007. 137 p. Dissertation (Master Thesis) - Engineering School of São Carlos, University of São Paulo, São Carlos, 2007.

A synthetic O-D matrix estimation method, based on incremental loading of traffic flow, was proposed in this work. This research was motivated because of the complexity of the iterative methods for synthetic matrix estimation that might produce bias accumulation in the results. The referred incremental loading method could be defined as the inverse of the incremental assignment method for trips to links of a traffic network. The O-D matrix is gathered by successively summing the sub-matrices obtained from parts of the traffic flow counted on the links of the traffic network. This method could be applied to any traffic networks: congested or uncongested and with or without volumetric continuity. As a part of verification proceeding, several experimental tests were carried out to evaluate the method performance. In these tests the estimated results were compared with the real values. These results show that the incremental loading method performance was not satisfatctory. Thus, aiming to test the utility of the incremental method, a second round of experimental tests was conducted to evaluate two iterative methods. In these second round tests, the results show that theses methods performance was worse those of the incremental method. The main conclusion of this work is that the incremental loading method for synthetic matrices estimation could be used as an alternative to the iterative methods.

Key-words: Transportation Planning; Estimation of O-D Matrices; O-D Trip Table; Traffic Flows; Incremental Loading; Congested Traffic Networks; Uncongested Traffic Networks. 


\section{LISTA DE FIGURAS}

\section{I = INTRODUÇÃO}

Figura 1.1: (a) Representação gráfica das demandas; (b) Representação matricial de demandas.

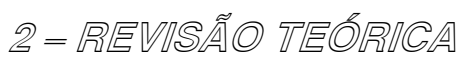

Figura 2.1: Rede hipotética para ilustrar o modelo sintético

Figura 2.2: Representação dos três estados de comportamento das moléculas de um gás: (a) macro e meso-estados representados; (b) respectivos micro-estados do mesoestado representado na parte (a)

Figura 2.3: Forma matricial de representar o sistema de equações para a rede viária da Figura 2.1.

Figura 2.4: Representação do escalonamento de uma matriz aumentada

Figura 2.5: Curva representativa do valor mais provável de $Q_{13}$ para a rede da Figura 2.1

Figura 2.6: Determinação do valor mais provável de $Q_{13}$, considerando matriz semente com $s_{13}=20$ veíc/h.

Figura 2.7: Continuidade em arcos contíguos: (a) Rede com continuidade; (b) Rede sem continuidade

Figura 2.8: Estrutura de funcionamento do QuEENSOD (Fonte: Manual do usuário do QUEENSOD, VAN AERDE, 1998)

B $=$ 财店TOD(0

Figura 3.1: Estrutura do Método

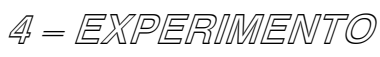

Figura 4.1: Hipotética rede viária utilizada para verificar o desempenho dos modelos de estimação de matrizes O-D. 
Figura 5. 1: Distribuição das freqüências absolutas em função do erro relativo considerando o carregamento incremental dos fluxos.

Figura 5. 2: Somatório das diferenças absolutas entre a matriz O-D “real” e a estimada em função dos casos analisados e dos programas utilizados.

Figura 5. 3: Somatório das diferenças quadráticas entre a matriz O-D “real” e a estimada em função dos casos analisados e dos programas utilizados.

Figura 5. 4: Distribuição das freqüências absolutas em função do erro relativo. Viagens estimadas pelo QUEENSOD

Figura 5. 5: Distribuição das freqüências absolutas em função do erro relativo. Viagens estimadas pelo TransCAD.

Figura 5. 6: Distribuição dos dez maiores valores de erros relativos em função da distância (Considerando o QUEENSOD).

Figura 5. 7: Distribuição dos dez maiores valores de erros relativos em função da distância (Considerando o TransCAD). 


\section{LISTA DE TABELAS}

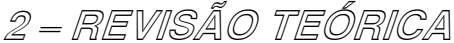

Tabela 2.1: Matriz O-D para a rede hipotética da Figura 2.1 (Fonte: PARAMAHAMSAN, 1999)

Tabela 2.2: Matriz O-D semente para a rede da Figura 2.1 (Fonte: PARAMAHAMSAN, 1999)

Tabela 4.1: Características dos arcos da rede apresentada na Figura 4.1

Tabela 4.2: Hipotética Matriz O-D da rede apresentada na Figura 4.1....

Tabela 4.3: Fluxos alocados à rede viária da Figura 4.1 através do processo de equilíbrio do usuário

Tabela 4.4: Matriz O-D estimada pelo carregamento incremental de volumes, utilizando o QUEENSOD para maximizar a entropia

Tabela 4.5: Matriz O-D estimada pelo carregamento incremental de volumes, utilizando o TransCAD para maximizar a entropia.

Tabela 4.6: Fluxos estimados através do carregamento incremental de volumes para estimar matriz O-D, considerando QUEENSOD e TransCAD.

Tabela 4.7: Matriz semente binária, utilizada no Caso B e no processo incremental......

Tabela 4.8: Matriz O-D estimada pelo QUEENSOD considerando o processo iterativo e a utilização de uma matriz semente binária.

Tabela 4.9: Matriz O-D estimada pelo TransCAD considerando o processo iterativo e a utilização de uma matriz semente binária

Tabela 4.10: Fluxos estimados pelo processo iterativo para a rede viária da Figura 4.1, considerando matriz semente unitária

Tabela 4.11: Matriz semente utilizada no Caso $C$ equivalente a $70 \%$ da matriz "real"

Tabela 4.12: Matriz O-D estimada pelo QUEENSOD, considerando o processo iterativo e a utilização de uma matriz semente equivalente a $70 \%$ da matriz "real" 
Tabela 4.13: Matriz O-D estimada pelo TransCAD, considerando o processo iterativo e a utilização de uma matriz semente equivalente a $70 \%$ da matriz "real”

Tabela 4.14: Fluxos estimados considerando o processo iterativo, utilizando uma $\begin{array}{llllll}\text { matriz semente equivalente a } 70 \% \text { da matriz } & \text { O-D }\end{array}$ “real”.

Tabela 4. 15: Modelos para cálculo de Qij embutidos nos programas.

\section{S = ANARISE DOS RESURZADOS}

Tabela 5.1: Diferença absoluta entre as viagens "reais" e as estimadas pelo método incremental, utilizando o QUEENSOD...

Tabela 5.2: Diferença absoluta entre as viagens "reais" e as estimadas pelo método incremental, utilizando o TransCAD.

Tabela 5.3: Diferença quadrática entre as viagens “reais” e as estimadas pelo método incremental, utilizando o QUEENSOD...

Tabela 5.4: Diferença quadrática entre as viagens "reais" e as estimadas pelo método incremental, utilizando o TransCAD.

Tabela 5.5: Distribuição do valor absoluto dos erros relativos entre a matriz O-D "real” e a matriz O-D estimada pelo método incremental

Tabela 5.6: Diferença absoluta entre as viagens “reais” e estimadas pelo QUEENSOD, utilizando o método iterativo e matriz semente binária.

Tabela 5.7: Diferença absoluta entre as viagens “reais” e estimadas pelo QUEENSOD, utilizando o método iterativo e matriz semente equivalente a $70 \%$ da matriz "real” ......

Tabela 5.8: Diferença absoluta entre as viagens “reais” e estimadas pelo TransCAD, utilizando o método iterativo e matriz semente binária.

Tabela 5.9: Diferença absoluta entre as viagens "reais" e estimadas pelo TransCAD, utilizando o método iterativo e matriz semente equivalente a $70 \%$ da matriz "real" ......

Tabela 5.10: Diferença quadrática entre a matriz "real” e a matriz estimada pelo QUEENSOD, método iterativo e uma matriz semente binária.

Tabela 5.11: Diferença quadrática entre a matriz “real” e a matriz estimada iterativamente pelo QUEENSOD, utilizando uma matriz semente equivalente a 70\% da matriz "real" 
Tabela 5.12: Diferença quadrática entre a matriz “real” e a matriz estimada pelo TransCAD, o método iterativo e uma matriz semente binária

Tabela 5.13: Diferença quadrática entre a matriz "real" e a matriz estimada iterativamente pelo TransCAD, utilizando uma matriz semente equivalente a $70 \%$ da matriz "real".

Tabela 5.14: Distribuição dos erros relativos entre a matriz "real” e a estimada, obtida com a utilização do QUEENSOD

Tabela 5.15: Distribuição dos erros relativos entre matriz "real” e estimada, obtida com a utilização do TransCAD.

Tabela 5.16: Erro relativo agrupado em função do tempo de viagem entre os pares OD. Viagens estimadas considerando o QUEENSOD.

Tabela 5.17: Erro relativo agrupado em função do tempo de viagem entre os pares OD. Viagens estimadas considerando o TransCAD. 


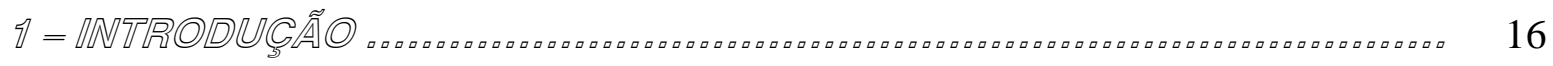

1.1 - O QUE É DEMANDA POR TRANSPORTES............................................ 16

1.1.2 - Como ela pode ser estimada? ............................................... 17

1.2 - OBJETIVO DO TRABALHO ….......................................... 19

1.3 - JUSTIFICATIVA PARA O ESTUDO ....................................... 19

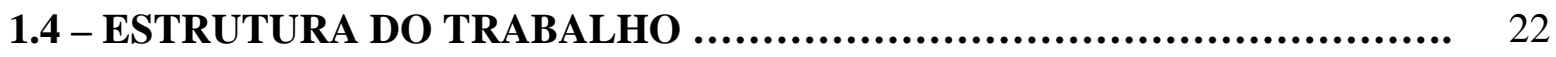

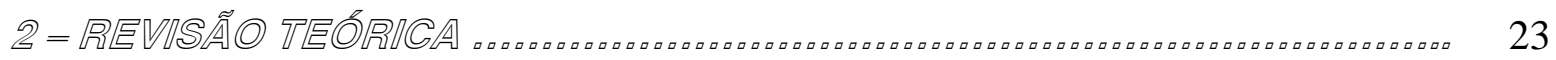

2.1 - ESTIMAÇÃO DA DEMANDA ......................................................................... 23

2.2 - MÉTODO TRADICIONAL ........................................................................... 24

2.3 - ESTIMAÇÃO DA MATRIZ O-D A PARTIR DAS CONTAGENS DE

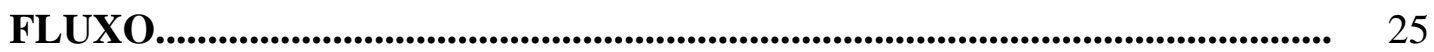

2.3.1 - Minimização da quantidade de informações.................................................. 28

2.3.2-Maximização da entropia................................................................................... 31

2.4 - DIFICULDADES PRÁTICAS ENCONTRADAS NA APLICAÇÃO DO MODELO SINTÉTICO......................................................................................... 35

2.4.1 - Existência de múltiplas soluçø̃es........................................................................ 36

2.4.2 - Falta de continuidade de fluxo em arcos contíguos..................................... 42

2.4.3 - Estimativa das viagens quando a rede se encontra congestionada......... $\quad 45$

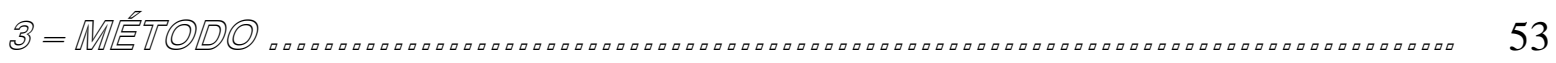

3.1 - CONSIDERAÇÕES INICIAIS.......................................................................... 53

3.2 - FORMULAÇÃO DO PROCESSO DE ESTIMAÇÃO DE MATRIZ O-D COM BASE NO CARREGAMENTO INCREMENTAL DOS FLUXOS OBSERVADOS AOS CAMINHOS DE CUSTO MÍNIMO................................. 55

3.2.1 - Número de incrementos a ser adotado........................................................... 59 


\section{3 - PROCEDIMENTO EMPREGADO PARA VERIFICAR O DESEMPENHO} DO MÉTODO INCREMENTAL_........................................................................ 61

3.3.1 - Adoção de uma rede viária e de uma matriz O-D....................................... 61

3.3.2 - Alocação da demanda à rede viária............................................................ 62

3.3.3 - Hipotética contagem nos arcos................................................................ 63

3.3.4 - Estimação da matriz O-D em função das contagens volumétricas........ 64

3.3.4.1 - Carregamento incremental dos fluxos para estimação da demanda. 64

3.3.4.2 - Estimação da matriz O-D utilizando o método iterativo.................. 68

3.3.5 - Comparação entre matrizes e análise dos resultados............................. 69

3.3.5.1 - Análise das diferenças dos valores da matriz O-D estimada incrementalmente em relação à matriz O-D "real”

3.3.5.2 - Análise entre os erros de estimação resultantes do método incremental em relação aos resultantes dos métodos iterativos

4.1.1 - Definição da rede de transporte, de uma matriz O-D que demanda essa rede e dos fluxos de tráfego observados.

4.1.2 - Estimação da matriz O-D considerando o carregamento incremental dos fluxos de tráfego.

4.1.3 - Estimação da matriz O-D considerando o método iterativo 
5.1.1 - Verificação da diferenças absolutas entre as viagens "reais" e as estimadas pelo método incremental

5.1.2 - Verificação da diferença quadrática entre as viagens “reais” e as estimadas pelo método incremental

5.1.3 - Verificação da distribuição dos erros relativos entre os valores das viagens "reais" e estimadas pelo processo incremental.

5.2 - COMPARAÇÃO DAS DIFERENÇAS DOS VALORES DA MATRIZ O-D ESTIMADA ATRAVÉS DO MÉTODO INCREMENTAL EM RELAÇÃO ÀS DIFERENÇAS DAS MATRIZES O-D ESTIMADAS ATRAVÉS DOS MÉTODOS ITERATIVOS.

5.2.1 - Comparação da somatória total das diferenças absolutas obtidas entre as viagens "reais" $e$ as estimadas

5.2.2 - Comparação da somatória total das diferenças quadráticas obtidas entre as viagens “reais” $\mathrm{e}$ as estimadas

5.2.3 - Verificação da distribuição dos valores absolutos dos erros relativos entre as viagens "reais" $\mathrm{e}$ as estimadas

5.2.4 - Verificação da distribuição dos erros relativos em função da distância

5.3 - CONSIDERAÇÕES FINAIS SOBRE AS ANÁLISES DOS RESULTADOS.

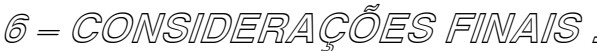

6.1 - CONCLUSÕES 


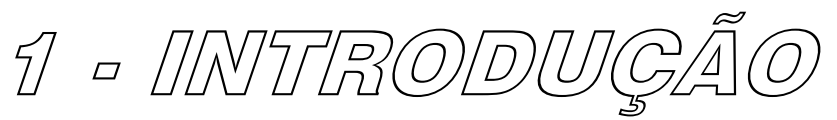

\section{1 - O QUE É DEMANDA POR TRANSPORTES?}

A demanda por transportes pode ser definida como o desejo de uma pessoa ou grupo de pessoas de se locomoverem ou locomover algum outro bem, de um lugar para outro, em um determinado momento e, em complementação à demanda, esta pode estar relacionada a uma dada modalidade de transporte e a uma determinada rota (KANAFANI, 1983).

A demanda por viagens está inserida neste conceito e a forma mais usual de representá-la é através de uma matriz contendo os pares O-D e as respectivas viagens entre estes, também denominada matriz de viagens ou matriz O-D.

Uma matriz O-D é uma forma bi-dimensional de agrupar as viagens entre cada origem (linhas, $i$ ) e cada destino (colunas, $j$ ). Portanto, o valor da célula ij representa a quantidade de veículos, caso esteja sendo consideradas viagens veiculares, para aquele intervalo de tempo que viajam entre este respectivo par O-D (ij).

Outras informações podem ser obtidas de uma matriz O-D, por exemplo, através da soma das linhas obtêm-se o total de viagens produzidas em cada zona de tráfego e através da soma das colunas têm-se a quantidade de viagens que estas zonas atraíram. 
Considere o exemplo apresentado na Figura 1.1, pode-se observar que na Figura 1.1 (a) existem três zonas de tráfego e suas respectivas demandas $Q_{i j}$ apresentadas de uma forma gráfica. A correspondente matriz O-D para esta situação pode ser observada na Figura 1.1 (b).

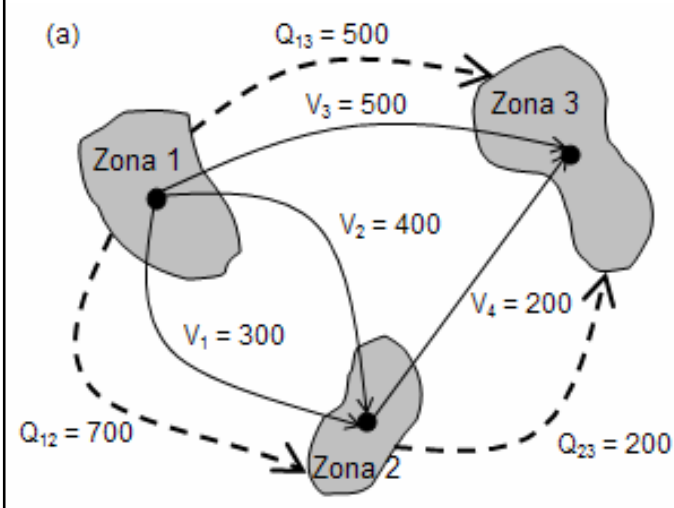

(b)

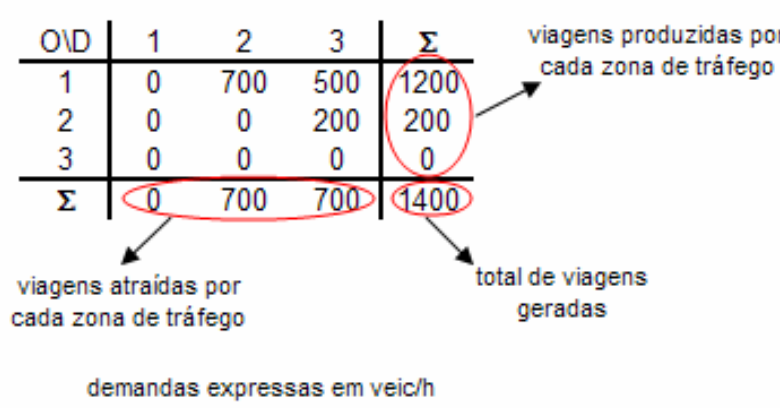

Figura 1.1: (a) Representação gráfica das demandas; (b) Representação matricial de demandas

\subsection{2 - Como a demanda pode ser estimada?}

O procedimento a ser utilizado para a estimativa de demandas depende basicamente dos dados disponíveis, do custo para obter tais informações e principalmente do propósito de utilização das demandas (VAN AERDE; RAKHA; PARAMAHAMSAN, 2003).

Tradicionalmente, as demandas são estimadas em função de um método que possui quatro etapas (geração de viagens; distribuição de viagens; divisão modal; alocação do tráfego) e que necessita da aplicação de pesquisas do tipo origem-destino, de forma a obter as informações necessárias para a realização destas etapas.

Geralmente, esta forma tradicional de obtenção da matriz O-D é muito cara, demanda muito tempo, além de estar suscetível a erros: (i) durante a realização das pesquisas; e (ii) devido à necessidade de limitar o tamanho da amostra em virtude de restrições orçamentárias, o que poderá comprometer a representatividade dos dados (HELLINGA, 1994). Além disso, raramente é possível (pois ficaria inviável em termos econômicos e de tempo) a obtenção de matrizes para períodos fragmentados de tempo, como por exemplo, períodos de 15 min., que 
constitui informação importante para a tomada de decisão em engenharia de tráfego, bem como aplicação das técnicas de simulação de tráfego (RAKHA et al., 1998).

Mas, seria possível uma forma mais simples e alternativa aos métodos tradicionais para obtenção de uma matriz O-D? Na década de 1970 pesquisadores chegaram à conclusão de que sim. Isto poderia ser feito através de um método mais simples, levando em consideração os fluxos de tráfego observados nos segmentos viários. Esta nova forma de estimar a matriz O-D foi denominada de modelo sintético.

O modelo sintético pode ser considerado como o inverso das técnicas de alocação de tráfego. Nessas técnicas uma matriz O-D é alocada a uma rede de transportes de forma a obter os fluxos nos arcos; já o modelo sintético, a grosso modo, faz exatamente o processo inverso, ou seja, em função dos fluxos de tráfego, uma matriz O-D é estimada.

A utilização de modelos sintéticos torna-se interessante para situações de análise operacional de um sistema viário já existente, onde os recursos são insuficientes para a coleta dos dados necessários à aplicação dos métodos tradicionais, e que necessitam de pesquisas mais sofisticadas para obtenção de uma matriz O-D e também no processo de calibração de simuladores de tráfego.

A vantagem do modelo sintético é que os fluxos de tráfego podem ser obtidos de maneira relativamente simples e com menor custo a partir de sensores permanentes, no caso de redes monitoradas por uma central de controle de tráfego, através de filmagem e de sensores portáteis ou mesmo através de contagens manuais, no caso de redes não monitoradas.

O modelo sintético possui algumas restrições quanto ao tipo de uso, por exemplo, não é aconselhado para a estimação de demandas em cenários ainda inexistentes e não possibilita uma relação entre demanda e condições socioeconômicas dos usuários. Conforme o tipo de 
informações sobre contagens de tráfego a demanda estimada poderá ser dividida em dois grupos: estática ou dinâmica.

Nas últimas décadas, alguns métodos têm sido propostos para estimar matriz O-D a partir de contagens de tráfego. Destes, podem ser destacados os trabalhos de: Robbilard (1975); Willumsen (1978); Van Zuylen (1978); Van Zuylen e Willumsen (1980); McNeil e Henderickson (1985); Bell (1991); Nielsen (1993); Van Aerde (1998). O estudo do modelo sintético fará parte do presente trabalho e irá considerar a matriz O-D estática, ou seja, matriz O-D estimada sem levar em consideração a variação do tráfego.

\section{2 - OBJETIVO DO TRABALHO}

O objetivo deste trabalho é apresentar um método para a estimação de matriz O-D sintética considerando o carregamento incremental dos fluxos observados nos arcos, de forma que não seja necessária a utilização de processos iterativos para garantir o equilíbrio do usuário na rede de tráfego e assim estimar uma matriz O-D.

Além disso, pretende-se verificar a utilidade do método proposto e, para tal, os resultados obtidos por este método para uma rede exemplo serão comparados com os obtidos ao utilizar o método iterativo embutido nos programas QuEENSOD e TransCAD, ambos disponíveis para uso na Escola de Engenharia de São Carlos da Universidade de São Paulo (EESC-USP) e de larga utilização em trabalhos envolvendo a estimação de matrizes O-D a partir de contagens de tráfego.

\section{3 - JUSTIFICATIVA PARA O ESTUDO}

O problema de estimar uma matriz de viagens origem-destino (O-D) através de contagens de fluxo de veículos tem sido estudado por diversos pesquisadores. Métodos comuns incluem a maximização da entropia: Inoue (1977), Van Zuylen e Willumsen (1980); 
maximização da verossimilhança: Inoue (1983), Iida, Takayama e Kaneko (1987), Spiess (1987); e técnicas de estimação por inferência Bayesiana: Maher (1983).

Embora vários trabalhos referentes aos métodos de estimação de matrizes O-D sintéticas utilizando contagens de fluxo tenham sido publicados desde a década de 1970, eles ainda não são amplamente conhecidos e utilizados por pesquisadores e analistas de sistemas de transportes, ao contrário do que ocorre com os métodos tradicionais que envolvem a aplicação de pesquisas O-D. O próprio desconhecimento dos detalhes da base teórica do método e as dificuldades práticas encontradas no processo de estimação das viagens entre pares O-D, contribuem para esta situação (VAN AERDE; RAKHA; PARAMAHAMSAN, 2003).

O processo para estimar a matriz O-D em função das contagens de fluxo consiste, basicamente, na resolução de um sistema de equações que envolvem dados referentes a fluxos observados e porcentagem de utilização dos arcos da rede viária por parte da demanda. Uma maneira de tornar a resolução de tais sistemas mais simples é representá-los de forma linearizada, o que é computacionalmente vantajoso, pois assim os resultados podem ser obtidos analiticamente sem a utilização de procedimentos matemáticos complexos (YANG et al., 1992).

Atualmente as matrizes O-D sintéticas são estimadas considerando um método iterativo, na maioria das vezes complexo, envolvendo geração, distribuição e alocação de viagens. De uma forma geral, em uma primeira iteração uma matriz semente ou observada, que poderia conter informação de pesquisas anteriores, seria alocada à rede de tráfego de forma a garantir o equilíbrio do usuário e assim uma matriz O-D seria estimada. O processo se repetiria até que acabassem as iterações ou então até que um outro critério de parada fosse satisfeito. 
Este processo exige que se tenha cuidado com os dados de entrada, em especial com os fluxos de tráfego observados, pois erros na observação dos fluxos podem, de alguma forma, causar inconsistência e, assim, não satisfazer as condições de equilíbrio da rede (VAN AERDE; RAKHA; PARAMAHAMSAN, 2003). Quando se tem uma situação como esta, onde o equilíbrio da rede não está sendo observado, poderá haver um reflexo direto na matriz O-D estimada, já que a técnica consiste em estimar a matriz em função do equilíbrio (YANG; SASAKI, 1991).

Outra questão em relação ao método iterativo é que para garantir o equilíbrio da rede, ou então, para que um arco não ultrapasse uma taxa pré-estabelecida de congestionamento, algumas viagens deixam de ser estimadas, o que influencia diretamente na qualidade dos resultados. Um exemplo, pode ser encontrado ao utilizar o programa QUEENSOD (VAN AERDE, 1998); neste, a relação fluxo de tráfego estimado e capacidade (V/C) é limitada em 1,50 e muitas vezes viagens acabam sendo desconsideradas para que esta restrição seja respeitada.

Acredita-se que a consideração de um processo iterativo para estimação de matriz O-D de forma a garantir o equilíbrio do usuário na rede de tráfego possui alguns problemas, não sendo capaz de estimar uma matriz O-D de maneira satisfatória, principalmente quando: a rede apresenta congestionamento, os fluxos não refletem as condições de equilíbrio e não se dispõe de uma matriz semente confiável.

Tendo em vista esta situação, este trabalho procura propor uma alternativa. A idéia que será apresentada nos próximos capítulos é a de que os fluxos observados nos arcos sejam carregados de forma incremental, ou seja, aos poucos, em um processo de estimação de matriz O-D sintética. Assim, supõe-se que o número de viagens resultante do incremento seja pequeno e evite que a alteração no tempo de percurso nos arcos seja grande. 
De uma maneira geral, pode-se afirmar que o procedimento proposto neste trabalho consiste em uma técnica inversa ao processo de alocação incremental. Na alocação incremental, uma matriz O-D é dividida em partes e cada uma é então alocada à rede. Já no método proposto, pequenas quantidades de fluxo de tráfego serão carregadas nos caminhos mínimos e, a partir desses dados, será estimada uma matriz O-D.

Nos próximos capítulos, um melhor detalhamento do modelo sintético com carregamento incremental de fluxos será apresentado.

\section{4 - ESTRUTURA DO TRABALHO}

Além deste capítulo introdutório, constam neste trabalho mais seis capítulos divididos da seguinte forma:

O Capítulo 2 apresenta uma revisão teórica sobre os pontos a serem estudados na pesquisa, em forma de itens, como estimação da demanda, modelo sintético e os problemas encontrados na sua utilização.

No Capítulo 3 são apresentados o desenvolvimento matemático do método proposto e as etapas a serem seguidas para verificar o funcionamento do método.

No quarto capítulo é apresentado o experimento para verificar o funcionamento do método que está sendo proposto neste trabalho, bem como os resultados obtidos.

O quinto capítulo apresenta a análise dos resultados obtidos de forma a verificar o desempenho do método proposto em relação aos dados “reais” e também em relação ao método iterativo.

O Capítulo 6 apresenta as conclusões obtidas com esta pesquisa e as recomendações para trabalhos futuros. Por fim, serão apresentadas as referências utilizadas. 


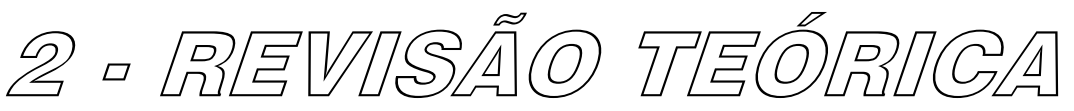

\section{1 - ESTIMAÇÃO DA DEMANDA}

A estimativa da demanda por transportes consiste em uma das etapas fundamentais no planejamento e operação de sistemas de transportes. A partir das demandas é possível, por exemplo, estimar qual será o fluxo de veículos circulantes pelas vias, além do tipo de estratégia operacional e de controle de tráfego a serem adotadas (KANAFANI, 1983). Além disso, a estimativa da demanda também é necessária para o processo de calibração dos simuladores de tráfego, podendo inclusive ser considerada como uma etapa de calibração isolada, inserida dentro de um processo mais amplo, tamanha sua complexidade (RAKHA et al., 1998).

A estimação das demandas veiculares pode ser feita, de uma forma geral, utilizando modelos derivados de duas correntes. A primeira consiste em estimar demandas a partir dos totais de viagens geradas em função das atividades dos ocupantes de uma região. Esse método, tido como tradicional ou de quatro etapas, requer a realização de pesquisas origemdestino (O-D) através de entrevistas domiciliares ou em pontos de controle, por exemplo.

Uma corrente alternativa ao método tradicional tem como objetivo estimar as demandas a partir de contagens de fluxos em segmentos de via e foi proposta na década de 1970. As demandas estimadas através desse método "alternativo" são chamadas de demandas sintéticas. O processo para sua obtenção pode ser considerado, de certa forma, como sendo o inverso do método tradicional. Neste processo, as demandas são estimadas a partir do fluxo de 
tráfego, ao contrário do método tradicional que "estima" fluxo a partir do conhecimento da demanda; porém, este método é restrito em relação ao tipo de situação que se quer analisar. Não é indicado para as situações em que se deseja fazer projeção de demandas para cenários futuros. Além disso, este modelo não permite estabelecer uma relação entre as demandas estimadas e as condições socioeconômicas dos usuários. O modelo sintético em algumas situações pode ser complementar ao método tradicional, um exemplo está nas situações em que se quer atualizar uma matriz O-D. A seguir maiores detalhes serão apresentados.

\section{2 - MÉTODO TRADICIONAL}

A utilização do método tradicional é a mais indicada para situações de planejamento ou projeto do sistema viário ainda inexistente. O nível de detalhamento exigido, em uma situação como esta, é maior em função da própria inexistência de várias informações que devem ser adotadas ou extrapoladas a partir de tendências de crescimento populacional, distribuição de atividades e mudanças nos padrões de atividade da população.

Para a obtenção das informações necessárias ao método tradicional três tipos de pesquisas de campo costumam ser utilizadas: (i) consiste em escolher uma amostra de domicílios que possam representar uma determinada população. Em cada domicílio é aplicado um questionário contendo perguntas sobre as origens, destinos, motivos para a realização da viagem, modo de transporte utilizado, além de outras informações (Ex: quantidade diária de viagens realizadas por cada indivíduo; idade de cada indivíduo; se possui ou não carteira de habilitação; renda etc) que podem variar em função dos objetivos da pesquisa. A aplicação destes questionários pode ser feita através: de um telefonema, da internet ou com a presença do recenseador no próprio domicílio; (ii) consiste em selecionar uma porção do tráfego e, para cada motorista selecionado, é aplicado um questionário para obter as informações sobre as viagens, e; (iii) consiste em colocar postos de controle nas entradas e saídas das zonas de tráfego e a partir destes são tomadas uma série de anotações, tais como: placas dos veículos, 
modelo do veículo e horário em que a observação foi feita, posteriormente estas informações serão cruzadas de forma a obter a matriz O-D.

Com as informações obtidas pelas pesquisas de campo e posse da distribuição espacial de atividades, pode-se estabelecer qual é a atração e qual é a produção de uma determinada zona e, utilizando em seguida modelos de distribuição de viagens, tais como Fratar ou Gravitacional, estimar as viagens entre as zonas. As demandas estimadas são então estratificadas por modo (automóvel, ônibus, a pé) e, em seguida, alocadas à rede viária (ORTÚZAR; WILLUMSEN, 1994).

Em resumo, o método tradicional para estimação da matriz O-D consistirá em realizar quatro etapas listadas a seguir:

$\Rightarrow$ Geração de viagens;

$\Rightarrow \quad$ Distribuição de viagens;

$\Rightarrow \quad$ Divisão modal; e

$\Rightarrow \quad$ Alocação do tráfego.

Não constitui parte desta pesquisa a abordagem do método tradicional. $\mathrm{O}$ foco principal está no modelo sintético, apresentado no próximo item.

\section{3 - ESTIMAÇÃO DA MATRIZ O-D A PARTIR DAS CONTAGENS DE FLUXO}

Considere a rede hipotética da Figura 2.1. Nesta figura existem duas zonas de origem ( 1 e 2) conectadas a 2 zonas de destino (3 e 4). A ligação entre os pares O-D é feita através de cinco arcos, sendo que no arco 3 (central) é possível observar o fluxo total de veículos entre os pares O-D, pois por este arco passam todas as viagens da rede. Junto a cada arco observase a identificação $V_{a}$, que indica fluxo de veículos $(V)$ no $\operatorname{arco}(a)$. 


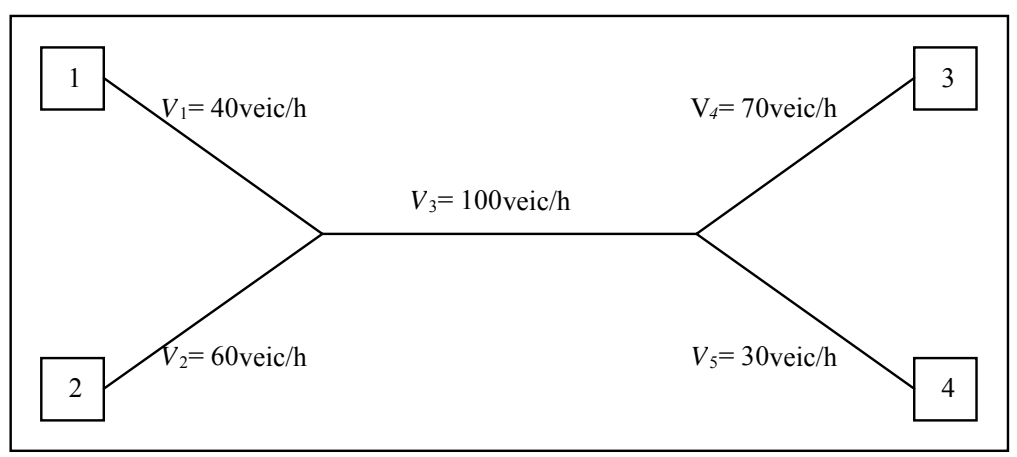

Figura 2. 1: Rede hipotética para ilustrar o modelo sintético

Esta rede, da forma como se apresenta, permite que sejam obtidas inúmeras soluções para a matriz O-D, por exemplo, se o número de viagens de 1 para 3 for considerado $\mathrm{X}$, o número de viagens entre todos pares O-D restantes podem ser especificados automaticamente, conforme se observa na Tabela 2.1.

Tabela 2. 1: Matriz O-D para a rede hipotética da Figura 2.1 (Fonte: PARAMAHAMSAN, 1999)

\begin{tabular}{c|c|c|c}
\hline O-D & $\mathbf{3}$ & $\mathbf{4}$ & Total \\
\hline $\mathbf{1}$ & $\mathrm{X}$ & $40-\mathrm{X}$ & 40 \\
\hline $\mathbf{2}$ & $70-\mathrm{X}$ & $\mathrm{X}-10$ & 60 \\
\hline Total & 70 & 30 & 100 \\
\hline
\end{tabular}

$\mathrm{Na}$ tentativa de resolver situações como esta é que vários pesquisadores propuseram, na década de 1970, modelos para estimação de matrizes O-D em função de contagens de fluxo.

Inicialmente, procuraram resolver esta questão utilizando o modelo gravitacional. Robillard (1975) sugeriu o uso de um modelo gravitacional generalizado que dependeria de uma função para o custo da viagem e de parâmetros referentes às zonas de origem e de destino. Low (1972), Hogberg (1976), Holm et al. (1976) e Symons et al. (1976) calibraram o modelo gravitacional utilizando os dados de tamanho da população e quantidade de empregos por zona. 
Low (1972) utilizou para obter seu modelo a regressão linear, Hogberg (1976) considerou uma regressão não linear, Holm et al. (1976) desenvolveram um modelo utilizando a maximização da verossimilhança e Symons et al. (1976) propuseram um modelo gravitacional para viagens intermunicipais, combinando conceitos do Teorema do Limite Central.

Em 1977, Nguyen sugeriu que fosse incorporado a estes modelos o conceito de equilíbrio do usuário na rede, que poderia ser alcançado utilizando um método iterativo, mas sua proposta acabou gerando indeterminações que prejudicaram a estimação da matriz O-D. Gur et al. (1978) fizeram adaptações no modelo de Nguyen, onde inseriram uma matriz objetivo, ou semente, na tentativa de reduzir algumas das indeterminações.

Van Zuylen e Willumsen diferentemente dos demais pesquisadores, procuraram propor um modelo diferente dos que vinham sendo propostos.

Van Zuylen (1978) propôs que a minimização da quantidade de informações, envolvendo fluxo observado e matriz semente seria capaz de estimar uma matriz O-D. Já Willumsen (1979), seguindo uma linha similar a de Van Zuylen, propôs que a maximização da entropia, onde o micro-estado seria representado por informações referentes a cada viagem (Ex: origem, destino, modo, tempo etc) e o meso-estado representado pelo número total de viagens entre os pares $\mathrm{O}-\mathrm{D}$, seria capaz de resultar na matriz O-D mais provável de ocorrer.

As demandas estimadas por estes modelos, denominadas demandas sintéticas, são estimadas a partir de contagens de tráfego obtidas em seções de vias ou interseções. Estas contagens podem considerar as classes veiculares, como por exemplo, automóveis, caminhões e ônibus, bem como podem ser feitas em períodos fragmentados de tempo, por exemplo, uma contagem horária pode ser dividida em quatro intervalos de $15 \mathrm{~min}$, o que torna o modelo atrativo para ser utilizado em conjunto com os simuladores de tráfego. A seguir serão 
apresentados os fundamentos dos modelos propostos por Van Zuylen (1978) e Willumsen (1979).

\subsection{1 - Minimização da quantidade de informações}

Em algumas situações é difícil estimar uma matriz O-D apenas considerando os fluxos observados nos arcos. Uma alternativa para esta questão foi inserir uma mínima quantidade de informação auxiliar, de forma que o problema fosse resolvido. Esta proposta foi desenvolvida por Van Zuylen (1978) utilizando, para tal, o conceito de medida da informação de Brillouin (1956).

De acordo com este conceito, a informação contida em um conjunto de observações $N$, quando um conjunto $k$ foi observado $n_{k}$ vezes é definido como:

$$
I=\ln N ! \cdot \prod_{k}\left[\frac{\left(r_{k}\right)^{n_{k}}}{n_{k} !}\right]
$$

Sendo:

$\Rightarrow I$ : informação contida em um conjunto de observações;

$\Rightarrow N$ : número de observações do conjunto $k$;

$\Rightarrow r_{k}$ : probabilidade a priori de observar o estado $k ; \mathrm{e}$

$\Rightarrow n_{k}$ : número de vezes que o conjunto $k$ foi observado.

Van Zuylen fez a suposição de que as observações seriam as contagens de tráfego em um arco a qualquer e o estado ij representaria todos os veículos observados trafegando da origem $i$ para o destino $j$. Então:

$$
n_{i j}^{a}=Q_{i j} \cdot p_{i j}^{a}
$$

Sendo $Q_{i j}$ a quantidade de viagens entre o par O-D ij e $p_{i j}^{a}$ é a porcentagem de utilização dos arcos em função das viagens. 
A probabilidade a priori de observar o estado ij para o arco $a\left(r_{i j}^{a}\right)$ pode ser definida em função do conhecimento prévio de uma matriz O-D semente $\left(s_{i j}\right)$ :

$$
r_{i j}^{a}=\frac{S_{i j} p_{i j}^{a}}{\sum_{i j} s_{i j} p_{i j}^{a}}
$$

Portanto, a informação contida em um conjunto de observações de fluxo de tráfego $\left(V_{o b s}^{a}\right)$ pode ser expressa por:

$$
I_{a}=\ln V_{o b s}^{a} ! \prod\left[\frac{\left(\frac{s_{i j} p_{i j}^{a}}{\sum_{i j} s_{i j} p_{i j}^{a}}\right)^{Q_{i j} p_{i j}^{a}}}{Q_{i j} p_{i j}^{a} !}\right]
$$

Para resolver problemas como este, Stirling (DONALD, 1976) propôs uma aproximação para $\ln X$ ! (2.5), desta forma a equação (2.4) ficará expressa de uma maneira mais fácil de ser utilizada (2.6).

$$
\begin{gathered}
\ln X !=X \ln X-X \\
I_{a}=\sum_{i j} Q_{i j} p_{i j}^{a} \ln \left[\frac{Q_{i j}\left(\sum_{i j} s_{i j} p_{i j}^{a}\right)}{V_{o b s}^{a} \cdot s_{i j}}\right]
\end{gathered}
$$

Considerando todos os arcos da rede viária $\left(\sum_{i j} s_{i j} p_{i j}^{a}=S\right)$, a quantidade de informações pode ser representada por:

$$
I_{a}=\sum_{a} \sum_{i j} Q_{i j} p_{i j}^{a} \ln \left(\frac{Q_{i j} S}{V_{o b s}^{a} \cdot S_{i j}}\right)
$$


De acordo com Van Zuylen (1978), para obter uma matriz O-D considerando a adição de uma quantidade mínima de informações, deve-se fazer a minimização da equação (2.7) sujeita as restrições (2.8). É válido observar que a restrição (2.8) pode ser considerada como o principal fator que possibilitou o desenvolvimento de todos os modelos de estimação de demanda a partir de contagens volumétricas. Aplicando o multiplicador Lagrangeano $\left(\lambda_{\mathrm{a}}\right)$, têm-se (2.9):

$$
\begin{gathered}
V_{o b s}^{a}=\sum_{i j} p_{i j}^{a} Q_{i j} \text { e } Q_{i j} \geq 0 \\
\ell=\sum_{a} \sum_{i j} Q_{i j} p_{i j}^{a} \ln \left(\frac{Q_{i j} S}{V_{o b s}^{a} \cdot s_{i j}}\right)+\sum_{a} \lambda_{a}\left(\sum_{i j} Q_{i j} p_{i j}^{a}-V_{o b s}^{a}\right)
\end{gathered}
$$

Minimizando a equação (2.9) será possível obter a equação que permite estimar a matriz O-D.

$$
\begin{gathered}
\frac{\partial \ell}{\partial Q_{i j}}=\sum_{a} p_{i j}^{a} \ln \left(\frac{Q_{i j} S}{V_{o b s}^{a} \cdot S_{i j}}\right)+\sum_{i j} Q_{i j} p_{i j}^{a} \frac{1}{Q_{i j}}+\sum_{a} \lambda_{a} p_{i j}^{a} \\
\frac{\partial \ell}{\partial Q_{i j}}=\sum_{a} p_{i j}^{a} \ln \left(\frac{Q_{i j} S}{V_{o b s}^{a} \cdot S_{i j}}\right)+\sum_{a}\left[p_{i j}^{a}\left(1+\lambda_{a}\right)\right]=0 \\
\ln \left\{\prod_{a}\left(\frac{Q_{i j} S}{V_{o b s}^{a} \cdot S_{i j}}\right)^{p_{i j}^{a}}\right\}=-\sum_{a}\left[p_{i j}^{a}\left(1+\lambda_{a}\right)\right] \\
\left.\left(\frac{Q_{i j}}{S_{i j}}\right)_{a}^{\sum_{a j}^{a}}=\prod_{a}\left(\frac{V_{o b s}^{a}}{S}\right)^{p_{i j}^{a}} e^{\left[-\sum_{a} p_{i j}^{a}\left(1+\lambda_{a}\right)\right.}\right] \\
Q_{i j}=s_{i j} \prod\left\{\frac{V_{o b s}^{a}}{S} e^{-\left(1+\lambda_{a}\right)}\right\} \sum_{a}^{\sum_{i j}^{a} p_{i j}^{a}}
\end{gathered}
$$


Com a equação (2.14) é possível estimar a matriz O-D, de acordo com a proposta de Van Zuylen (1978).

\subsection{2-Maximização da entropia}

Willumsen na segunda metade da década de 1970 propôs um outro modelo para estimar matriz O-D em função dos fluxos veiculares. Este modelo seria basicamente uma derivação do modelo entrópico proposto por Wilson (1970). Constitui um tipo de modelo que permite ao usuário estimar o tráfego gerado, distribuído e alocado.

A consideração da entropia feita por Wilson surgiu por uma analogia com o estado físico de um gás, e veio a servir para a resolução de uma série de questões. Uma destas é a estimação das demandas veiculares, pois as viagens, assim como os gases, também possuiriam estágios de divisão, sendo estes estágios definidos como micro, meso e macroestados (ORTÚZAR; WILLUMSEN, 1994).

O macro-estado representaria a quantidade total de moléculas no sistema, o meso corresponde à distribuição de cada molécula nos compartimentos do sistema e o micro-estado equivale à distribuição individual das moléculas dentro de cada compartimento do sistema. A Figura 2.2 traz uma representação desta situação; os quatro pontos da Figura 2.2 (a) representam o macro estado, além do que a configuração na qual eles se apresentam constitui um meso-estado e a Figura 2.2 (b) procura esquematizar os micro-estados correspondente a este meso-estado apresentado. 


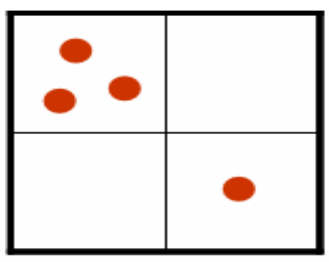

(a)
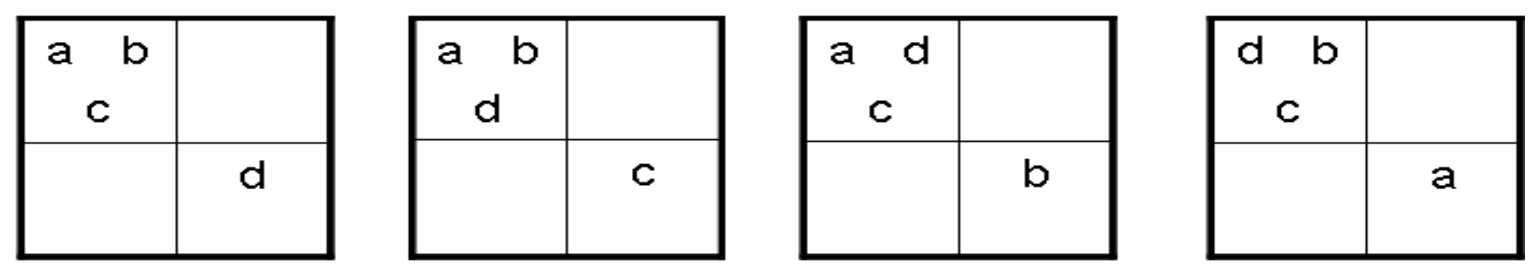

(b)

Figura 2. 2: Representação dos três estados de comportamento das moléculas de um gás: (a) macro e meso-estados representados; (b) respectivos micro-estados do meso-estado representado na parte (a)

O modelo sintético foi formulado associando o micro-estado $Z\left(Q_{i j}\right)$, que representa as informações de cada viajante individualmente, como sua origem, destino, modo e tempo de viagem, ao meso-estado $\left(Q_{i j}\right)$, que, em geral, é representado pelo número total de viajantes entre cada origem e cada destino. De acordo com esta proposta as viagens tendem a se distribuir uniformemente pela rede de tráfego.

Este modelo pode ser representado através da equação (2.15), proposta por Wilson (1970), levando em consideração os fundamentos de análise combinatória (ORTÚZAR; WILLUMSEN, 1994):

$$
Z\left(Q_{i j}\right)=\frac{Q !}{\prod_{i j}\left(Q_{i j} !\right)}
$$

Em que:

$\Rightarrow Q:$ quantidade total de viagens;

$\Rightarrow Q_{i j}$ : total de viagens entre $i j$.

Willumsen (1978a e 1978b) demonstrou que realizando a maximização da entropia (2.15), sujeito às restrições $(2.15 \mathrm{a}),(2.15 \mathrm{~b})$ e $(2.15 \mathrm{c})$, seria possível chegar a uma equação que permitisse a estimação das demandas entre os pares O-D. 


$$
\begin{aligned}
& V_{o b s}^{a}=\sum_{i j} p_{i j}^{a} Q_{i j} \\
& Q_{i j} \geq 0 \quad \forall i, j \\
& Q=\sum_{i j} Q_{i j}
\end{aligned}
$$

Em que:

$\Rightarrow \quad V_{o b s}^{a}:$ fluxo observado no arco $a[$ veíc $/ \mathrm{h}]$;

$\Rightarrow \quad Q_{i j}$ : demanda horária cuja origem é o nó $i$ e tem como destino o nó $j$ [veíc/h];

$\Rightarrow \quad p_{i j}^{a}$ : fração de viagens da demanda $Q_{i j}$ que utiliza o $\operatorname{arco} a$;

$\Rightarrow \quad Q$ : soma das demandas na rede.

De acordo com Willumsen, os valores de $Q_{i j}$, que maximizam a equação da entropia, representam a solução mais provável de acontecer em função dos dados iniciais fornecidos. De forma a tornar mais fácil a sua maximização e também para que possa ser mais facilmente implementada computacionalmente, deve-se aplicar o logaritmo natural na equação (2.15) e, desta forma, obter a equação linearizada apresentada em (2.16).

$$
Z\left(Q_{i j}\right)=\ln \left(\frac{Q !}{\prod_{i j}\left(Q_{i j} !\right)}\right)=\ln Q !-\sum_{i j} \ln Q_{i j} !
$$

Ainda assim a expressão (2.16) continua complexa devido ao logaritmo natural de um fatorial. Utilizando a aproximação de Stirling (2.5), desenvolvida para resolver situações como esta, a função de entropia passará a ser representada conforme indicado na equação (2.17).

$$
Z\left(Q_{i j}\right)=Q \ln Q-Q-\sum_{i j}\left(Q_{i j} \ln Q_{i j}-Q_{i j}\right)
$$


O passo inicial do modelo sintético está em maximizar a função de entropia. Willumsen fez, para tanto, a suposição de que $Q$ é constante. Baseado nesta suposição, os primeiros dois termos podem ser retirados da equação (2.17), transformando-a em uma função objetivo, um pouco mais simples, como definido na equação (2.18), sujeita às restrições impostas nas equações (2.18a) e (2.18b).

$$
\begin{gathered}
Z\left(Q_{i j}\right)=-\sum_{i j}\left(Q_{i j} \ln Q_{i j}-Q_{i j}\right) \\
V_{o b s}^{a}=\sum_{i j} p_{i j}^{a} Q_{i j} \\
Q_{i j} \geq 0 \quad \forall i, j
\end{gathered}
$$

Aplicando o multiplicador Lagrangeano $\left(\lambda_{a}\right)$ na restrição $(2.18 \mathrm{a})$ é possível incorporala à equação (2.18), obtendo-se a equação (2.19).

$$
F=\sum_{i j}\left(Q_{i j} \ln Q_{i j}-Q_{i j}\right)+\sum_{a} \lambda_{a}\left(V_{o b s}^{a}-\sum_{i j} Q_{i j} p_{i j}^{a}\right)
$$

Ao maximizar a equação (2.19), obtêm-se o modelo proposto por Willumsen (2.22).

$$
\begin{gathered}
\frac{\partial F}{\partial Q_{i j}}=-\ln Q_{i j}-\sum_{a} \lambda_{a} p_{i j}^{a}=0 \\
Q_{i j}=e^{\left[-\sum_{a} \lambda_{a} p_{i j}^{a}\right]} \\
Q_{i j}=\prod_{a}\left(e^{-\lambda_{a}}\right)^{p_{i j}^{a}}
\end{gathered}
$$

Atualmente qualquer programa que possua aplicações matemáticas é capaz de resolver a proposta feita por Willumsen. Um exemplo é a utilização de planilhas eletrônicas como o 
Microsoft Excel, onde a maximização da equação (2.18), sujeita às restrições (2.18a e 2.18b), poderá ser feita utilizando o suplemento solver, porém existem algumas limitações referentes ao método matemático utilizado pelo solver que não consegue convergir pra um resultado válido quando se tem uma rede com maior complexidade.

Tanto o modelo baseado na minimização da informação, quanto o baseado na maximização da entropia possuem bastante similaridade. A diferença entre as duas considerações é que, no modelo proposto por Van Zuylen, o meso-estado é representado pela contagem de tráfego; já no proposto por Willumsen, as viagens entre os pares O-D seriam o meso-estado.

A seguir serão apresentadas algumas das principais dificuldades práticas encontradas na aplicação do modelo sintético.

\section{4 - DIFICULDADES PRÁTICAS ENCONTRADAS NA APLICAÇÃO DO MODELO SINTÉTICO}

O modelo sintético tem grande importância no processo de estimação das demandas, o grande mérito está na pouca quantidade de informações iniciais necessárias para se chegar aos resultados, porém apresenta algumas dificuldades práticas:

a) possibilidade de haver múltiplas soluções;

b) falta de continuidade de fluxo em arcos contíguos; e

c) estimativa correta da matriz O-D quando a rede se encontra congestionada.

Diversos trabalhos, como os desenvolvidos por Robbilard (1975), Nguyen (1977), Van Zuylen e Willumsen (1980), Yang et al (1992), Nielsen (1993), Van Aerde (1998), Parahmamsan (1999), Van Aerde, Rakha e Paramahamsan (2003), objetivaram solucionar tais problemas. 
Os próximos subitens trarão um melhor detalhamento sobre estes problemas, bem como as soluções até então definidas pelos pesquisadores citados.

\subsection{1 - Existência de múltiplas soluções}

Para determinar as quantidades de viagens realizadas entre diferentes pares O-D a partir de contagens de fluxo, faz-se necessária a resolução de um sistema de equações que relacionam fluxos e viagens conforme pode-se observar na equação genérica (2.23). A Figura 2.3 procura retratar o equacionamento do sistema de equações na forma matricial para a rede viária da Figura 2.1.

$$
\mathbf{V}=\mathbf{P} \times \mathbf{Q}
$$

Em que:

$\Rightarrow \mathbf{V}$ : matriz de fluxos observados na rede;

$\Rightarrow \mathbf{P}$ : porcentagens de viagens das demanda $Q_{i j}$ que utilizam cada um dos arcos; e

$\Rightarrow \mathbf{Q}:$ matriz de demandas na rede.

$$
\left[\begin{array}{llll}
1 & 1 & 0 & 0 \\
0 & 0 & 1 & 1 \\
1 & 1 & 1 & 1 \\
1 & 0 & 1 & 0 \\
0 & 1 & 0 & 1
\end{array}\right] \times\left[\begin{array}{l}
q_{13} \\
q_{14} \\
q_{23} \\
q_{24}
\end{array}\right]=\left[\begin{array}{r}
40 \\
60 \\
100 \\
70 \\
30
\end{array}\right]
$$

Figura 2. 3: Forma matricial de representar o sistema de equações para a rede viária da Figura 2.1

Geralmente no sistema de equações o número de incógnitas é maior que o número de restrições (ou fluxos), o que produz um sistema que admite múltiplas soluções como resposta. Qual dentre estas soluções seria a mais correta? Pensando nisso é que Van Zuylen e Willumsen (1980) afirmam que ao maximizar a entropia, sujeita às devidas restrições, a matriz obtida será a mais provável de acontecer, para aquele conjunto de dados de entrada considerado.

Em geral, para identificar quando um sistema de equações possui múltiplas soluções, pode-se utilizar o método de Gauss-Jordan (Noble, 1969) que consiste, inicialmente, em 
escrever a matriz aumentada de porcentagem de utilização dos arcos e fluxos observados [P | V] e, em seguida, escaloná-la de forma a obter sua forma reduzida (ou canônica), como mostra a Figura 2.4, que representa o escalonamento da matriz $[\mathbf{P} \mid \mathbf{V}]$ da rede viária apresentada na Figura 2.1 (DEMARCHI; BERTONCINI, 2003a):

$\left.\left[\begin{array}{rrrr:r}1 & 1 & 0 & 0 & 40 \\ 0 & 0 & 1 & 1 & 60 \\ 1 & 1 & 1 & 1 & 100 \\ 1 & 0 & 1 & 0 & 70 \\ 0 & 1 & 0 & 1 & 30\end{array}\right] \Rightarrow\left[\begin{array}{llll:r}1 & 0 & 0 & 1 & 10 \\ 0 & 1 & 0 & 1 & 30 \\ 0 & 0 & 1 & 1 & 60 \\ 0 & 0 & 0 & 0 & 0 \\ 0 & 0 & 0 & 0 & 0\end{array}\right]\right\} \begin{aligned} & \text { Posto ou rank da } \\ & \text { matriz escalonada } \\ & \mathrm{k}=3\end{aligned}$

Figura 2. 4: Representação do escalonamento de uma matriz aumentada

Pode ser observado na matriz escalonada que suas duas últimas linhas são nulas, ou seja, todos seus componentes são 0 . Neste caso específico, tanto o posto (ou rank) da matriz escalonada $[\mathbf{P} \mid \mathbf{V}]$ como da matriz $\mathbf{P}$ correspondem ao número de linhas não nulas, ou seja, $k=3$. Noble (1969) define que, de uma forma geral, sempre que os postos de $[\mathbf{P} \mid \mathbf{V}]$ e de $\mathbf{P}$ forem iguais e o posto da matriz aumentada for menor que o número de incógnitas do sistema (no caso, $3<4$ ), o sistema possui infinitas soluções.

Considere que o número de viagens entre 1 e 3 da rede apresentada na Figura 2.1 seja de 20 veículos, por exemplo. De acordo com Paramahamsan (1999), existirão $\frac{100 !}{(20 ! \cdot 80 !)}$ maneiras válidas de extrair as 20 viagens da população total que é de 100 veículos, para que a continuidade volumétrica seja mantida; consequentemente haverá 80 viagens entre 1 e 4 , implicando em $\frac{80 !}{(20 ! \cdot 60 !)}$ maneiras diferentes de se fazer isto. Similarmente, há $\frac{60 !}{(10 ! \cdot 50 !)}$ maneiras de selecionar viagens entre 2 e 3 , e $\frac{10 !}{(10 ! \cdot 0 !)}$ entre 2 e 4 . 
Fazendo as devidas simplificações matemáticas, chega-se que há $\frac{100 !}{(20 ! \cdot 20 ! \cdot 50 ! \cdot 10 !)} \approx 1,43 \cdot 10^{50}$ maneiras de criar uma matriz simples com $20,20,50$ e 10 viagens entre 1-3, 1-4, 2-3 e 2-4 respectivamente, mostrando assim que realmente este sistema possui infinitas soluções.

No geral, este número pode ser representado pela análise combinatória (2.24), conforme definição do modelo sintético (VAN ZUYLEN; WILLUMSEN, 1980).

$$
Z\left(Q_{i j}\right)=\frac{Q !}{\prod_{i j}\left(Q_{i j} !\right)}
$$

Sendo, $Q$ : quantidade total de viagens e $Q_{i j}$ : total de viagens entre $i j$.

Considerando a Tabela 2.1, se for feita a suposição de que X pertence ao intervalo de 10 à $40(10 \leq X \leq 40)$, existem 31 combinações possíveis de demandas que podem ser adotadas como solução do sistema, tomando somente valores inteiros de demandas (PARAMAHAMSAN, 1999). Para X variando nesse intervalo seria possível, utilizando a equação (2.24), obter valores para $Z\left(Q_{13}\right)$.

A partir de uma relação gráfica destas informações, onde nas abscissas estariam os valores de $Q_{13}$ e nas ordenadas os respectivos valores de $Z\left(Q_{13}\right)$ (Figura 2.5), chega-se à conclusão de que o valor mais provável para $Q_{13}$ é 28 veic/h, que corresponde ao máximo da função $Z\left(Q_{13}\right)\left(7,8 \times 10^{52}\right)$. 


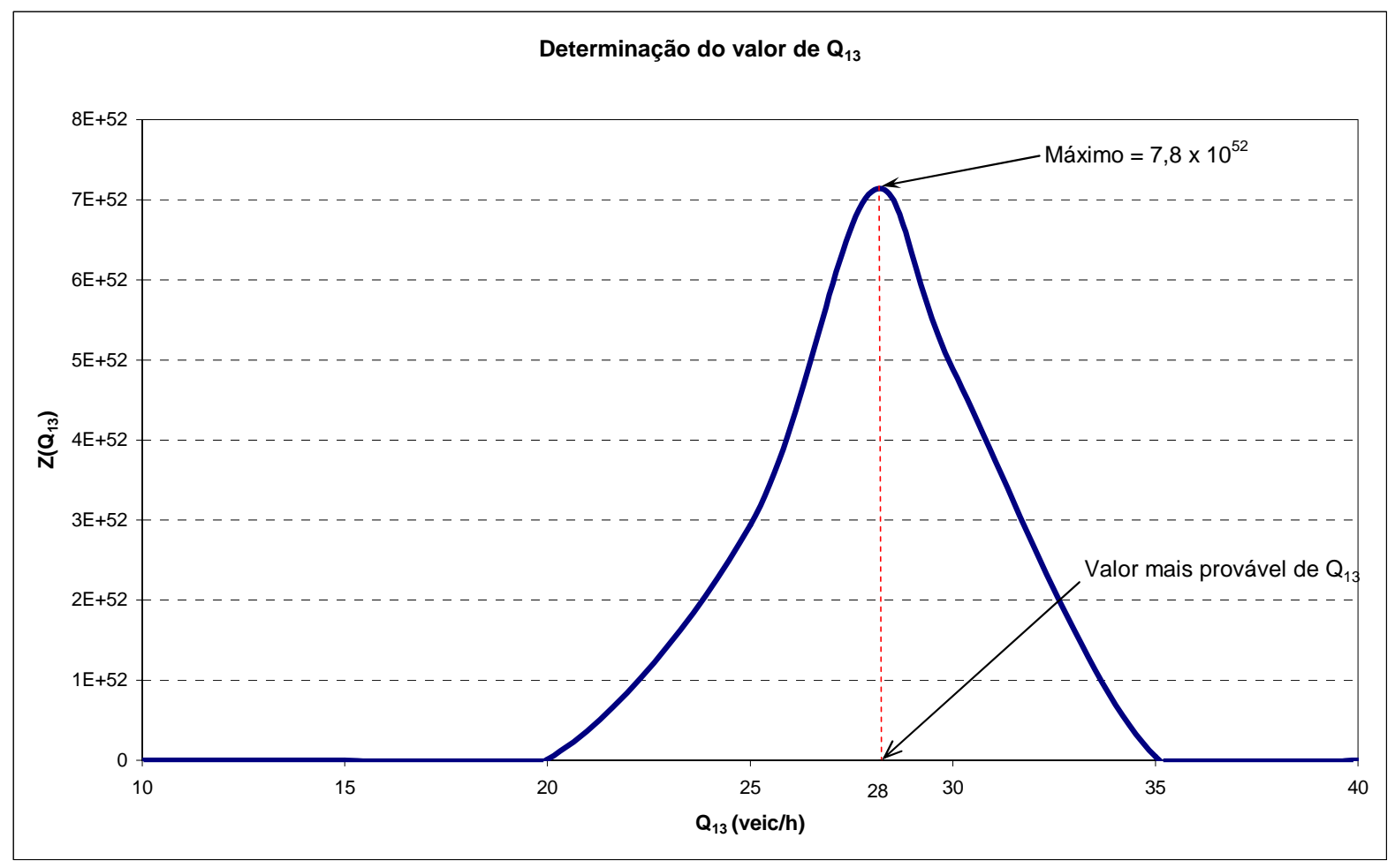

Figura 2. 5: Curva representativa do valor mais provável de $Q_{13}$ para a rede da Figura 2.1

$\mathrm{Na}$ tentativa de melhorar o modelo sintético baseado na maximização da entropia, Willumsen adicionou ao modelo uma quantidade adicional de informação, que seria representada pela probabilidade das viagens contidas em uma matriz semente ocorrerem. Considerando que a probabilidade de uma viagem individual $\left(r_{i j}\right)$ ocorrer entre os pares O-D ( $i$ e $j$ ), pode ser apresentada conforme a equação (2.25), conseqüentemente, a probabilidade de ocorrer as $Q_{i j}$ viagens entre $i$ e $j$ passará a ser expressa pela equação (2.26).

$$
\begin{gathered}
r_{i j}=\frac{\mathrm{s}_{\mathrm{ij}}}{\sum_{i j} s_{i j}} \\
r_{i j}^{Q_{i j}}=\left(\frac{\mathrm{s}_{\mathrm{ij}}}{\sum_{i j} s_{i j}}\right)^{Q_{i j}}
\end{gathered}
$$

Van Zuylen e Willumsen (1980) propuseram que fosse adicionado ao modelo de maximização da entropia o termo que permite obter a máxima probabilidade de ocorrência de $Q_{i j}$ viagens em função da utilização de uma matriz semente (2.27). 


$$
Z\left(Q_{i j}, s_{i j}\right)=\frac{Q !}{\prod_{i j}\left(Q_{i j} !\right)} \prod_{i j}\left(\frac{s_{i j}}{S}\right)^{Q_{i j}}
$$

Em que:

$\Rightarrow Q=\sum_{i j} Q_{i j}:$ soma das demandas que serão estimadas;

$\Rightarrow Q_{i j}$ : fluxo entre $i$ e $j$

$\Rightarrow s_{i j}$ : fluxo entre $i$ e $j$ fornecido na matriz semente;

$\Rightarrow S=\Sigma S_{i j}$ : soma das células da matriz semente.

Entretanto, considerando que é difícil trabalhar com derivadas de fatoriais e a equação (2.26) sempre fornece valores positivos, é mais simples derivar os logaritmos naturais destas funções. Para isto, pode-se utilizar a aproximação de Stirling: $\ln X !=X \ln X-X$, obtendo-se assim a equação (2.28).

As demandas veiculares são então estimadas maximizando a equação (2.28) sujeita às restrições (2.28a).

$$
\begin{gathered}
\ln Z\left(Q_{i j}, s_{i j}\right)=Q \ln Q-Q \ln S-\sum_{i j}\left(Q_{i j} \ln Q_{i j}-Q_{i j} \ln s_{i j}\right) \\
V_{o b s}^{a}=\sum_{i j} p_{i j}^{a} Q_{i j} ; Q_{i j} \geq 0 \quad \forall i, j ; Q=\sum_{i j} Q_{i j}
\end{gathered}
$$

Procedendo a maximização da equação (2.28) sujeita as restrições (2.28a), conforme procedimento adotado no item 2.3.2, obtém-se a equação (2.29) que permite a estimação de uma matriz O-D.

$$
Q_{i j}=s_{i j} \prod\left[\left(\sum_{i j} s_{i j}\right)^{\frac{1}{o}} e^{-\lambda_{a}}\right]^{p_{i j}^{a}}
$$

Sendo $o$ o número total de arcos onde houve contagem de tráfego e $\lambda_{a}$ o multiplicador Lagrangeano. 
Considerando a rede viária da Figura 2.1, fazendo a suposição de que $10 \leq Q_{13} \leq 40$ e que existe para esta rede existe o conhecimento prévio de uma matriz O-D, conforme Tabela 2.2, é possível através da equação (2.27) determinar os valores de $Z\left(Q_{13}, S_{13}\right)$.

Tabela 2. 2: Matriz O-D semente para a rede da Figura 2.1 (Fonte: PARAMAHAMSAN, 1999)

\begin{tabular}{c|c|c|c}
\hline O-D & $\mathbf{3}$ & $\mathbf{4}$ & Total \\
\hline \hline $\mathbf{1}$ & 20 & 20 & 40 \\
\hline $\mathbf{2}$ & 50 & 10 & 60 \\
\hline Total & 70 & 30 & 100 \\
\hline
\end{tabular}

Ao construir uma curva considerando os valores de $Z\left(Q_{13}, s_{13}\right)$ em função de $Q_{13}$, verifica-se que o valor mais provável de $Q_{13}$ é 20 veíc/h, o que corresponde à $Z\left(Q_{13}, s_{13}\right)=$ $1,4 \times 10^{-3}$, conforme apresentado por Paramahamsan (1999). O gráfico pode ser visualizado na Figura 2.6.

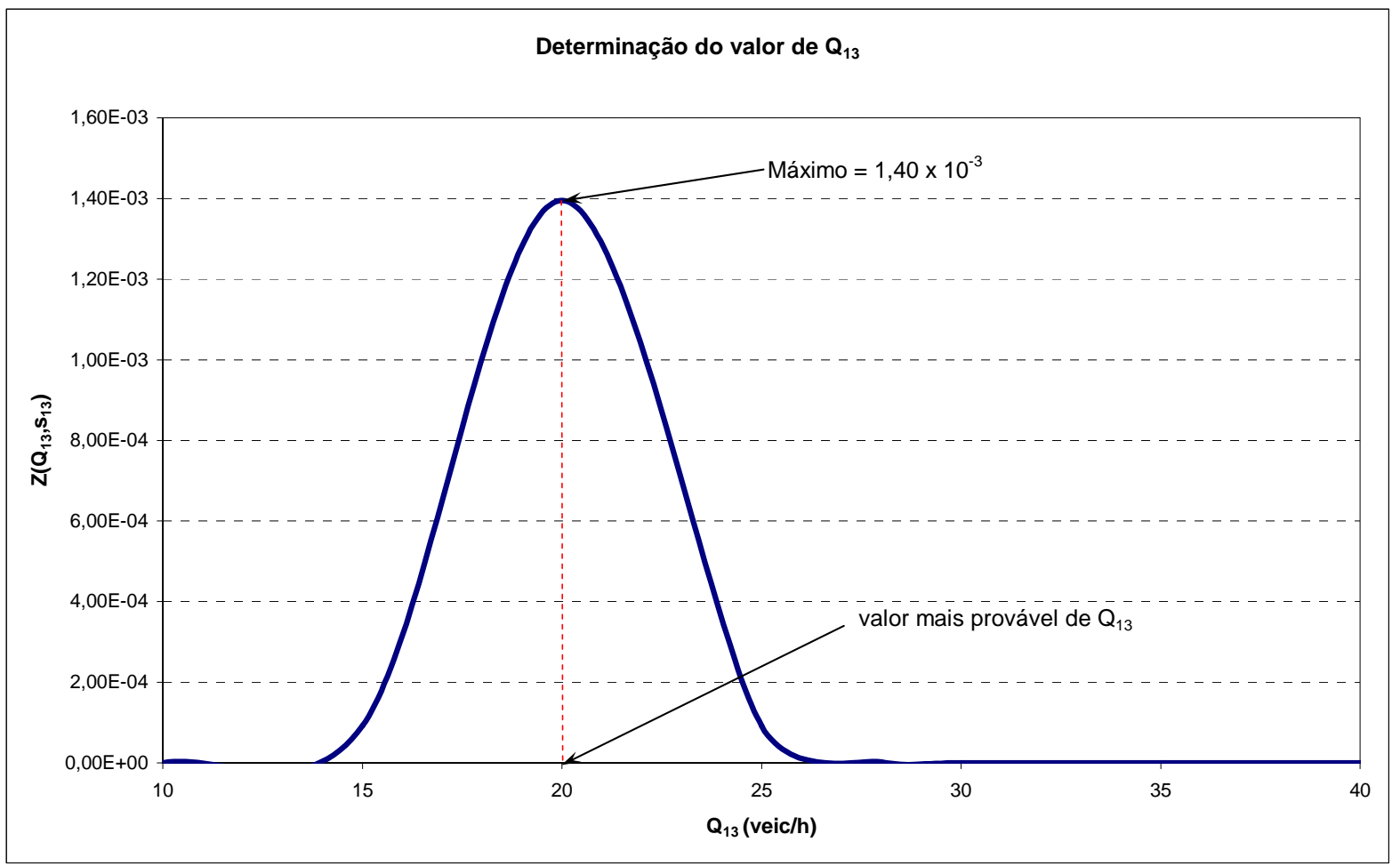

Figura 2. 6: Determinação do valor mais provável de $Q_{13}$, considerando matriz semente com $s_{13}=20$ veíc/h 
A matriz O-D estimada neste caso, considerando a Tabela 2.1 em que $Q_{13}=X=20$ veic/h, será exatamente igual a matriz semente (Tabela 2.2); a explicação é que a rede avaliada por Paramahamsan (1999) apresentava condições favoráveis à aplicação do modelo sintético, já que apresentava continuidade volumétrica em seus arcos e os caminhos entre os pares O-D eram únicos.

De acordo com Van Zuylen e Willumsen (1980) estes resultados seriam mais precisos que os obtidos sem considerar a matriz semente, porém, esta precisão está condicionada a qualidade da matriz semente a ser utilizada. Nas situações práticas em que não se tem uma matriz de viagens semente, pode-se utilizar uma matriz semente uniforme, mas isto implicará em um maior tempo de processamento e, apesar dos resultados estimados apresentarem maior probabilidade de ocorrência, não haverá garantias de que estes correspondam às expectativas. Caso uma matriz semente não seja conhecida aconselha-se utilizar a equação (2.23) para, desta maneira, evitar o surgimento de erros adicionais. Outra questão que poderá acarretar problemas é quando não há continuidade de fluxo em arcos contíguos.

\subsection{2 - Falta de continuidade de fluxo em arcos contíguos}

Na Figura 2.6 é apresentada uma rede com quatro pares O-D (1, 2, 3 e 4). É possível observar nesta figura duas situações distintas. Na Figura 2.7 (a) está havendo equilíbrio nos nós e observa-se continuidade de fluxo, ou seja, o fluxo que chega a um nó é igual ao fluxo que sai deste nó. Na Figura 2.7 (b), o equilíbrio nos nós já não é observado e a rede deixa de apresentar continuidade. 


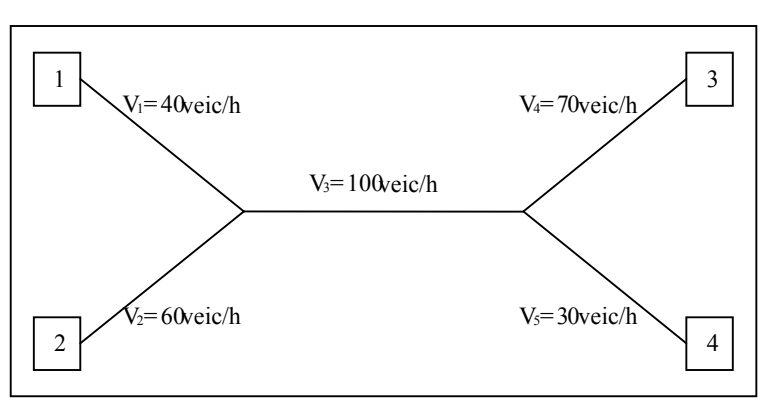

(a)

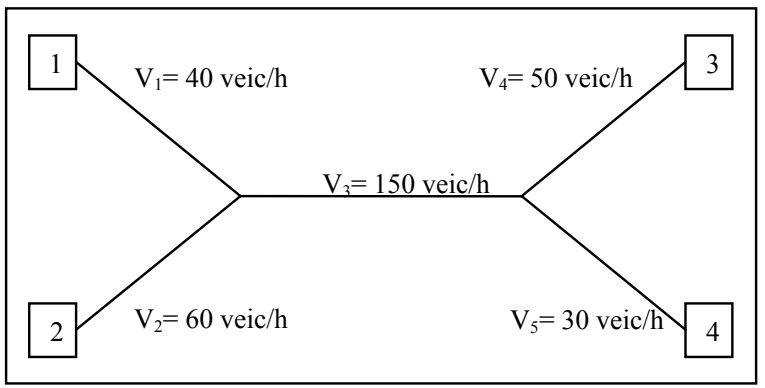

(b)

Figura 2. 7: Continuidade em arcos contíguos: (a) Rede com continuidade; (b) Rede sem continuidade Em situações práticas, é comum que a continuidade não seja observada, em função de dois aspectos. Em primeiro lugar, os fluxos de tráfego de diferentes arcos podem ter sido coletados em dias ou horários distintos e, dessa forma, nada garante que a continuidade seja obtida. Mesmo no caso em que as contagens de fluxo em todos os arcos da rede fossem realizadas em um mesmo período de um mesmo dia, a continuidade pode não ser obtida porque os veículos que saem da rede logo após o início do período de coleta não são contabilizados nos arcos mais próximos às origens da rede. Da mesma forma, é possível que os veículos que entram na rede um pouco antes do período de contagem terminar não sejam contabilizados nos arcos seguintes. Além disso, existem os próprios erros causados no procedimento de coleta de fluxos, como por exemplo, falhas no equipamento, no caso de redes monitoradas, ou então falha humana, nos casos de coletas manuais.

O primeiro critério adotado por Willumsen (1978) para que houvesse uma minimização dos erros envolvendo os fluxos, seria que $V_{o b s}^{a}=p_{i j}^{a} \cdot Q_{i j}=V_{e s t}^{a}$, porém conforme anteriormente descrito, diversos fatores não permitem a verificação desta condição. Muitos métodos para identificar e eliminar possíveis inconsistências nos fluxos observados têm sido propostos; dentre eles podem ser citados os trabalhos de Van Zuylen e Willumsen (1980), Van Zuylen (1981), Van Zuylen e Branston (1982), Bell (1983), Cascetta (1984), Carey e Revelli (1986) e Nielsen (1993), dentre outros. 
Van Zuylen e Willumsen (1980) apresentaram uma proposta para estimar o fluxo nos arcos com a eliminação das inconsistências, este conceito é baseado no equilíbrio do nó. Considere que $V_{\text {est }}^{a}$ seja o fluxo de veículos estimados em um arco a qualquer da rede viária e que $A_{a m}$ representa o equilíbrio do fluxo em um nó $m\left(A_{a m}\right.$ será 1 para o fluxo que entra no nó, -1 para o que sai do nó fazendo conversão e 0 para o fluxo no nó), considerando o equilíbrio em todos os nós da rede e os fluxos observados nos arcos, o modelo proposto seria representado pela seguinte equação (2.30):

$$
\sum_{a} A_{a m} V_{e s t}^{a}=0
$$

Considerando que foi realizada apenas uma observação de fluxo em cada arco $a$ e que o valor observado é representado por $V_{o b s}^{a}$ e este fluxo segue uma distribuição Poissoniana seria possível escrever $V_{e s t}^{a}$ da seguinte forma (2.31).

$$
V_{e s t}^{a}=\frac{V_{o b s}^{a}}{\left(1+\sum_{m} \lambda_{m} A_{a m}\right)}
$$

sendo $\lambda_{m}$ o multiplicador Lagrangeano.

O processo consiste em substituir (2.31) em (2.30) para se obter uma resposta. Os autores propuseram um algoritmo que torna isto mais fácil. Van Zuylen (1981) considerou esta mesma questão para a situação de tráfego misto, e posteriormente Van Zuylen e Branston (1982) consideraram a situação dos fluxos terem sido obtidos através de várias contagens, realizadas em períodos diferentes e propõem um algoritmo para esta resolução.

Porém este modelo muitas vezes se torna idealizado já que nem sempre é possível garantir a nulidade do erro; em algumas situações extremas pode até resultar em valores 
negativos de fluxos estimados. Por essas razões, pesquisas como a de Cascetta (1984) são consideradas importantes para superar esses problemas.

Cascetta (1984) propõe que as quantidades de viagens entre diferentes pares O-D sejam determinadas de tal forma que os fluxos resultantes destas viagens sejam os mais próximos possíveis dos respectivos fluxos observados, o que é obtido ao se minimizar a soma das diferenças quadráticas entre os fluxos observados e respectivos fluxos estimados, conforme apresentado na expressão (2.32).

$$
E=\sum_{a=1}^{o}\left(V_{o b s}^{a}-\sum_{i, j}^{z} p_{i j}^{a} \cdot Q_{i j}\right)^{2}, \forall a
$$

em que:

$\Rightarrow \quad E$ : erro a ser minimizado;

$\Rightarrow \quad V_{o b s}^{a}:$ fluxo observado no $\operatorname{arco} a[$ veíc $/ \mathrm{h}] ;$

$\Rightarrow \quad V_{e s t}^{a}:$ fluxo estimado para o $\operatorname{arco} a[\mathrm{veíc} / \mathrm{h}] ;$

$\Rightarrow \quad p_{i j}{ }^{a}$ : porcentagem das viagens $Q_{i j}$ que utiliza o arco $a$ e

$\Rightarrow \quad Q_{i j}$ : fluxo de viagens entre o nó de origem $i$ e o nó de destino $j[$ veíc/h].

Este modelo proposto por Cascetta pode ser considerado como o mais importante para solucionar os problemas referentes à continuidade do fluxo, muitos outros modelos foram derivados desta proposta. A maior parte dos programas que estimam matriz O-D sintética, já possuem em sua programação formas de, ao menos, minimizar os erros causados pelas observações de tráfego. Além desta dificuldade, existe uma questão que ainda não foi solucionada devidamente e se refere ao processo utilizado para estimação das viagens, principalmente quando a rede se encontra congestionada.

\subsection{3 - Estimativa das viagens quando a rede se encontra congestionada}

Os métodos convencionais, inicialmente propostos, para estimação de matriz O-D a partir de contagens de tráfego consideravam que o conjunto de rotas utilizadas por cada uma 
das viagens seria uma variável inalterada em função do carregamento da rede, sendo definida em função da alocação tudo-ou-nada (YANG et al., 1992). Possivelmente esta consideração foi feita desconsiderando os efeitos de congestionamento, pois do contrário esta não teria validade e faria com que a matriz O-D estimada, possivelmente, apresentasse erro (YANG; IIDA; SASAKI, 1994).

Diante de situações como esta, pesquisadores propuseram uma alternativa ao modelo, fazendo com que a matriz $p_{i j}$ não mais fosse fixa. Nguyen (1977), Gur et Al (1978) e Fisk (1988) apresentaram contribuições importantes neste campo, onde foi proposta a utilização de um método iterativo, levando em consideração a utilização em conjunto de modelos de geração e alocação do tráfego, como uma espécie de técnica bi-nível. De maneira geral, este método proposto considera que as viagens estimadas devem ser carregadas no caminho de custo mínimo até este deixar de sê-lo. Caso isso aconteça, o carregamento das viagens restantes passará a ser realizado em um novo caminho mínimo, e assim sucessivamente, até que todas as viagens estimadas estejam devidamente alocadas. Assim haveria garantia de que a escolha da rota poderia ser alterada em função do carregamento da rede, eliminando os problemas encontrados pelas simplificações apresentadas nos métodos convencionais. Porém as questões de congestionamento poderiam, mesmo assim, não ser totalmente resolvidas (YANG et al., 1992).

Yang et al (1992) apresentaram uma nova proposta para a técnica bi-nível na tentativa de resolver a questão das redes congestionadas. Nela, um modelo de mínimos quadrados para estimação de matriz O-D seria utilizado em conjunto com uma técnica de alocação do tipo equilíbrio do usuário. Estes dois procedimentos funcionariam simultaneamente através de técnicas de otimização. A grande dificuldade encontrada foi em relação à programação, principalmente devido à questão das possíveis inconsistências entre os fluxos observados e 
também em função de que, a cada etapa, os fluxos deveriam ser alocados de forma a garantir o equilíbrio da rede (YANG, 1995).

O algoritmo da técnica bi-nível proposto por Yang et al (1992), de uma maneira geral, poderia ser descrito da seguinte forma. Primeiramente, os efeitos do congestionamento teriam que ser incorporados ao modelo, e a forma mais usual seria a de inserir uma função de custo para cada arco, esta relacionando o fluxo observado com a capacidade do arco, como por exemplo, a função de impedância do Bureau of Public Roads (BPR) (BPR, 1964) (2.33). A rota escolhida a cada iteração seria a que apresentasse menor custo.

$$
t_{s}=T_{o}\left(1+\alpha \cdot\left(\frac{V_{o b s}^{s}}{C_{a p}^{s}}\right)^{\beta}\right)
$$

sendo:

$$
\begin{aligned}
& \Rightarrow t_{s}: \text { tempo no arco } s, \text { sendo este um arco pertencente ao conjunto L; } \\
& \Rightarrow T_{o}: \text { tempo de percurso no arco para condição de fluxo livre; } \\
& \Rightarrow V_{o b s}^{s}: \text { fluxo observado no arco s; } \\
& \Rightarrow C_{a p}^{s}: \text { capacidade do arco s; } \\
& \Rightarrow \alpha, \beta \text { : parâmetros de calibração, geralmente são utilizados } 0,15 \text { e } 4 \text { para cada um } \\
& \quad \text { dos parâmetros, respectivamente. }
\end{aligned}
$$

Após definidos os custos nos arcos uma matriz semente deverá ser alocada de forma que o equilíbrio do usuário na rede, proposto por Wardrop (1952), seja garantido. A partir desta alocação o processo vai se repetindo até que o número de iterações, ou alguma outra restrição, seja atingido. Este algoritmo foi incorporado pela grande maioria das pesquisas posteriores desenvolvidas sobre este tema.

Uma outra maneira adotada para resolver a técnica bi-nível é através da teoria dos jogos, como a técnica do "siga o líder" ou jogo de Stackelberg, utilizando a matriz semente 
como líder e o vetor de fluxos observados como seguidor; Fisk (1984) apresenta uma adaptação para esta questão. De maneira geral, é assumido que ao líder é dado o direito da primeira escolha e seleciona uma semente de acordo com suas viagens para minimizar a função objetivo, em função da comparação entre os fluxos observados e estimados. À luz desta decisão o seguidor estima, em seguida, um vetor de fluxo para minimizar sua função objetivo. O jogo de Stackelberg vem sendo utilizado em outras áreas do planejamento de sistemas de transportes com êxito, como por exemplo, em situações de otimização de projetos de redes de transportes e também na otimização de sistemas de controle de tráfego; nestes casos o sistema é o líder e os usuários da rede são os seguidores (YANG, 1995).

Seja qual for o procedimento adotado, devido à complexidade prática inerente à solução do sistema de equações, considerando o método iterativo, faz-se necessário o uso de rotinas computacionais ou programas específicos, especialmente no caso de redes maiores.

Nielsen (1993) desenvolveu um procedimento de estimação de matrizes O-D baseado no método iterativo. Este método foi implementado pela Caliper (1996) no TransCAD, que é uma importante ferramenta de modelagem da demanda baseada na plataforma SIG (Sistema de Informações Geográficas) utilizada em planejamento e operação de transportes.

A vantagem de seu método está em tratar os fluxos como uma variável estocástica e deve ser utilizado em conjunto com algum método de alocação de tráfego. Dentre os modelos de alocação, os mais indicados para este caso são: a) método de alocação de equilíbrio estocástico e b) método de equilíbrio.

A matriz prévia (semente) é então alocada à rede, definindo-se assim as porcentagens de utilização dos arcos; nesta primeira iteração é considerado que a rede opere na condição de fluxo livre. Com a matriz de utilização dos arcos já definida e com os fluxos observados nos arcos, é então realizado o processo de estimação da nova matriz O-D. 
A nova matriz O-D é então alocada à rede com a consideração de que a rede já não mais opere em regime de fluxo livre, passando a considerar a função de impedância do método do BPR, por exemplo. Este processo iterativo continua até que o número de iterações se complete ou até que a diferença entre os fluxos observados e estimados em cada arco chegue a um mínimo estipulado pelo usuário. As viagens são calculadas da seguinte forma (2.34).

$$
Q_{i j}=\frac{N_{a}}{\sum_{a} \frac{1}{Q_{(E) i j}^{a}}} ; \text { sendo } Q_{(E) i j}^{a}=\frac{V_{o b s}^{a}}{V_{a l o c}^{a}} S_{i j}
$$

Em que $N_{a}$ : é o número de viagens realizadas pelo caminho mínimo; $Q_{(E) i j}^{a}$ : expectativa de demanda entre $i j$ que passam pelo arco $a ; V_{a l o c}^{a}$ : fluxo alocado no arco $a$; os demais termos são como definidos anteriormente.

$\mathrm{Na}$ prática, o método de Nielsen foi estudado em alguns trabalhos e vários pesquisadores têm afirmado que obtiveram bons resultados com seu uso. Uma importante aplicação da técnica de estimar uma matriz O-D por este método, conforme sugerido no manual do TransCAD e pelo próprio Nielsen (1993), é quando se deseja fazer uma atualização da matriz de viagens obtida através de um recenseamento. A matriz é então atualizada para o ano horizonte, porém mantendo a proporção de viagens do ano base.

O TransCAD não estima uma matriz O-D sem a utilização de matriz semente. Também é possível fazer a escolha do processo de alocação que se deseja utilizar. São seis no total: equilíbrio do usuário, equilíbrio estocástico, otimização do sistema, restrição de capacidade, incremental e tudo-ou-nada. O número máximo de iterações a ser utilizado irá variar em função do critério de alocação adotado e o valor do erro máximo é definido em função dos critérios de cada usuário. 
Uma outra aplicação do método iterativo para estimação de matrizes O-D foi proposta por Van Aerde (1998) que, visando estimar as demandas necessárias para a calibração do simulador de tráfego INTEGRATION (RAKHA, 2001), desenvolveu o programa QUEENSOD (QOD). O QUEENSOD estima as demandas a partir de contagens de tráfego em vias e dos tempos de viagem dos arcos da rede viária.

O procedimento do QOD consiste em alocar a matriz O-D semente através do método do tudo-ou-nada em uma primeira iteração na rota de caminhos mínimos, à rede viária em estudo. Caso não exista uma semente, o programa automaticamente considerará uma matriz uniforme entre todos os pares O-D definidos. Desta forma é então definida a matriz de porcentagem de utilização do arco a cada uma das viagens. Com os fluxos de tráfego observados é feita a maximização da entropia, conforme definida por Van Zuylen e Willumsen (1980) (2.35) e então é estimada uma nova matriz O-D.

$$
\max Z\left(Q_{i j}, s_{i j}\right)=\frac{Q !}{\prod_{i j}\left(Q_{i j} !\right)} \prod_{i j}\left(\frac{s_{i j}}{S}\right)^{Q_{i j}}
$$

Sujeito a: $E=\sum_{a}\left(V_{o b s}^{a}-p_{i j}^{a} Q_{i j}\right)^{2} w^{a}$. Sendo $w^{a}$ fator de ponderação que varia conforme o tipo de critério de minimização de erro. Os demais fatores foram anteriormente definidos.

Esta nova matriz será alocada à rede viária seguindo os mesmos princípios anteriores, porém objetivando atingir o equilíbrio do usuário na rede viária; uma nova matriz de porcentagem de utilização do arco será definida e o processo se repetirá até completar o número de iterações definidos pelo usuário ou até a diferença entre fluxos observados e estimados chegar a um valor mínimo, de acordo com o critério $\left(w^{a}\right)$ adotado. 
Se em alguma iteração o caminho mínimo se tornar congestionado, uma porcentagem das viagens que utilizam este caminho será retirada e alocada ao segundo caminho definido como sendo mínimo, modificando desta forma a matriz de utilização do arco.

O QUEENSOD permite o estudo de até 5 caminhos por par O-D e a divisão em até 100 partes das viagens alocadas nos arcos (ex: o fluxo seria dividido em 100 partes de $1 \%$ e a cada iteração uma parte seria retirada da rota congestionada e alocada na próxima rota de menor caminho) para, dessa forma, evitar a questão da saturação da rede. A versão média do QUEENSOD permite a realização de no máximo 1000 iterações (VAN AERDE, 1998). A estrutura básica de funcionamento do QOD pode ser visualizada na Figura 2.8, que pretende refletir as características de funcionamento apresentadas em seu manual.

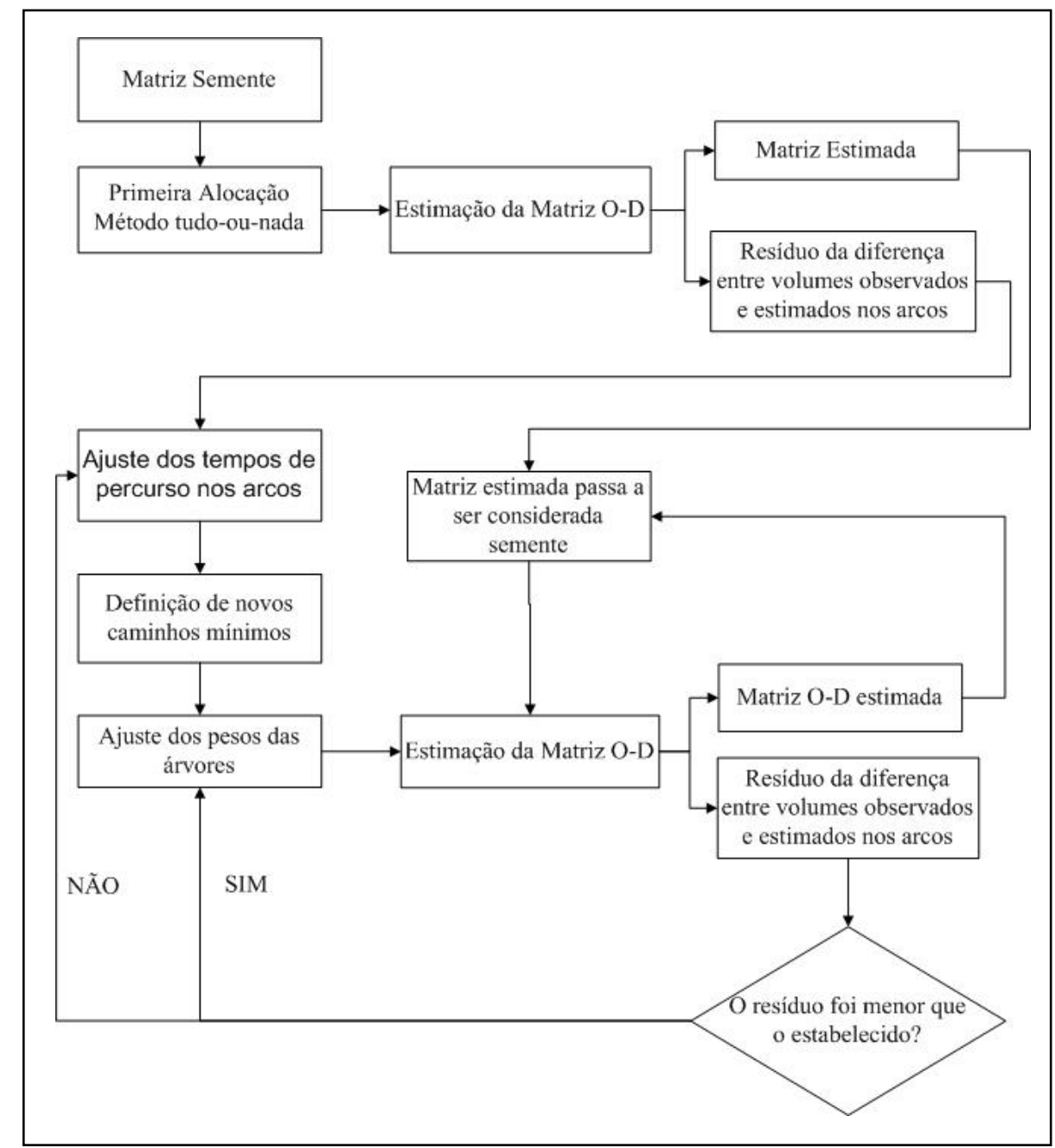

Figura 2. 8: Estrutura de funcionamento do QUEENSOD (Fonte: Manual do usuário do QUEENSOD, VAN AERDE, 1998) 
A técnica bi-nível para estimação de matriz O-D, de uma maneira geral, possui três aspectos positivos em relação ao método convencional inicialmente proposto: (i) O método sempre apresenta soluções possíveis; (ii) O método trabalha com apenas um subconjunto de fluxos observados nos arcos, e; (iii) A proporção de utilização dos arcos é determinada em função do carregamento garantido pelo equilíbrio dos arcos (YANG, 1995). Apesar de apresentar estes pontos positivos para sua utilização, este método necessita de rotinas computacionais mais elaboradas para que as iterações sejam realizadas. Uma outra questão é que as considerações de equilíbrio da rede exigem que os dados de entrada reflitam as condições de continuidade e consistência, para garantir bons resultados (YANG et al., 1992).

Em algumas situações, na tentativa de garantir o equilíbrio do usuário na rede, os valores dos fluxos estimados e observados são diferentes, não respeitando inclusive as restrições quanto a erro máximo tolerado. Também, é possível observar em situações extremas que viagens deixam de ser estimadas para que as condições de equilíbrio sejam respeitadas (NIELSEN, 1998).

Acredita-se que uma matriz O-D possa ser estimada sem a preocupação de utilizar uma programação complexa para realização de iterações, que muitas vezes não consegue convergir para uma boa solução, e também sem fazer simplificações quanto à escolha da rota, como era feito no início do desenvolvimento do modelo sintético. Um método alternativo ao atualmente em uso seria uma forma de contribuir para a melhoria dos resultados obtidos pelo modelo sintético.

No próximo capítulo será apresentado um método alternativo aos métodos iterativos para estimação da matriz O-D sintética e que consiste no objetivo deste trabalho. 
3.购豆回○(

\section{1 - CONSIDERAÇÕES INICIAIS}

O presente capítulo descreve o método a ser utilizado para atingir os objetivos desta pesquisa. Em uma primeira etapa será apresentada a formulação do processo de estimação de matriz O-D com base no carregamento incremental dos fluxos observados aos caminhos de custo mínimo. Posteriormente será apresentado o procedimento para verificar o desempenho do processo. O fluxograma apresentado na Figura 3.1 sintetiza as tarefas desenvolvidas ao longo desta dissertação. 


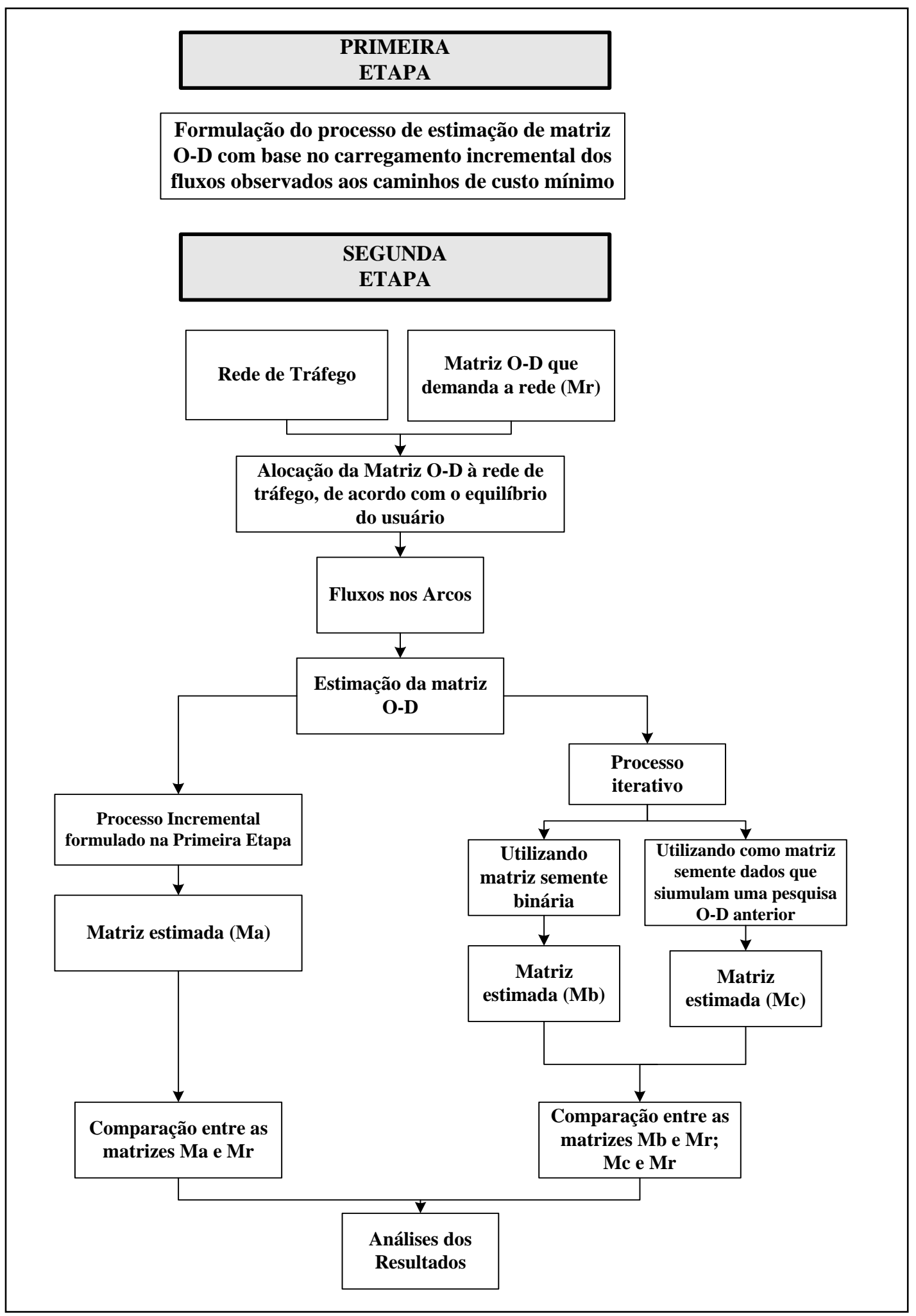

Figura 3. 1: Estrutura do Método 
$\Rightarrow$ PRIMEIRA ETAPA

\section{2 - FORMULAÇÃO DO PROCESSO DE ESTIMAÇÃO DE MATRIZ O-D COM BASE NO CARREGAMENTO INCREMENTAL DOS FLUXOS OBSERVADOS AOS CAMINHOS DE CUSTO MÍNIMO}

O método proposto relaciona o conceito de maximização da entropia associado a um carregamento incremental dos fluxos observados nos arcos da rede, considerando que a demanda é o resultado da soma sucessiva das demandas incrementais estimadas em função dos fluxos incrementais alocados à rede de tráfego através do processo tudo-ou-nada.

A idéia que se tem é que este método possa ser utilizado nas mais diversas situações de rede viária, como por exemplo: situações em que a rede viária encontra-se congestionada e também para aquelas em que não haja congestionamento, situações em que a rede apresenta ou não continuidade de fluxo nos arcos.

Na tentativa de detalhar o método que está sendo proposto considere R(N,L) uma rede de transporte composta por um conjunto $\mathrm{N}$ de nós e um conjunto $L$ de arcos orientados. Seja $O \subset L$ o conjunto contendo arcos cujos fluxos foram contados e $V=\left(V_{1}, V_{2}, \ldots, V_{o}\right)$ o conjunto de fluxos contados nos arcos $1,2, \ldots, o$, respectivamente.

Seja $v_{a}^{k}$ a $k$-ésima parcela do fluxo observado no arco $a \in O$, este valor pode ser expresso através da equação (3.1).

$$
v_{a}^{k}=f_{k} \cdot V_{o b s}^{a}
$$

Onde $f_{k} \in R_{+}$e se refere ao fator de incremento utilizado, dado em porcentagem, que satisfaz a condição $0<f_{k} \leq 1$, para $k=1,2, \ldots, m$, e a seguinte relação: 


$$
\sum_{k=1}^{m} f_{k}=1
$$

O tempo mínimo de percurso $\left(T_{i j}^{\text {min }}\right)$ entre $i$ e $j$ pelo caminho de custo mínimo $\left[C_{i j}^{\min }=\min \left(C_{i j}\right)\right]$, onde $C_{i j} \subset L$ representa o conjunto de caminhos alternativos de $i$ para $j$, é a soma dos tempos nos arcos $s \in c_{i j}^{\min }$ que compõem o caminho mínimo, ou seja:

$$
T_{i j}^{\min }=\sum_{s \in c_{i j}^{\min }} t_{s}
$$

sendo,

$\Rightarrow t_{s}=t_{s}\left(V_{s}, C_{s}\right)$ é o tempo de viagem no arco $s$ e dependente da relação entre fluxo e capacidade do arco $s$;

$\Rightarrow V_{s}$ : é o fluxo no arco orientado $s$;

$\Rightarrow C_{s}:$ é a capacidade do arco orientado $s$.

Considere, agora, o fluxo $V_{\text {est }}^{a}$ estimado para o arco $a$ pertencente ao conjunto $O$. Ele é composto por todos os fluxos $Q_{i j}$ da matriz O-D, com z origens e $z$ destinos, cujos caminhos de tempo mínimo passam pelo arco $a$. Se o fluxo $Q_{i j}$ passa pelo arco $a, p_{i j}^{a}=1$, senão $p_{i j}^{a}=0$.

$$
V_{e s t}^{a}=\sum_{i, j}^{z} p_{i j}^{a} \cdot Q_{i j}
$$

Se os arcos não tivessem restrição quanto à capacidade, todos os fluxos $Q_{i j}$ poderiam sempre utilizar os mesmos caminhos de tempo mínimo; assim, a matriz de $p_{i j}$ não seria alterada. Com isso, os fluxos $Q_{i j}$ poderiam ser satisfatoriamente estimados utilizando o princípio da maximização da entropia e as contagens de fluxo nos arcos. Em termos matemáticos, bastaria obter a solução para o problema de maximização do tipo:

$$
\operatorname{Maximizar} \sum_{i, j}^{z}\left(-Q_{i j} \ln Q_{i j}+Q_{i j}\right)
$$


Sujeito a $\sum_{a=1}^{o}\left(V_{o b s}^{a}-\sum_{i, j}^{z} p_{i j}^{a} \cdot Q_{i j}\right)^{2}$ para $i, j=1,2, \ldots, z$ (restrição propostas por Cascetta, 1984). sendo,

$\Rightarrow p_{i j}^{a}$ : porcentagem de viagens entre $i j$ que utilizam arco $a$;

$\Rightarrow o:$ total de arcos com contagem;

$\Rightarrow z:$ total de zonas de tráfego.

Considerando, porém, uma rede em que arcos estão sujeitos a congestionamento e que possua mais de uma rota em potencial entre $i$ e $j$, o caminho de tempo mínimo inicial é apenas válido para uma parte do fluxo $Q_{i j}$. Assim, tome-se um $f_{k}$ de tal maneira que os fluxos $f_{k} \cdot Q_{i j}^{k}$ alterem os tempos de viagem nos arcos de no máximo uma pequena porcentagem arbitrária P.

Desta forma, multiplicando ambos os membros da equação (3.4) por $f_{k}$, têm-se:

$$
f_{k} \cdot V_{\text {est }}^{a}=\sum_{i, j}^{n} p_{i j}^{a} \cdot f_{k} \cdot Q_{i j}^{k} \Rightarrow v_{a}^{k}=\sum_{i, j}^{n} p_{i j}^{a} \cdot q_{i j}^{k}
$$

Ou seja, desde que se assegure que o caminho de tempo mínimo praticamente se mantém para cada um dos elementos dos fluxos $f_{k} \cdot Q_{i j}^{k}$, é possível estimar satisfatoriamente o valor de $q_{i j}^{k}$, atribuindo aos arcos do conjunto $O$ os fluxos correspondentes a $f_{k} \cdot Q_{i j}^{k}$, repetindo o raciocínio desenvolvido acima.

$$
\text { Maximizar } \sum_{i, j}^{z}\left(-q_{i j}^{k} \ln q_{i j}^{k}+q_{i j}^{k}\right)
$$

Sujeito a $\sum_{a=1}^{o}\left(v_{a}^{k}-\sum_{i, j}^{z} p_{i j}^{a} \cdot q_{i j}^{k}\right)^{2}$ para $i, j=1,2, \ldots, z$

sendo $p_{i j}^{a}$, o e $z$ conforme definidos anteriormente.

Assim, ao considerar a primeira das $m$ parcelas das contagens nos arcos pertencentes ao conjunto $O, v_{a}^{1}=f_{1} \cdot V_{o b s}^{a}$, será obtido o valor de $q_{i j}^{1}$ que, alocado à rede, fará com que os 
tempos nos arcos aumentem de no máximo P\%. O tempo em cada arco $s$ deve ser corrigido utilizando a função $t_{s}^{1}=t_{s}^{1}\left(V_{s}^{1}, C_{s}\right)$, onde $V_{s}^{1}$ é o fluxo resultante no arco $s$ devido à primeira parcela $f_{1} \cdot V_{o b s}^{a}$.

Considerando os novos caminhos de custo mínimo corrigidos por $t_{s}^{1}$ e a segunda parcela das contagens nos arcos pertencentes ao conjunto $O, v_{a}^{2}=f_{2} \cdot V_{o b s}^{a}$, obtém-se a segunda parcela da matriz O-D, $q_{i j}^{2}=f_{2} \cdot Q_{i j}^{2}$. Corrigem-se novamente os tempos de percurso nos arcos da rede atribuindo a cada arco $s$ da rede o fluxo $V_{s}^{2}$, carregamento resultante das primeiras duas parcelas na função $t_{s}^{2}=t_{s}^{2}\left(V_{s}^{2}, C_{s}\right)$.

O processo deverá ser repetido até a última parcela $v_{a}^{m}=f_{m} \cdot V_{o b s}^{a}$ que, juntamente com os tempos de percurso nos arcos, $t_{s}^{m-1}=t_{s}^{m-1}\left(V_{s}^{m-1}, C_{s}\right)$, corrigidos pela (m-1)-ésima vez, dará a base para a estimação da $m$-ésima parcela da matriz O-D, $q_{i j}^{m}=f_{m} \cdot Q_{i j}^{m}$.

A matriz O-D, representada por $Q_{i j}$, será obtida usando a expressão (3.8), que representa a média ponderada das matrizes O-D $\left(Q_{i j}^{k}\right)$, obtidas para cada um dos $m$ conjuntos de caminhos mínimos. O peso da matriz $Q_{i j}^{k}$, na média, é o fator $f_{k}$.

$$
Q_{i j}=\sum_{k=1}^{m} q_{i j}^{k}=\sum_{k=1}^{m} f_{k} \cdot Q_{i j}^{k}
$$

Este procedimento gerará $m$ sub-matrizes O-D $\left(q_{i j}^{k}\right)$ que, depois de somadas, resultarão na matriz O-D final $\left(Q_{i j}\right)$. A matriz O-D será tanto mais precisa quanto menor for o valor de $f_{k}$. A explicação é que, quanto menor for cada parcela de incremento, menor será a variação no tempo de percurso em cada arco entre antes e depois do carregamento da parcela, fazendo com isto que o caminho mínimo não varie abruptamente. Portanto, erra-se menos ao 
supor que o tempo de viagem entre $i$ e $j$, pelo caminho de tempo mínimo, não se altera ao adicionar nos arcos fluxos devido à esta parcela, sendo que o erro máximo nestas condições será de no máximo o valor do fator de incremento.

A vantagem, teoricamente, deste método está no fato de que as viagens sempre irão utilizar os caminhos mínimos; assim, basta uma simples alocação do tipo tudo-ou-nada, em função dos tempos de percurso dos $(k-1)$ volumes incrementais acumulados para que a matriz $p_{i j}^{k}$ seja definida. A cada incremento uma nova matriz $p_{i j}$ deverá ser obtida para que se possa estimar a matriz O-D.

\subsection{1 - Número de incrementos a ser adotado}

A quantidade de incrementos a ser utilizada será função do erro máximo que se deseja obter em relação à escolha do caminho mínimo. O erro, em termos de fluxo, será no máximo igual ao fator de incremento adotado. Assim, caso se queira um erro máximo de 1\%, por exemplo, o valor de $f_{k}$ a ser adotado será 0,01 , e poderiam ser adotados 100 incrementos iguais $\left(\sum_{k=1}^{m} f_{k}=1,00\right)$. Da mesma forma, se o erro admissível fosse de $2 \%$, bastaria adotar um $f_{k}$ igual a 0,02 , nesse caso existiriam 50 incrementos de $2 \%$ cada.

Na realidade, o número de incrementos pode ser menor do que 100 para um erro máximo de $1 \%$ ou menor do que 50 para um erro máximo de $2 \%$, pois os primeiros incrementos praticamente não alteram o caminho mínimo inicial entre os pares O-D.

De fato, admitindo-se que a expressão proposta pelo BPR em 1964 (3.9) expresse bem a relação entre o tempo de percurso e a razão fluxo/capacidade (V/C), e admitindo que os parâmetros $\alpha=0,15$ e $\beta=4,00$ sejam apropriados para a área em estudo, pode-se dizer que o tempo de percurso aumenta em $1 \%$ quando a relação V/C for igual a 0,51. Desta forma, a 
menos que a primeira alternativa ao caminho mínimo tenha um tempo de percurso em fluxo livre menor que este tempo aumentado em 1\%, um fluxo igual a 0,51 vezes o valor da capacidade não irá alterar o caminho mínimo.

$$
t_{s}=T_{o}\left(1+\alpha \cdot\left(\frac{V_{o b s}^{s}}{C_{a p}^{s}}\right)^{\beta}\right)
$$

Sendo,

$\Rightarrow t_{s}$ : tempo no arco $s$, sendo este um arco pertencente ao conjunto $L$;

$\Rightarrow T_{o}$ : tempo de percurso no arco para condição de fluxo livre;

$\Rightarrow V_{o b s}^{s}$ : fluxo observado no arco s;

$\Rightarrow C_{a p}^{s}:$ capacidade do arco s;

$\Rightarrow \alpha, \beta$ : parâmetros de calibração, geralmente são utilizados 0,15 e 4 para cada um dos parâmetros respectivamente.

Então, para se obter o valor do fator de incremento inicial, em função de um erro máximo, basta dividir o valor de V/C, que provoca um aumento de apenas $1 \%$ no tempo de percurso, caso este seja o valor que provoque alteração no tempo de percurso, pelo valor máximo de V/C observado.

A título de exemplo, suponha que uma contagem nos arcos de uma rede tenha indicado um V/C máximo de 1,20. Se o erro máximo admissível é de $2 \%$ e adotando V/C = 0,50 , que provoca um aumento de $0,9 \%$ no tempo de percurso, o fator de incremento $f_{1}$ pode ser calculado como segue (3.10):

$$
f_{1}=\frac{(V / C)_{e s p}}{(V / C)_{\text {máx }}}=\frac{0,5}{1,2}=0,42
$$


Nesta situação, fazer um carregamento inicial de 42\%, considerando um erro de $2 \%$, equivale a afirmar que, caso fosse feita a opção por utilizar 50 incrementos cada um $\operatorname{com} f_{k}$ de $2 \%$ somente após o $21^{\circ}$ carregamento de volume é que o tempo de percurso alteraria de no máximo 0,9\%. Assim ao invés de utilizar 50 incrementos de $2 \%$ cada, será utilizado um incremento de $42 \%$ e 29 incrementos de 2\%, ou seja, foi possível reduzir 20 incrementos, sem alterar o erro. Desta forma, pode-se fazer a opção por erros ainda menores sem, no entanto, aumentar muito a quantidade de incrementos utilizada bem como o tempo de processamento para a obtenção da matriz O-D. É importante ressaltar que os eventuais erros resultantes do primeiro carregamento serão corrigidos pelos carregamentos seguintes.

$\Rightarrow$ SEGUNDA ETAPA

\section{3 - PROCEDIMENTO EMPREGADO PARA VERIFICAR O DESEMPENHO DO MÉTODO INCREMENTAL}

O seguinte experimento foi adotado para verificar o desempenho do método de carregamento incremental de fluxos para estimação da matriz O-D, apresentado na primeira etapa: a) adoção de uma rede viária e de uma matriz O-D que demanda a rede; b) alocação da demanda à rede usando o método de equilíbrio do usuário, considerando como custo o tempo de viagem entre pares O-D; c) hipotética contagem nos arcos, em que se supôs que os fluxos observados serão exatamente iguais aos fluxos resultantes da alocação; d) estimação da matriz O-D a partir das contagens nos arcos; este item será desmembrado em dois subitens: $d_{1}$ ) estimação da matriz O-D com carregamento incremental dos fluxos, $d_{2}$ ) estimação da matriz O-D através do método iterativo; e e) comparação entre matrizes e análise dos resultados. Neste capítulo será apresentada apenas a seqüência teórica a ser adotada; a realização de cada uma destas etapas é apresentada nos Capítulos 4 e 5. 


\subsection{1 - Adoção de uma rede viária e de uma matriz O-D}

Para testar o método proposto faz-se necessário o conhecimento de uma rede viária, hipotética ou não, que possua mais de um caminho ligando cada par O-D e que tenha uma matriz O-D conhecida, para que ela possa ser utilizada como referência para comparação dos resultados obtidos.

Em relação ao tamanho da rede viária a ser utilizada, não seria interessante, em termos de verificação do método, que esta seja muito grande, pois poderia implicar dificuldades na avaliação dos resultados obtidos. Por outro lado, uma rede muito pequena apresentaria resultados óbvios e não contribuiria para a análise comparativa entre a matriz O-D estimada e a matriz O-D original.

Devido à dificuldade de encontrar uma rede com tais características, que possuísse uma matriz O-D observada e também um levantamento de fluxo em seus arcos, optou-se por realizar o experimento utilizando uma rede viária hipotética.

\subsection{2 - Alocação da demanda à rede viária}

Os métodos mais comuns de alocação de tráfego, encontrados na grande maioria dos programas voltados à engenharia e ao planejamento de transportes, são: alocação tudo-ounada; estocástica; incremental; restrição de capacidade; equilíbrio do usuário; equilíbrio estocástico do usuário, e; otimização do sistema.

Alguns métodos, como por exemplo o de alocação tudo-ou-nada, ignoram o fato de que o tempo de viagem em um arco depende da possível variação do fluxo, ao longo do tempo, nele observado.

Em contrapartida, os métodos baseados na teoria do equilíbrio (WARDROP, 1952) buscam, de alguma forma, fazer com que a alocação do tráfego siga uma tendência mais 
realista, procurando representar a variação do fluxo ao longo do tempo. Em suma, estes métodos consideram que o tempo é dependente do fluxo observado no arco e procuram fazer com que os tempos de viagem pelos mais variados caminhos sejam equivalentes. Atualmente os métodos baseados no equilíbrio dividem-se em dois conjuntos, um considera o equilíbrio do usuário e o outro o equilíbrio estocástico do usuário (ORTÚZAR; WILLUMSEN, 1994).

O equilíbrio do usuário possui como princípio o fato de que todo usuário da via tem conhecimento prévio dos caminhos e alternativas da rede em estudo e que este sempre irá escolher a rota que minimizar os custos de viagem por ele definidos (Ex.: tempo, monetário etc). O primeiro a propor este conceito foi Wardrop (1952), onde, de acordo com ele, um viajante não poderia individualmente possuir o menor custo de viagem em um caminho.

Neste trabalho será feita a opção de alocar a matriz O-D à rede viária utilizando o método do equilíbrio do usuário, garantindo assim que os volumes alocados reflitam as condições de equilíbrio e continuidade.

\subsection{3 - Hipotética contagem nos arcos}

Para efeito da verificação proposta, os fluxos nos arcos, resultantes da alocação (item 3.3.2), serão aqui considerados como se tivessem sido obtidos através da contagem. A idéia que está por trás da consideração é: se a alocação da matriz O-D à rede de transportes resultou nos fluxos nos arcos da rede, e se os fundamentos teóricos do modelo sintético estiverem corretos, deve-se obter a mesma matriz O-D que originou esta hipotética contagem dos fluxos nos arcos, desde que a mesma relação de tempo em função de V/C seja utilizada tanto na alocação quanto na obtenção da matriz O-D a partir dos fluxos.

Aos fluxos observados serão garantidas as condições referentes à continuidade e ao equilíbrio, que são requisitos para se obter resultados de qualidade ao utilizar o método iterativo para estimação de matriz O-D (YANG et al., 1992). 


\subsection{4 - Estimação da matriz O-D em função das contagens volumétricas}

O processo de estimação da matriz O-D adotado neste trabalho será dividido em duas etapas, a fim de cumprir os objetivos definidos no Capítulo 1: (i) uma matriz O-D será estimada levando em consideração a proposta principal deste trabalho, que é a de carregar incrementalmente os fluxos observados, e; (ii) outras duas matrizes serão estimadas através de processos iterativos, de forma a atender aos objetivos secundários deste trabalho.

Para estimação da matriz O-D sintética, nos dois casos, serão utilizados o QUEENSOD e o TransCAD. A escolha destes programas deve-se a disponibilidade na EESC-USP e ao fato de serem largamente utilizados no processo de estimação de matrizes O-D sintéticas. Para a etapa (i) será necessário que algumas “adaptações” sejam feitas, pois estes programas não estimam matriz O-D seguindo tais considerações. A seguir serão apresentados os detalhes de como se dará o procedimento de estimação da matriz O-D em cada uma das duas etapas.

\subsubsection{1 - Carregamento incremental dos fluxos para estimação da demanda}

O objetivo neste item é descrever como será realizado o processo de estimação da matriz O-D considerando o carregamento incremental esta etapa será denominada Caso A. Por não ter sido possível neste trabalho desenvolver um programa que estimasse demandas considerando o processo incremental de carregamento de fluxos, fez-se a opção por utilizar os programas QUEENSOD e TransCAD, de uma maneira adaptada. As adaptações estarão presentes na definição dos parâmetros e na quantidade de vezes que cada programa deverá ser processado para estimar as sub-matrizes.

Para que o QUEENSOD e o TransCAD estimem matrizes O-D faz-se necessário que sejam estabelecidos alguns parâmetros, tais como: número de iterações, erro máximo entre o fluxo observado e o estimado, critérios a serem utilizados para minimização do erro, número de caminhos entre cada par O-D e o critério de alocação a ser utilizado. Também é necessário 
que uma matriz O-D semente seja adotada. A adoção destes valores se dará em função dos resultados obtidos em outras pesquisas realizadas considerando o impacto que sua variação causa nos resultados. A seguir, serão detalhados os valores dos parâmetros adotados.

- Número de iterações:

Este parâmetro representa o primeiro critério de parada dos programas. Em relação ao número de iterações será estabelecida a utilização de 1 iteração para cada programa, pois no processo incremental basta apenas a definição do caminho mínimo, que será utilizado pelas viagens, para a estimação da matriz O-D.

- Erro máximo pretendido entre a diferença dos volumes observados e estimados:

A proporção entre o fluxo estimado e o observado nos arcos constitui o segundo critério de parada dos dois programas. O valor para este erro que será adotado é de 1\%, em ambos os programas.

- Critérios adotados para minimização dos erros:

Este parâmetro é necessário apenas para o QUEENSOD e está relacionado com a minimização do erro adotado para a estimativa das demandas e volumes. Existem três opções possíveis: erro quadrático (código 1), erro Poissoniano (código 2) e erro relativo (código 3). Como essas opções valem tanto para a estimativa de demandas como para volumes, existem no total nove combinações possíveis de critérios para o cálculo dos erros.

De acordo com Demarchi, Bertoncini e Lima (2004), os melhores resultados são obtidos quando se utiliza a combinação “31”, que considera um erro relativo (3.11) para as demandas e erro quadrático (3.12) para os volumes. Essa combinação no estudo por eles realizado apresentou que $80 \%$ dos erros volumétricos relativos, para a rede viária de MaringáPr, estariam contidos na faixa de $-20 \%$ a $+20 \%$ e o coeficiente de correlação entre volumes 
observados e estimados seria para este caso 0,9033, o melhor desempenho dentre as 9 combinações estudadas.

$$
\begin{gathered}
E R=\sum_{a}\left(V_{o b s}^{a}-p_{i j}^{a} Q_{i j}\right)^{2} \cdot \frac{1}{V_{o b s}^{a}} \\
E Q=\sum_{a}\left(V_{o b s}^{a}-p_{i j}^{a} Q_{i j}\right)^{2} \cdot 1
\end{gathered}
$$

Sendo,

$\Rightarrow E R$ : erro relativo (código 3). Critério adotado para minimizar o erro entre a matriz semente e a estimada;

$\Rightarrow E Q$ : erro quadrático (código 1). Critério adotado para minimizar o erro volumétrico;

$\Rightarrow V_{\text {obs }}^{a}$ : volume observado no $\operatorname{arco} a$;

$\Rightarrow \quad p_{i j}^{a}$ : porcentagem de utilização do arco $a$ pelas viagens $i j$;

$\Rightarrow Q_{i j}$ : demanda estimada entre $i j$.

- Quantidade de caminhos a ser verificada a cada iteração:

O QUEENSOD requer a definição da quantidade de caminhos alternativos, entre cada par O-D, que deverá ser verificada a cada iteração. Rakha et al. (1998) mencionam que o valor do coeficiente de correlação entre volumes observados e estimados, para diferentes períodos do dia na região metropolitana de Salt Lake City nos Estados Unidos, aumentou em média 0,01 quando duas rotas para cada par O-D foram consideradas, em comparação ao uso de um único conjunto de rotas. Desta maneira foi adotado, para este estudo, que o QOD poderá avaliar até 5 possibilidades de caminhos, sendo que esta é a quantidade máxima permitida pela versão disponível do programa na Escola de Engenharia de São Carlos Universidade de São Paulo.

- Método de alocação a ser utilizado: 
A técnica de alocação a ser utilizada será a do tudo-ou-nada.

- Matriz semente:

É importante ressaltar que o método proposto neste trabalho independe do conhecimento prévio de uma matriz O-D, mas, para garantir o funcionamento dos dois programas será adotada a utilização de uma matriz semente do tipo binário.

Além destes parâmetros para a calibração de cada um dos programas, existem outros inerentes ao método incremental. A quantidade de incrementos que será utilizada, por exemplo, é um destes parâmetros e com este valor será possível saber quantas vezes cada programa precisará ser acionado, lembrando que a cada vez que isso ocorrer uma sub-matriz será estimada. Esta quantidade de incrementos será função de um outro parâmetro que é o erro máximo pretendido devido à escolha dos caminhos mínimos, e este permitirá definir o chamado fator de incremento, conforme item 3.2.1.

Definidos os valores da quantidade de incrementos e seus respectivos fatores, será necessário que os volumes de cada arco sejam multiplicados pelas parcelas de incremento $\left(f_{k}\right)$, estabelecidas em função do erro máximo. Deve-se também calcular os tempos de percurso em cada arco relacionando o fluxo acumulado e a capacidade, de acordo com a equação do BPR (1964), e então proceder a construção dos arquivos referentes a estes dados em cada um dos programas (QOD e TransCAD), para desta maneira estimar as sub-matrizes O-D.

De posse de todas as sub-matrizes estimadas será determinada a matriz O-D estimada e para isso foi desenvolvida uma planilha no Microsoft Excel que fará a soma das submatrizes. Uma planilha semelhante também foi desenvolvida para fazer a soma dos volumes estimados nos arcos. 


\subsubsection{2 - Estimação da matriz O-D utilizando o método iterativo}

Esta etapa servirá para gerar os resultados necessários à verificação do objetivo secundário desta pesquisa. A estimação das matrizes nesta etapa será feita utilizando também o QuEENSOD e o TransCAD, porém, sem nenhuma adaptação. Os parâmetros considerados foram:

- Número de iterações:

Em relação ao número de iterações será estabelecido que cada programa poderá utilizar até 1000 iterações para se chegar na resposta, porém se antes de completar estas iterações o segundo critério de parada for satisfeito, suspende-se a realização das iterações restantes. A escolha desta quantidade de iterações deve-se às limitações existentes na versão média do QUEENSOD, disponível na EESC-USP.

- Método de alocação a ser utilizado:

A técnica de alocação a ser utilizada varia conforme o programa. O QOD trabalha primeiramente com a alocação tudo-ou-nada e com o transcorrer das iterações ele procura atingir o equilíbrio da rede. Já o TransCAD permite a escolha de até nove formas diferentes de alocação. Neste trabalho será adotada a técnica de equilíbrio do usuário, com a função de impedância desenvolvida pelo BPR (1964).

- Matriz semente a ser utilizada:

Por fim, sabe-se que a utilização de uma matriz semente é necessária para o processo iterativo. Mesmo o QOD que não impõe este arquivo como uma variável de entrada obrigatória, considera que em sua ausência existirá uma matriz semente uniforme onde permitirá que viagens sejam realizadas entre todos os pares O-D. Tendo em vista estas circunstâncias foi definido que seriam utilizados dois tipos de matrizes semente. 
No primeiro, definido como Caso B, a matriz semente será do tipo binária, onde se atribuirá o valor 1 para os pares que possuírem viagens e 0 para aqueles que não possuírem, assim evita-se que os pares O-D que não possuam viagens entre si venham a apresentá-las.

Alguns pesquisadores como, por exemplo, Nielsen (1993) afirmam que através do método iterativo é possível realizar a atualização de dados a partir de pesquisas O-D anteriores. Na tentativa de verificar esta situação foi criado o Caso C. Este caso irá procurar ilustrar a situação de uma pesquisa O-D realizada, por exemplo, há 10 anos e é de interesse que seja feita a atualização da matriz O-D. Considerando uma taxa de crescimento das viagens de 2,7\% a.a. em média, nesta situação, a matriz semente corresponderá a $70 \%$ da matriz observada adotada no experimento, sendo que esta condição é amplamente favorável, teoricamente, a um melhor desempenho dos processos convencionais, pois além dos fluxos de tráfego refletirem os dados de viagem da matriz “real”, a matriz semente apresentará uma proporcionalidade com esta matiz.

Os demais parâmetros adotados correspondem aos definidos no subitem 3.3.4.1.

\subsection{5 - Comparação entre matrizes e análise dos resultados}

Esta etapa terá por objetivo fazer uma verificação do desempenho do método proposto em relação a amostra "real” e aos valores estimados pelos métodos iterativos, e será dividida em duas partes: (i) Análise das diferenças dos valores da matriz O-D estimada incrementalmente em relação à matriz O-D “real”; e (ii) Análise entre os erros de estimação resultantes do método incremental em relação aos resultantes dos métodos iterativos. A aplicação deste item para os resultados obtidos com os testes experimentais será apresentada no Capítulo 5. 
Não será feita uma análise envolvendo os fluxos “reais” e estimados. Acredita-se que as restrições adotadas por cada programa em relação ao fluxo possam interferir nas análises caso um comparativo entre estes valores seja realizado.

A rigor, os fluxos estimados pelo TransCAD devem ser muito mais próximos aos observados, pois, neste programa a restrição quanto aos fluxos segue a consideração fundamental do modelo sintético de que $V_{o b s}^{a}=\sum_{i j} p_{i j} Q_{i j}$. Enquanto que o QUEENSOD possui uma restrição adaptada da equação de Cascetta (1984) que pode favorecer as questões de continuidade.

3.3.5.1 - Análise das diferenças dos valores da matriz O-D estimada incrementalmente em relação à matriz O-D “real”

Neste item serão inicialmente apresentados os valores totais das viagens geradas pelo método incremental e estes serão comparados com o total de viagens geradas na situação “real”.

Posteriormente será feito uma análise entre os valores das viagens estimadas pelo método proposto e os valores "reais", de forma a verificar o desempenho do processo de carregamento incremental dos fluxos. No total serão realizadas três verificações:

a) verificação das diferenças absolutas obtidas entre o valor "real” e o valor estimado (3.17), sendo feita uma análise quanto a somatória total destas diferenças.

$$
\left|\Delta Q_{i j}\right|=\left|Q_{i j}^{o b s}-Q_{i j}^{e s t}\right|
$$

Sendo, $\left|\Delta Q_{i j}\right|$ a diferença absoluta entre matriz “real” e estimada.

b) verificação das diferenças quadráticas entre o observado e o estimado (3.18).

$$
\left(\Delta Q_{i j}\right)^{2}=\left(Q_{i j}^{o b s}-Q_{i j}^{e s t}\right)^{2}
$$


Sendo, $\left(\Delta Q_{i j}\right)^{2}$ correspondente ao valor da diferença quadrática entre matriz “real” e estimada.

c) verificação do erro relativo entre as viagens. Será calculado de acordo com a equação (3.16).

$$
\left|e_{r}^{Q_{i j}}\right|=\frac{\left|Q_{i j}^{\text {real }}-Q_{i j}^{\text {est }}\right|}{Q_{i j}^{\text {real }}}
$$

Sendo,

$\Rightarrow \quad\left|e_{r}^{Q_{i j}}\right|:$ valor absoluto do erro relativo referente as viagens entre $i j$;

$\Rightarrow \quad Q_{i j}^{\text {real }}$ : valor da viagem entre $i$ e $j$ “real”; e

$\Rightarrow \quad Q_{i j}^{\text {est }}$ : valor da viagem entre $i$ e $j$ estimado. 
O erro relativo posteriormente será agrupado em três tipos de freqüência, cuja amplitude será de 10\%: (i) absoluta: expressa o número de ocorrências dentro do intervalo considerado; (ii) relativa: é o percentual de ocorrência de erro para este intervalo em relação à soma das freqüências absolutas de cada intervalo; (iii) acumulada: é representada pela soma das freqüências relativas, até o intervalo de distribuição considerado. Esta comparação será realizada através da distribuição de freqüências dos erros relativos, entre os valores observados e estimados. Embora esta forma não ofereça critérios objetivos que permitam emitir juízo a respeito da comparação, ela possibilita a verificação intuitiva do desempenho do método.

A faixa para distribuição dos erros relativos será escolhida em função da que melhor representar a distribuição.

Os valores obtidos serão apresentados em formas de tabelas e serão feitas discussões a respeito das causas desses erros. Esta análise será descrita no Capítulo 5.

Apenas estas análises não são suficientes, desta forma será verificado também o desempenho dos métodos iterativos para desta forma ter um outro parâmetro de comparação e assim verificar a utilidade do método incremental.

3.3.5.2 - Análise entre os erros de estimação resultantes do método incremental em relação aos resultantes dos métodos iterativos

Com a realização deste item pretende-se atingir os objetivos secundários deste trabalho, que consiste em comparar os resultados obtidos pelo método proposto com os obtidos pelos métodos iterativos, embutidos no QOD e TransCAD. Para tal, serão utilizadas as seguintes análises: 
a) Inicialmente os totais de viagens geradas pelos métodos iterativos considerando os casos B e C, serão comparados com o total de viagem “real”.

b) Posteriormente serão realizadas duas análises comparativas:

(i) verificação das diferenças absolutas obtidas entre o valor "real” e o valor estimado (3.16), para ambos os métodos (incremental e iterativo).

(ii) verificação das diferenças quadráticas entre o observado e o estimado (3.17), para ambos os métodos.

c) Também será feita uma verificação em função da distribuição dos erros relativos. Serão considerados os erros relativos, obtidos para os dois métodos em relação aos valores “reais”, conforme (3.18) e estes valores também serão distribuídos em faixas de erros, conforme definido no subitem 3.3.5.1.

d) A última análise consistirá em verificar o comportamento do erro relativo em função dos tempos de percurso dos caminhos mínimos entre os pares O-D. Com isto será possível relacionar os erros relativos com as distâncias e, assim, verificar com qual distância estão relacionados os maiores erros. 


\section{1 - DESCRIÇÃO DOS TESTES EXPERIMENTAIS}

Os testes experimentais constituem um conjunto de etapas cujo objetivo é a obtenção dos dados necessários para que o desempenho do método proposto por este trabalho possa ser verificado. A seqüência que será apresentada a seguir é equivalente ao conjunto de procedimentos definidos na segunda etapa do método.

\subsection{1 - Definição da rede viária, de uma matriz O-D que demanda a rede e dos fluxos de tráfego observados \\ Conforme comentado no Capítulo 3, item 3.3.1, a rede em questão deverá possuir} mais de um caminho entre cada par O-D, para assim, permitir com que as viagens possuam mais de uma opção de rota para serem realizadas. Para fins de avaliação do método proposto, a rede escolhida não deverá ser formada por muitos arcos e muitos pares O-D, pois poderia de alguma forma prejudicar as análises, e também uma pequena quantidade de arcos ou pares O-D não é interessante, de forma a evitar que apresente apenas resultados óbvios que contribuam para a verificação do método, a rede escolhida irá procurar representar a região central de uma cidade de porte médio. Além disso, a rede deverá possuir uma matriz O-D conhecida, para que possa ser utilizada como referência nas análises. 
Devido ao fato de não se dispor de uma rede viária "real” com as características e informações necessárias para a realização deste experimento fez-se a opção por utilizar uma rede viária hipotética. Na Figura 4.1 é possível visualizar a rede adotada.

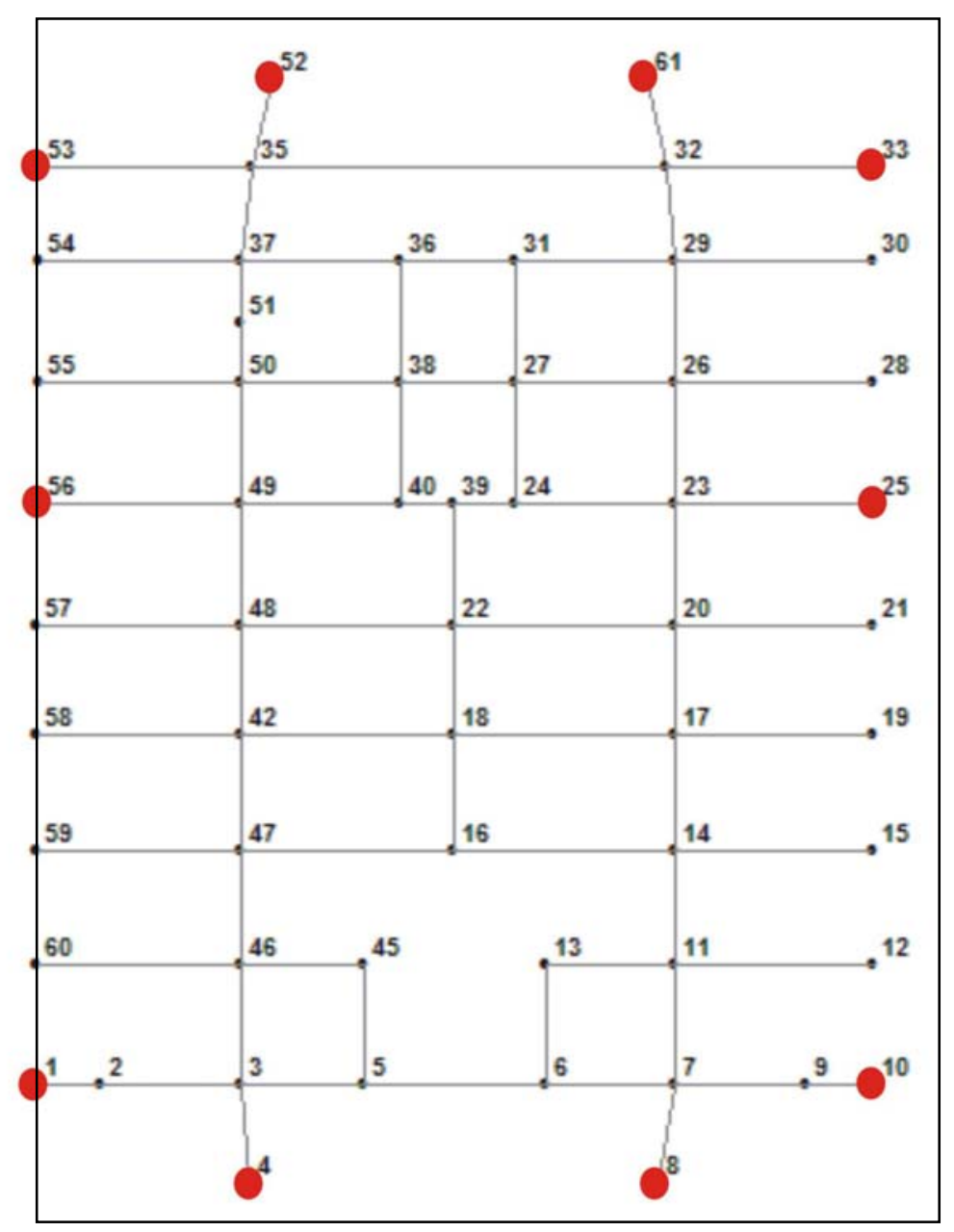

Figura 4. 1: Hipotética rede viária utilizada para verificar o desempenho dos métodos de estimação de matrizes O-D

Esta rede é formada por 57 nós, sendo que destes, 10 são do tipo origem-destino, conforme pode ser observado nos pontos destacados, e os 47 restantes são considerados intermediários ou de ligação. Além dos nós, 144 arcos bidirecionais completam a rede, conectando entre si cada um dos nós. Entre cada par O-D existe a possibilidade de que as viagens sejam realizadas por mais de um caminho possível, não existe restrição em relação a movimentos de conversão. Outras informações adicionais relevantes, tais como, capacidade e número de faixas, estão apresentadas na Tabela 4.1. 


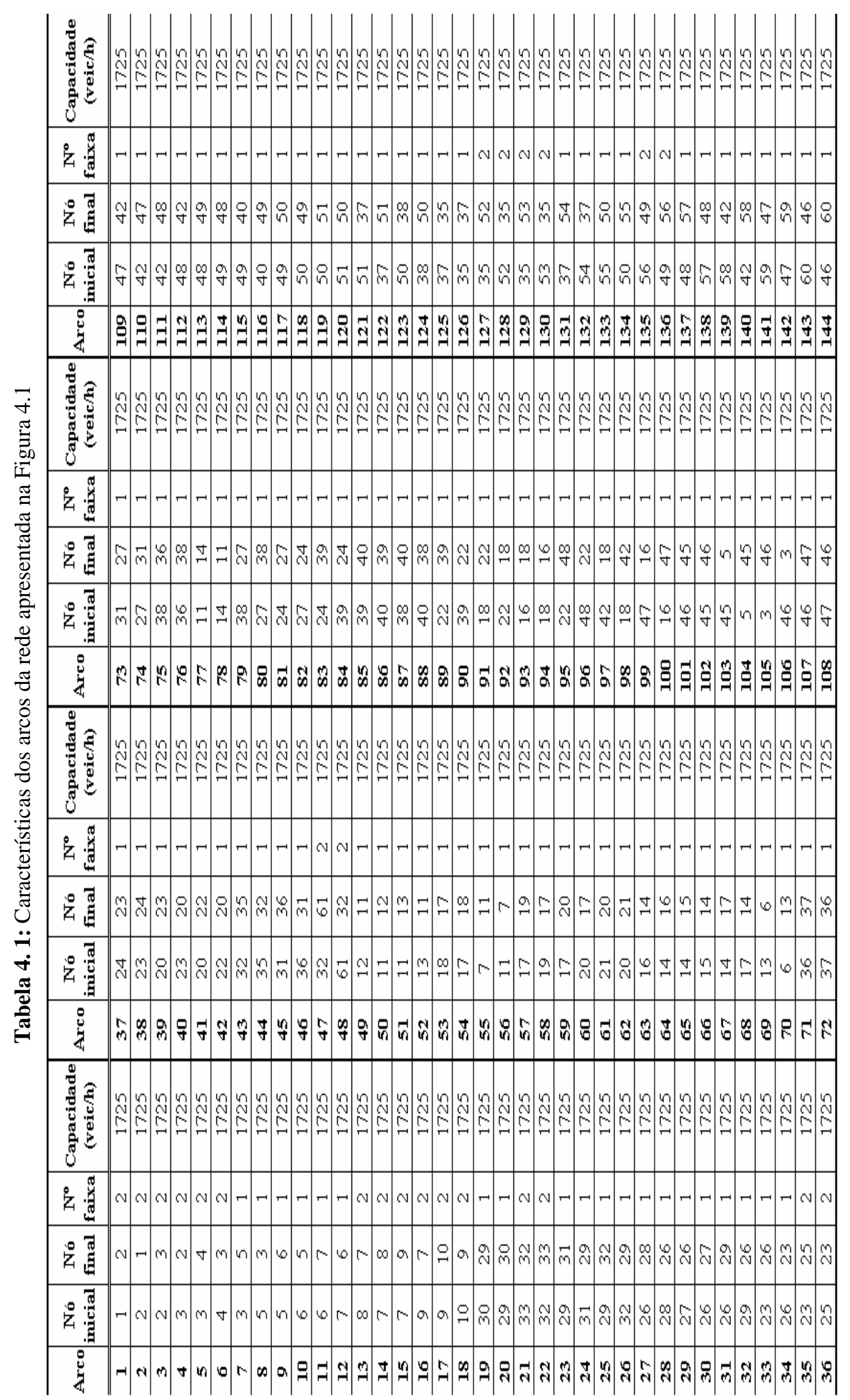


Para esta rede viária foi adotada uma matriz de viagens horária contendo apenas automóveis, podendo ser observada na Tabela 4.2.

Tabela 4. 2: Hipotética Matriz O-D da rede apresentada na Figura 4.1

\begin{tabular}{c|c|c|c|c|c|c|c|c|c|c|c}
\hline $\mathbf{0} \backslash \mathrm{D}$ & $\mathbf{1}$ & $\mathbf{4}$ & $\mathbf{8}$ & $\mathbf{1 0}$ & $\mathbf{2 5}$ & $\mathbf{3 3}$ & $\mathbf{5 2}$ & $\mathbf{5 3}$ & $\mathbf{5 6}$ & $\mathbf{6 1}$ & $\boldsymbol{\Sigma}$ \\
\hline $\mathbf{1}$ & 0 & 348 & 0 & 335 & 696 & 356 & 282 & 45 & 201 & 53 & 2317 \\
\hline $\mathbf{4}$ & 222 & 0 & 292 & 153 & 193 & 406 & 251 & 13 & 296 & 122 & 1947 \\
\hline $\mathbf{8}$ & 207 & 726 & 0 & 146 & 434 & 135 & 381 & 15 & 32 & 0 & 2076 \\
\hline $\mathbf{1 0}$ & 261 & 875 & 0 & 0 & 432 & 0 & 198 & 201 & 127 & 303 & 2397 \\
\hline $\mathbf{2 5}$ & 0 & 338 & 532 & 288 & 0 & 0 & 0 & 362 & 201 & 202 & 1922 \\
\hline $\mathbf{3 3}$ & 298 & 56 & 354 & 74 & 0 & 0 & 0 & 405 & 331 & 125 & 1644 \\
\hline $\mathbf{5 2}$ & 191 & 76 & 48 & 120 & 112 & 186 & 0 & 51 & 143 & 326 & 1253 \\
\hline $\mathbf{5 3}$ & 407 & 221 & 205 & 504 & 100 & 57 & 202 & 0 & 165 & 0 & 1860 \\
\hline $\mathbf{5 6}$ & 397 & 676 & 26 & 366 & 207 & 333 & 506 & 201 & 0 & 32 & 2744 \\
\hline $\mathbf{6 1}$ & 61 & 102 & 0 & 401 & 57 & 462 & 108 & 200 & 346 & 0 & 1737 \\
\hline $\mathbf{\Sigma}$ & 2043 & 3418 & 1456 & 2387 & 2232 & 1935 & 1930 & 1493 & 1841 & 1163 & $\mathbf{1 9 . 8 9 7}$ \\
\hline
\end{tabular}

Como os fluxos nos arcos da rede viária não são conhecidos, optou-se por alocar a matriz O-D apresentada na Tabela 4.2 à rede em questão, para assim obter os fluxos. Para a alocação da matriz O-D à rede viária foi adotada a técnica de alocação do tipo equilíbrio do usuário e a ferramenta utilizada para esta alocação foi o TransCAD. A função de impedância utilizada para o cálculo do custo de percurso do arco foi a proposta pelo Bureau of Public Roads (BPR, 1964), que relaciona o tempo de viagem com o fluxo e com a capacidade (V/C) no arco, conforme apresentado na equação (4.1).

$$
t_{s}=T_{o}\left(1+\alpha \cdot\left(\frac{V_{o b s}^{s}}{C_{a p}^{s}}\right)^{\beta}\right)
$$

Obs: os parâmetros desta equação já foram previamente definidos.

Para efeito da verificação proposta, os fluxos nos arcos, resultantes da alocação, serão aqui considerados como se tivessem sido obtidos através da contagem. A idéia que está por trás da consideração é: se a alocação da matriz O-D à rede de transportes resultou nos fluxos nos arcos da rede, e se os fundamentos teóricos do modelo sintético estiverem corretos, devese obter a mesma matriz O-D que originou esta hipotética contagem dos fluxos nos arcos, 
desde que, as considerações para o cálculo do tempo de percurso no arco sejam iguais tanto na alocação quanto no processo de estimação da matriz O-D.

Portanto, a matriz O-D apresentada na Tabela 4.2 será a que originará “contagens” e, ao mesmo tempo, constituirá uma referência com a qual os resultados dos métodos de obtenção da matriz O-D sintética serão comparados.

Os fluxos resultantes da alocação satisfazem as condições de equilíbrio e continuidade e seus valores encontram-se apresentados na Tabela 4.3.

Pode-se dizer, ao observar as Tabelas 4.1 e 4.3 , que $27 \%$ do total de arcos da rede apresentada na Figura 4.1 apresentam relação V/C > 1,00, sendo que se levar em consideração apenas os arcos que não tiveram fluxo nulo, o total de arcos que apresentam congestionamento corresponderá a 44\% dos arcos, podendo-se dizer que esta rede apresentará diversos pontos de congestionamento, assim, será possível avaliar se de fato ao utilizar o método incremental as viagens irão fazer as alterações de caminho quando necessário. 


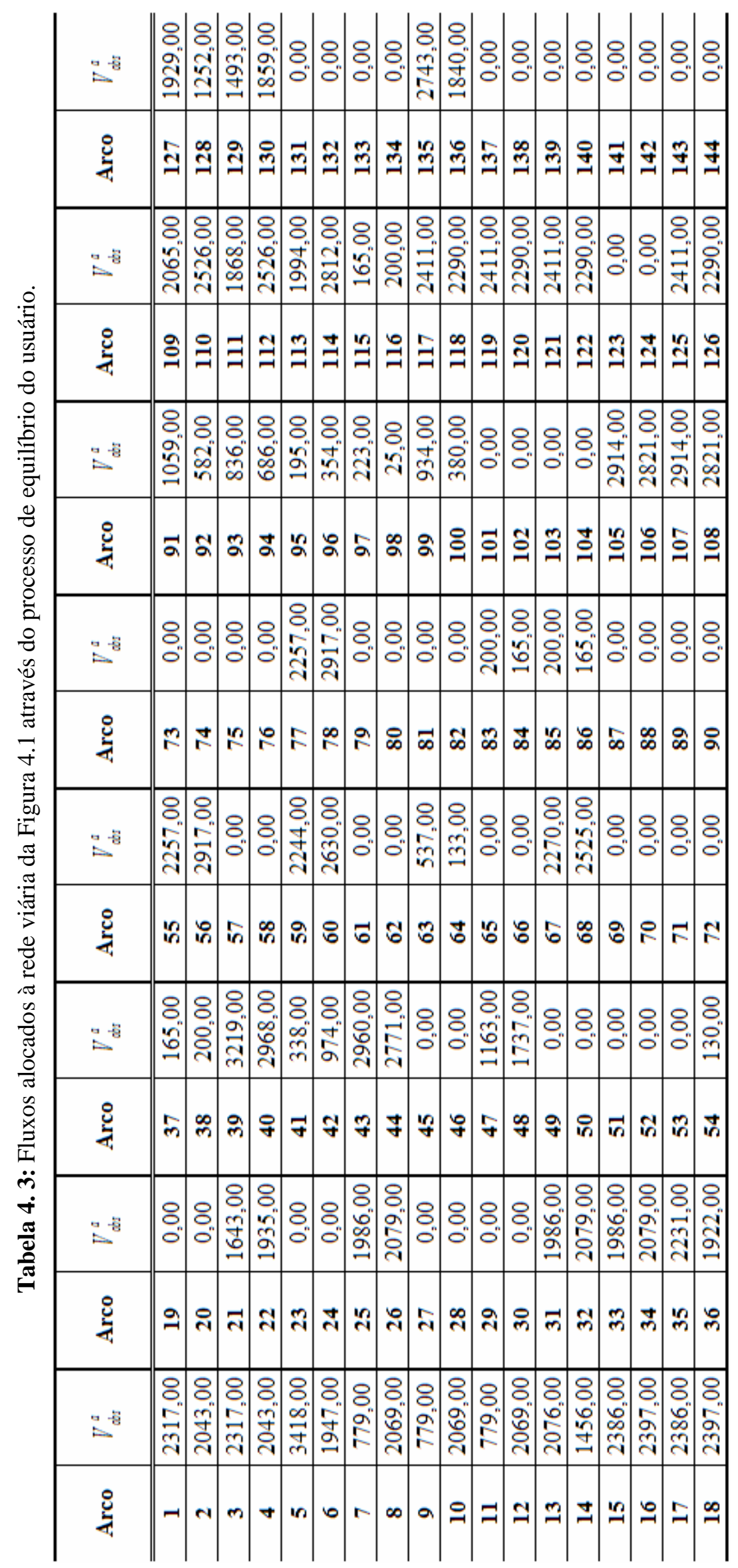


De posse destas informações, pôde-se proceder a estimação das matrizes O-D. As matrizes foram estimadas utilizando o QUEENSOD e o TransCAD, sendo que o processo de estimação das matrizes foi dividido em duas etapas. Na primeira, considerou-se que haveria uma divisão dos fluxos em incrementos, de forma a verificar se o método proposto poderá ser considerado uma alternativa ao método iterativo. Já na segunda, a matriz foi estimada através de um processo iterativo e, desta forma, foram obtidos valores que servirão para comparar o desempenho do método incremental em relação aos iterativos, conforme prevê os objetivos secundários.

\subsection{2 - Estimação da matriz O-D considerando o carregamento incremental dos fluxos de tráfego}

Este item pretende apresentar os resultados obtidos utilizando o método de carregamento incremental dos fluxos e será considerado o Caso A. O processo consiste em carregar incrementalmente os fluxos observados nos arcos nos quais há “contagens” fictícias. Para cada incremento será estimada uma matriz O-D parcial, ou sub-matriz O-D. A matriz OD será então representada pela soma das matrizes O-D parciais estimadas para cada um dos incrementos. O algoritmo do processo poderia ser resumido da seguinte forma:

$\Rightarrow$ Observação dos fluxos nos arcos;

$\Rightarrow$ Determinação do erro máximo pretendido em relação a escolha do caminho mínimo;

$\Rightarrow$ Determinação da quantidade de incrementos a ser utilizada;

$\Rightarrow$ Divisão do fluxo em incrementos (1 até $m$ );

$\Rightarrow$ Cálculo do tempo de percurso em cada arco em função do fluxo livre $\left(t_{s}\right)$;

$\Rightarrow$ Definição do caminho mínimo para cada ij;

$\Rightarrow$ Estimação da primeira sub-matriz $\left(q_{i j}^{1}\right)$;

$\Rightarrow$ Alocação das viagens $\left(q_{i j}^{1}\right)$ no caminho mínimo;

$\Rightarrow$ Cálculo do tempo de percurso em cada arco em função do fluxo alocado $\left(t_{s}^{1}\right)$;

$\Rightarrow$ Definição do caminho mínimo para cada ij; 
$\Rightarrow$ Estimação da segunda sub-matriz $\left(q_{i j}^{2}\right)$;

$\Rightarrow$ Alocação das viagens $\left(q_{i j}^{2}\right)$ no caminho mínimo;

$\Rightarrow$ Cálculo do tempo de percurso acumulado em cada arco $s\left(t_{s}^{2}\right)$;

$\Rightarrow \quad \ldots$

$\Rightarrow$ Cálculo do tempo de percurso acumulado em cada arco $s$ até $k-1\left(t_{s}^{m-1}\right)$;

$\Rightarrow$ Definição do caminho mínimo para cada ij;

$\Rightarrow$ Estimação da $k$-ésima sub-matriz $\left(q_{i j}^{k}\right)$;

$\Rightarrow$ Determinação da matriz O-D final $\left(Q_{i j}\right)$, dada pela soma das $(k)$ sub-matrizes O-D estimadas $\left(Q_{i j}=\sum_{k=1}^{m} q_{i j}^{k}\right)$.

O erro máximo adotado, em termos de variação do tempo de percurso, foi de $2 \%$. Também foi adotada uma simplificação: considerou-se que um aumento de 1\% no tempo de percurso, em relação ao tempo de percurso em fluxo livre, não provoca sérios erros na determinação do caminho mínimo, mesmo porque eventuais erros serão corrigidos pelos incrementos seguintes.

Usando a equação do BPR é possível estimar o primeiro incremento, em fluxo, que provoque um acréscimo de $1 \%$ no tempo em fluxo livre. Esse incremento inicial corresponderá a 50\% da capacidade da via. Considerando que o arco com maior relação V/C apresenta um valor próximo a 1,86 para a rede viária da Figura 4.1, conclui-se que carregar incrementalmente $26 \%(0,5 / 1,86)$ do fluxo provocará um aumento de no máximo 1\% no tempo de percurso em qualquer arco da rede. O restante dos fluxos foi dividido em incrementos de $2 \%$, o que seria equivalente a dividir os fluxos em 37 incrementos $\operatorname{com} f_{k}=$ 0,02 cada. Assim, no total os fluxos foram divididos em 38 incrementos, sendo o primeiro $\operatorname{com} f_{1}=0,26$ e os demais $\operatorname{com} f_{k}=0,02$. 
Para cada incremento foram calculados os valores de $v_{a}^{k}$, conforme apresentado na primeira etapa do método, e do $t_{s}^{k}$, de acordo com a equação do BPR. A estimação da matriz O-D foi realizada de uma forma adaptada. Para o QOD foi necessária a construção de 38 cenários, um para cada incremento e para o TransCAD foi necessária a codificação de 38 colunas referentes aos fluxos e outras 38 referentes aos tempos de percurso em cada arco, além disso foram utilizados os demais parâmetros de calibração conforme definidos no Capítulo 3.

Cada programa foi utilizado 38 vezes, cada uma correspondendo a um incremento. Desta forma, foram estimadas 38 sub-matrizes O-D $\left(q_{i j}^{k}\right)$, que ao serem somadas com o auxílio do Excel resultou na matriz O-D final. Os valores da matriz O-D final obtida pelo processo incremental encontram-se apresentados nas Tabelas 4.4 e 4.5 que trazem os resultados obtidos pelo QOD e pelo TransCAD, respectivamente. Os fluxos estimados totais $\left(V_{a}^{e s t}=\sum_{k} v_{a(\text { est })}^{k}\right)$ encontram-se apresentados na Tabela 4.6.

Tabela 4. 4: Matriz O-D estimada pelo carregamento incremental de volumes, utilizando o

\begin{tabular}{c|c|c|c|c|c|c|c|c|c|c|c}
\multicolumn{10}{c}{ QUEENSOD para maximizar a entropia } \\
\hline $\mathbf{0} \backslash \mathrm{D}$ & $\mathbf{1}$ & $\mathbf{4}$ & $\mathbf{8}$ & $\mathbf{1 0}$ & $\mathbf{2 5}$ & $\mathbf{3 3}$ & $\mathbf{5 2}$ & $\mathbf{5 3}$ & $\mathbf{5 6}$ & $\mathbf{6 1}$ & $\boldsymbol{\Sigma}$ \\
\hline $\mathbf{1}$ & 0 & 679 & 0 & 179 & 148 & 169 & 293 & 263 & 338 & 155 & 2224 \\
\hline $\mathbf{4}$ & 267 & 0 & 102 & 145 & 124 & 150 & 273 & 243 & 305 & 135 & 1744 \\
\hline $\mathbf{8}$ & 248 & 362 & 0 & 336 & 418 & 366 & 146 & 131 & 122 & 0 & 2128 \\
\hline $\mathbf{1 0}$ & 332 & 475 & 0 & 0 & 499 & 0 & 172 & 157 & 153 & 383 & 2170 \\
\hline $\mathbf{2 5}$ & 0 & 183 & 455 & 469 & 0 & 0 & 0 & 82 & 42 & 326 & 1556 \\
\hline $\mathbf{3 3}$ & 226 & 263 & 389 & 405 & 0 & 0 & 0 & 329 & 174 & 99 & 1885 \\
\hline $\mathbf{5 2}$ & 182 & 210 & 88 & 102 & 45 & 491 & 0 & 66 & 117 & 330 & 1630 \\
\hline $\mathbf{5 3}$ & 203 & 239 & 98 & 112 & 54 & 772 & 273 & 0 & 148 & 0 & 1899 \\
\hline $\mathbf{5 6}$ & 355 & 484 & 144 & 164 & 56 & 118 & 337 & 272 & 0 & 101 & 2031 \\
\hline $\mathbf{6 1}$ & 219 & 253 & 0 & 388 & 381 & 148 & 428 & 282 & 163 & 0 & 2261 \\
\hline $\mathbf{\Sigma}$ & 2030 & 3149 & 1275 & 2300 & 1725 & 2214 & 1923 & 1823 & 1562 & 1527 & $\mathbf{1 9 . 5 2 8}$ \\
\hline
\end{tabular}


Tabela 4. 5: Matriz O-D estimada pelo carregamento incremental de volumes, utilizando o TransCAD para maximizar a entropia

\begin{tabular}{c|c|c|c|c|c|c|c|c|c|c|c}
\hline $\mathbf{O} \backslash \mathrm{D}$ & $\mathbf{1}$ & $\mathbf{4}$ & $\mathbf{8}$ & $\mathbf{1 0}$ & $\mathbf{2 5}$ & $\mathbf{3 3}$ & $\mathbf{5 2}$ & $\mathbf{5 3}$ & $\mathbf{5 6}$ & $\mathbf{6 1}$ & $\boldsymbol{\Sigma}$ \\
\hline $\mathbf{1}$ & 0 & 415 & 0 & 269 & 143 & 149 & 319 & 292 & 315 & 139 & 2041 \\
\hline $\mathbf{4}$ & 258 & 0 & 229 & 240 & 128 & 137 & 304 & 276 & 291 & 127 & 1990 \\
\hline $\mathbf{8}$ & 374 & 480 & 0 & 306 & 385 & 404 & 130 & 121 & 72 & 0 & 2272 \\
\hline $\mathbf{1 0}$ & 417 & 529 & 0 & 0 & 421 & 0 & 144 & 134 & 83 & 382 & 2110 \\
\hline $\mathbf{2 5}$ & 0 & 175 & 428 & 410 & 0 & 0 & 0 & 167 & 59 & 348 & 1587 \\
\hline $\mathbf{3 3}$ & 136 & 137 & 374 & 367 & 0 & 0 & 0 & 252 & 124 & 192 & 1583 \\
\hline $\mathbf{5 2}$ & 287 & 308 & 122 & 129 & 122 & 247 & 0 & 123 & 237 & 182 & 1757 \\
\hline $\mathbf{5 3}$ & 314 & 341 & 132 & 139 & 127 & 350 & 282 & 0 & 277 & 0 & 1964 \\
\hline $\mathbf{5 6}$ & 359 & 421 & 81 & 88 & 45 & 129 & 338 & 282 & 0 & 113 & 1856 \\
\hline $\mathbf{6 1}$ & 134 & 135 & 0 & 356 & 314 & 275 & 319 & 228 & 129 & 0 & 1890 \\
\hline $\mathbf{\Sigma}$ & 2279 & 2941 & 1366 & 2305 & 1684 & 1692 & 1836 & 1876 & 1587 & 1484 & $\mathbf{1 9 . 0 5 0}$ \\
\hline
\end{tabular}

É importante ressaltar que para garantir o funcionamento dos dois programas foi necessária a adoção de uma matriz semente e esta foi do tipo binária (Tabela 4.7), mas a utilização de uma matriz semente não é requisito para a aplicação do processo incremental. 


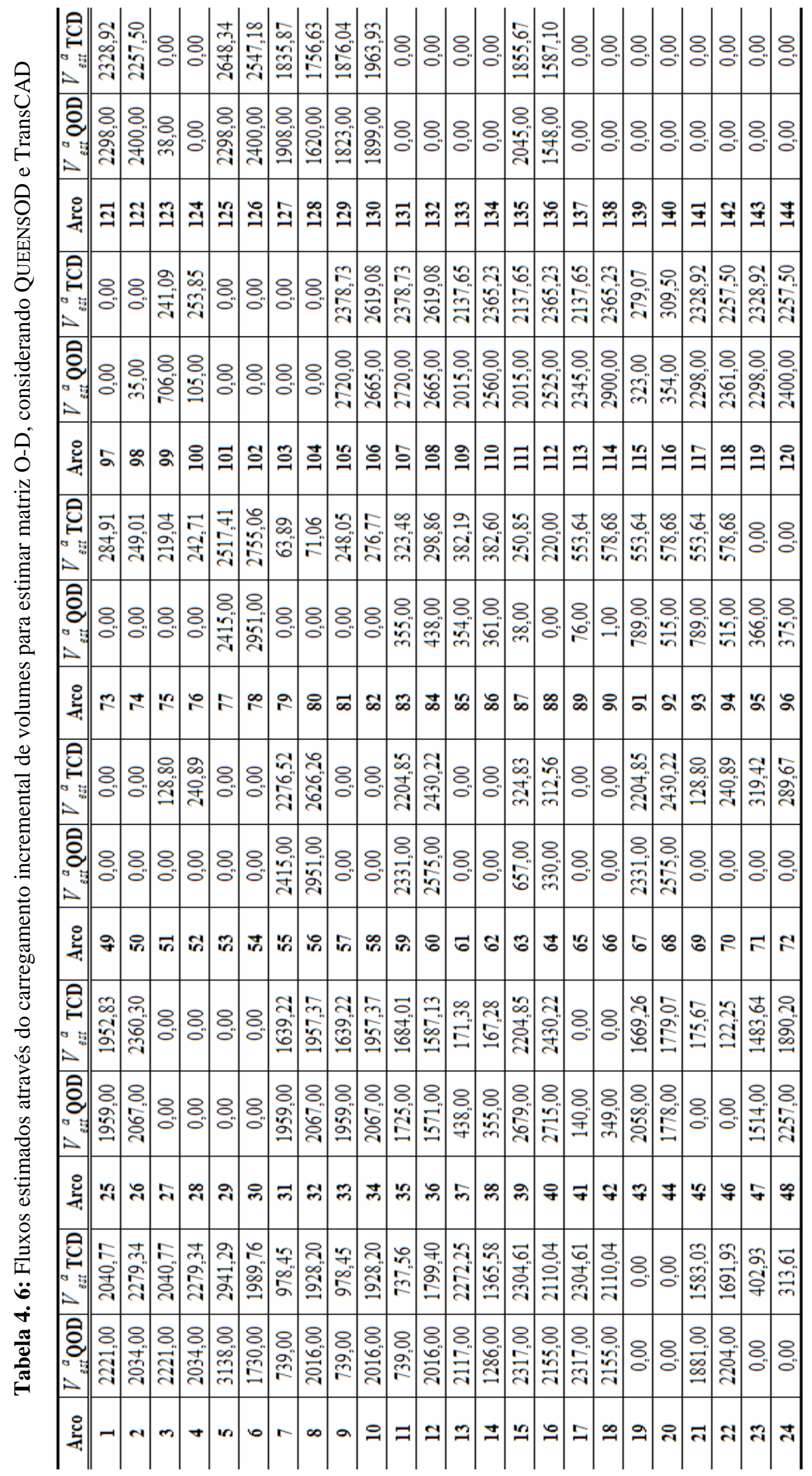


O total de viagens geradas considerando o método de carregamento incremental dos fluxos foi de 19.528 veic/h, ao utilizar o QuEENSOD, e de 19.050 veic/h, utilizando o TransCAD. No entanto, a matriz O-D “real” representa um total de 19.897 viagens/h geradas, o que permite verificar que ao considerar o carregamento incremental utilizando o QOD 369 viagens não foram estimadas e ao utilizar o TransCAD 847 viagens deixaram de ser estimadas. Em termos de fluxo pode-se dizer que o QuEENSOD foi capaz de estimar resultados mais próximos aos observados em se tratando de arcos com fluxos nulos.

Com o intuito de verificar a sua utilidade como um método alternativo os mesmos dados foram processados através de dois métodos iterativos, conforme será apresentado no próximo item.

\subsection{3 - Estimação da matriz O-D considerando o método iterativo}

O método iterativo para estimação de matriz O-D necessita basicamente de duas informações: fluxos veiculares observados nos arcos e disponibilidade de uma matriz semente. Em relação aos fluxos observados, o procedimento adotado já foi anteriormente apresentado e estas informações encontram-se disponíveis na Tabela 4.3. Já em relação a utilização de uma matriz semente foi considerada duas situações: Caso B e Caso C. Os métodos iterativos utilizados foram os embutidos no QUEENSOD e no TransCAD.

No Caso B, foi utilizada uma matriz semente do tipo binário (Tabela 4.7), onde, de acordo com a matriz "real”, os pares O-D que possuíam viagens receberam o número 1 e os demais o número 0. 
Tabela 4. 7: Matriz semente binária, utilizada no Caso B e no processo incremental

\begin{tabular}{c|c|c|c|c|c|c|c|c|c|c|c}
\hline $\mathbf{0} \backslash \mathrm{D}$ & $\mathbf{1}$ & $\mathbf{4}$ & $\mathbf{8}$ & $\mathbf{1 0}$ & $\mathbf{2 5}$ & $\mathbf{3 3}$ & $\mathbf{5 2}$ & $\mathbf{5 3}$ & $\mathbf{5 6}$ & $\mathbf{6 1}$ & $\boldsymbol{\Sigma}$ \\
\hline $\mathbf{1}$ & 0,00 & 1,00 & 0,00 & 1,00 & 1,00 & 1,00 & 1,00 & 1,00 & 1,00 & 1,00 & 8,00 \\
\hline $\mathbf{4}$ & 1,00 & 0,00 & 1,00 & 1,00 & 1,00 & 1,00 & 1,00 & 1,00 & 1,00 & 1,00 & 9,00 \\
\hline $\mathbf{8}$ & 1,00 & 1,00 & 0,00 & 1,00 & 1,00 & 1,00 & 1,00 & 1,00 & 1,00 & 0,00 & 8,00 \\
\hline $\mathbf{1 0}$ & 1,00 & 1,00 & 0,00 & 0,00 & 1,00 & 0,00 & 1,00 & 1,00 & 1,00 & 1,00 & 7,00 \\
\hline $\mathbf{2 5}$ & 0,00 & 1,00 & 1,00 & 1,00 & 0,00 & 0,00 & 0,00 & 1,00 & 1,00 & 1,00 & 6,00 \\
\hline $\mathbf{3 3}$ & 1,00 & 1,00 & 1,00 & 1,00 & 0,00 & 0,00 & 0,00 & 1,00 & 1,00 & 1,00 & 7,00 \\
\hline $\mathbf{5 2}$ & 1,00 & 1,00 & 1,00 & 1,00 & 1,00 & 1,00 & 0,00 & 1,00 & 1,00 & 1,00 & 9,00 \\
\hline $\mathbf{5 3}$ & 1,00 & 1,00 & 1,00 & 1,00 & 1,00 & 1,00 & 1,00 & 0,00 & 1,00 & 0,00 & 8,00 \\
\hline $\mathbf{5 6}$ & 1,00 & 1,00 & 1,00 & 1,00 & 1,00 & 1,00 & 1,00 & 1,00 & 0,00 & 1,00 & 9,00 \\
\hline $\mathbf{6 1}$ & 1,00 & 1,00 & 0,00 & 1,00 & 1,00 & 1,00 & 1,00 & 1,00 & 1,00 & 0,00 & 8,00 \\
\hline $\mathbf{\Sigma}$ & 8,00 & 9,00 & 6,00 & 9,00 & 8,00 & 7,00 & 7,00 & 9,00 & 9,00 & 7,00 & 79,00 \\
\hline
\end{tabular}

Os resultados da matriz O-D estimada pelo QOD estão apresentados na Tabela 4.8 e os obtidos pelo TransCAD encontram-se na Tabela 4.9.

Tabela 4. 8: Matriz O-D estimada pelo QUEENSOD considerando o processo iterativo e a utilização de uma matriz semente binária

\begin{tabular}{c|c|c|c|c|c|c|c|c|c|c|c}
\hline$O \backslash D$ & $\mathbf{1}$ & $\mathbf{4}$ & $\mathbf{8}$ & $\mathbf{1 0}$ & $\mathbf{2 5}$ & $\mathbf{3 3}$ & $\mathbf{5 2}$ & $\mathbf{5 3}$ & $\mathbf{5 6}$ & $\mathbf{6 1}$ & $\boldsymbol{\Sigma}$ \\
\hline $\mathbf{1}$ & 0 & 1393 & 0 & 123 & 173 & 71 & 303 & 215 & 243 & 35 & 2554 \\
\hline $\mathbf{4}$ & 527 & 0 & 541 & 135 & 163 & 60 & 247 & 169 & 222 & 28 & 2091 \\
\hline $\mathbf{8}$ & 146 & 93 & 0 & 1410 & 94 & 60 & 50 & 32 & 92 & 0 & 1977 \\
\hline $\mathbf{1 0}$ & 510 & 572 & 0 & 0 & 420 & 0 & 142 & 95 & 250 & 75 & 2064 \\
\hline $\mathbf{2 5}$ & 0 & 135 & 472 & 434 & 0 & 0 & 0 & 392 & 57 & 407 & 1896 \\
\hline $\mathbf{3 3}$ & 56 & 54 & 160 & 150 & 0 & 0 & 0 & 319 & 559 & 524 & 1821 \\
\hline $\mathbf{5 2}$ & 157 & 168 & 75 & 76 & 313 & 386 & 0 & 113 & 294 & 23 & 1605 \\
\hline $\mathbf{5 3}$ & 114 & 111 & 61 & 64 & 264 & 197 & 798 & 0 & 139 & 0 & 1749 \\
\hline $\mathbf{5 6}$ & 494 & 592 & 270 & 133 & 309 & 368 & 350 & 184 & 0 & 113 & 2812 \\
\hline $\mathbf{6 1}$ & 31 & 28 & 0 & 74 & 390 & 1001 & 117 & 26 & 197 & 0 & 1863 \\
\hline $\mathbf{\Sigma}$ & 2034 & 3146 & 1578 & 2600 & 2126 & 2143 & 2007 & 1544 & 2051 & 1203 & $\mathbf{2 0 . 4 3 1}$ \\
\hline
\end{tabular}

Tabela 4. 9: Matriz O-D estimada pelo TransCAD considerando o processo iterativo e a utilização de uma matriz semente binária

\begin{tabular}{c|c|c|c|c|c|c|c|c|c|c|c}
\hline $\mathbf{O} \backslash \mathrm{D}$ & $\mathbf{1}$ & $\mathbf{4}$ & $\mathbf{8}$ & $\mathbf{1 0}$ & $\mathbf{2 5}$ & $\mathbf{3 3}$ & $\mathbf{5 2}$ & $\mathbf{5 3}$ & $\mathbf{5 6}$ & $\mathbf{6 1}$ & $\boldsymbol{\Sigma}$ \\
\hline $\mathbf{1}$ & 0 & 560 & 0 & 240 & 187 & 111 & 387 & 304 & 394 & 94 & 2277 \\
\hline $\mathbf{4}$ & 193 & 0 & 180 & 199 & 159 & 94 & 359 & 278 & 353 & 78 & 1893 \\
\hline $\mathbf{8}$ & 336 & 532 & 0 & 319 & 481 & 521 & 40 & 31 & 25 & 0 & 2284 \\
\hline $\mathbf{1 0}$ & 447 & 702 & 0 & 0 & 591 & 0 & 54 & 43 & 53 & 482 & 2373 \\
\hline $\mathbf{2 5}$ & 0 & 53 & 607 & 572 & 0 & 0 & 0 & 551 & 2 & 399 & 2185 \\
\hline $\mathbf{3 3}$ & 59 & 61 & 506 & 492 & 0 & 0 & 0 & 345 & 73 & 135 & 1670 \\
\hline $\mathbf{5 2}$ & 290 & 350 & 45 & 53 & 81 & 348 & 0 & 22 & 250 & 173 & 1612 \\
\hline $\mathbf{5 3}$ & 348 & 429 & 54 & 63 & 116 & 740 & 155 & 0 & 354 & 0 & 2257 \\
\hline $\mathbf{5 6}$ & 466 & 688 & 29 & 35 & 1 & 55 & 539 & 329 & 0 & 38 & 2180 \\
\hline $\mathbf{6 1}$ & 55 & 56 & 0 & 444 & 354 & 232 & 638 & 242 & 59 & 0 & 2079 \\
\hline $\mathbf{\Sigma}$ & 2195 & 3431 & 1421 & 2418 & 1970 & 2100 & 2171 & 2145 & 1562 & 1399 & $\mathbf{2 0 . 8 1 1}$ \\
\hline
\end{tabular}


Ao analisar a matriz estimada pelo QUEENSOD foram estimadas 20.431 viagens, o que corresponde a um aumento de 534 viagens em relação a matriz "real”. Já analisando os resultados obtidos pelo TransCAD, 20.811 viagens foram estimadas, um aumento de 914 viagens em relação a matriz "real”.

Na Tabela 4.10 são apresentados os fluxos estimados pelo QOD e TransCAD. 


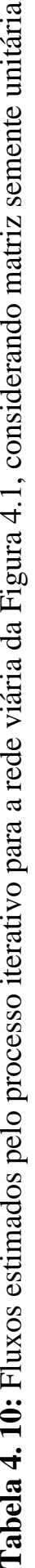

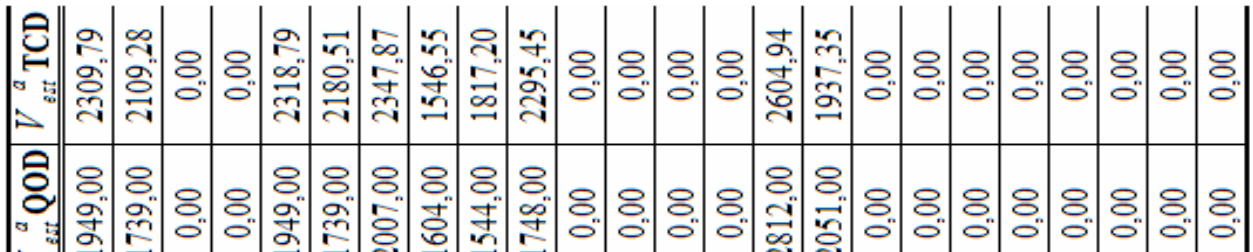

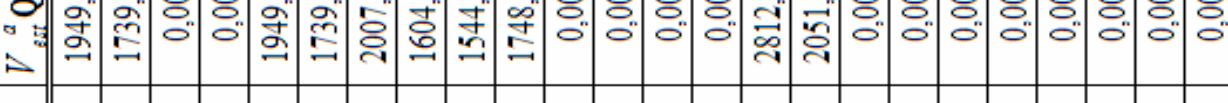

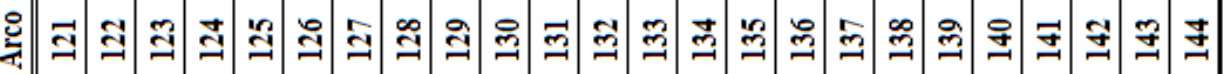

읍

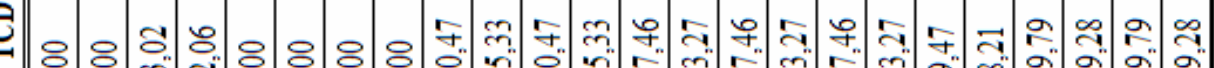

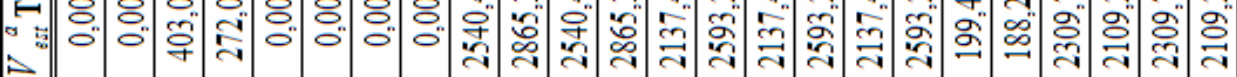

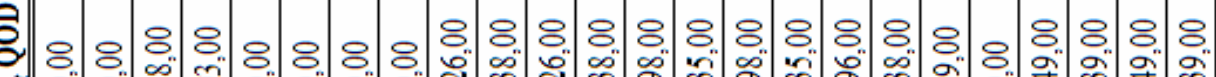

: 0 :

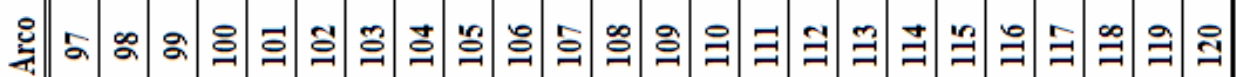

论

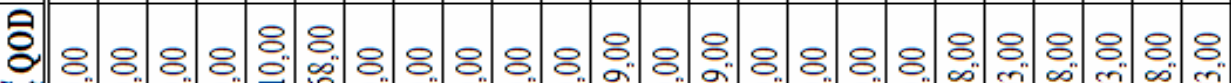

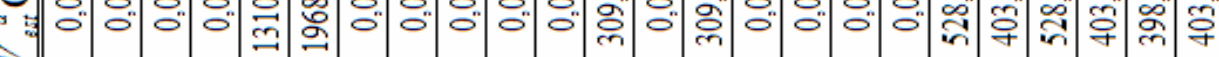

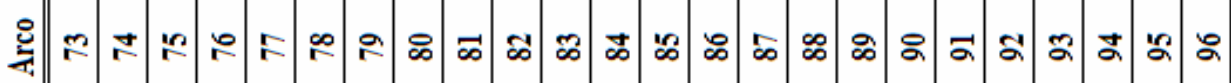

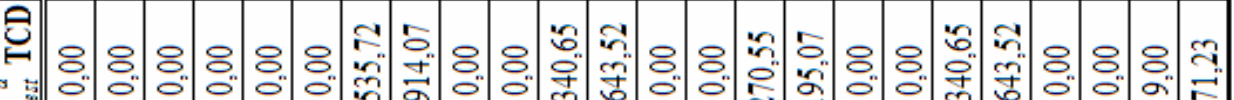

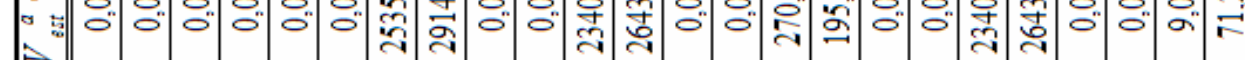

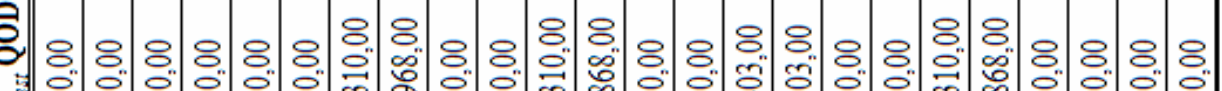

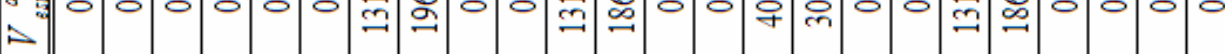

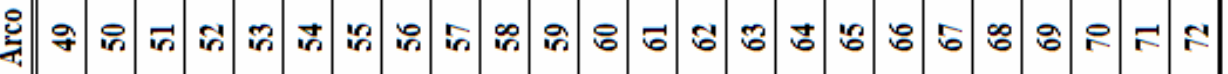

굽음

:

응

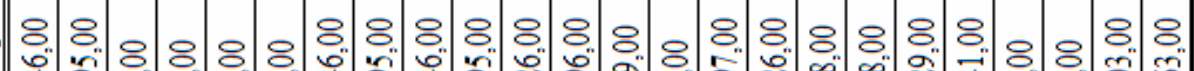

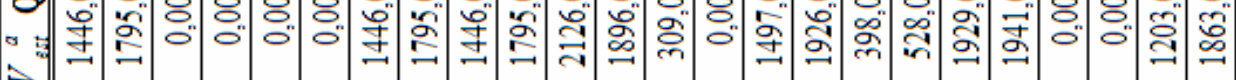

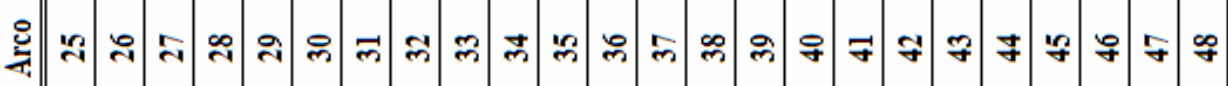

은 영영

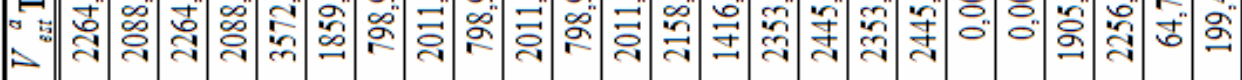

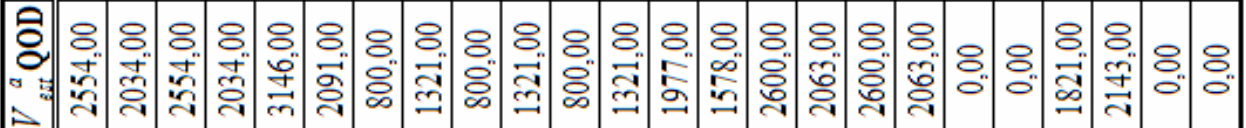

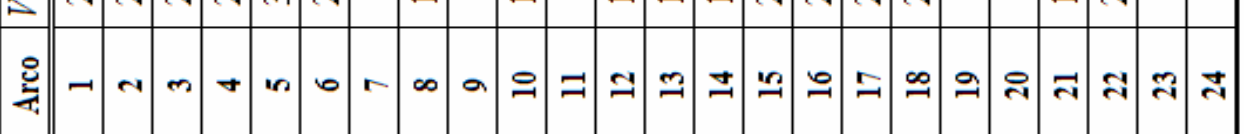


No Caso C, foi considerado que a matriz semente apresentaria viagens equivalentes a 70\% das apresentadas na matriz "real” (Tabela 4.11), o que, considerando uma taxa de 2,7\% aa em média de crescimento das viagens, permitiria afirmar que esta matriz teria sido obtida há cerca de 10 anos. Este cenário procura representar uma situação favorável à aplicação do método iterativo, pois além dos fluxos observados respeitarem as condições de equilíbrio e continuidade, a matriz semente possui relação com a matriz O-D real, conforme sugerido por Yang (1995) e Nielsen (1998).

As matrizes estimadas pelo QUEENSOD e pelo TransCAD, utilizando esta matriz como semente, estão apresentadas nas Tabelas 4.12 e 4.13 respectivamente.

Tabela 4. 11: Matriz semente utilizada no Caso C equivalente a 70\% da matriz "real"

\begin{tabular}{c|c|c|c|c|c|c|c|c|c|c|c}
\hline $\mathbf{O} \backslash \mathrm{D}$ & $\mathbf{1}$ & $\mathbf{4}$ & $\mathbf{8}$ & $\mathbf{1 0}$ & $\mathbf{2 5}$ & $\mathbf{3 3}$ & $\mathbf{5 2}$ & $\mathbf{5 3}$ & $\mathbf{5 6}$ & $\mathbf{6 1}$ & $\mathbf{\Sigma}$ \\
\hline $\mathbf{1}$ & 0,00 & 243,88 & 0,00 & 234,64 & 487,20 & 249,20 & 197,40 & 31,50 & 140,70 & 37,38 & 1621,90 \\
\hline $\mathbf{4}$ & 155,12 & 0,00 & 204,12 & 106,96 & 135,24 & 284,20 & 175,84 & 9,10 & 206,99 & 85,54 & 1363,11 \\
\hline $\mathbf{8}$ & 145,04 & 508,20 & 0,00 & 102,48 & 304,08 & 94,36 & 266,84 & 10,22 & 22,26 & 0,00 & 1453,48 \\
\hline $\mathbf{1 0}$ & 182,84 & 612,64 & 0,00 & 0,00 & 302,12 & 0,00 & 138,60 & 140,98 & 88,83 & 212,03 & 1678,04 \\
\hline $\mathbf{2 5}$ & 0,00 & 236,88 & 372,12 & 201,60 & 0,00 & 0,00 & 0,00 & 253,33 & 140,42 & 141,19 & 1345,54 \\
\hline $\mathbf{3 3}$ & 208,60 & 39,20 & 248,08 & 51,52 & 0,00 & 0,00 & 0,00 & 283,57 & 231,98 & 87,78 & 1150,73 \\
\hline $\mathbf{5 2}$ & 133,56 & 52,92 & 33,88 & 84,28 & 78,68 & 130,20 & 0,00 & 35,63 & 99,75 & 228,13 & 877,03 \\
\hline $\mathbf{5 3}$ & 284,90 & 154,70 & 143,22 & 352,56 & 70,00 & 39,69 & 141,61 & 0,00 & 115,29 & 0,00 & 1301,97 \\
\hline $\mathbf{5 6}$ & 277,55 & 473,13 & 17,92 & 256,13 & 144,90 & 233,38 & 354,48 & 140,84 & 0,00 & 22,19 & 1920,52 \\
\hline $\mathbf{6 1}$ & 42,49 & 71,12 & 0,00 & 280,70 & 39,90 & 323,61 & 75,88 & 140,00 & 242,20 & 0,00 & 1215,90 \\
\hline $\mathbf{\Sigma}$ & 1430,10 & 2392,67 & 1019,34 & 1670,87 & 1562,12 & 1354,64 & 1350,65 & 1045,17 & 1288,42 & 814,24 & $\mathbf{1 3 9 2 8 , 2 2}$ \\
\hline
\end{tabular}


Tabela 4. 12: Matriz O-D estimada pelo QUEENSOD, considerando o processo iterativo e a utilização de uma matriz semente equivalente a $70 \%$ da matriz "real"

\begin{tabular}{c|c|c|c|c|c|c|c|c|c|c|c}
\hline $\boldsymbol{O} \backslash \mathrm{D}$ & $\mathbf{1}$ & $\mathbf{4}$ & $\mathbf{8}$ & $\mathbf{1 0}$ & $\mathbf{2 5}$ & $\mathbf{3 3}$ & $\mathbf{5 2}$ & $\mathbf{5 3}$ & $\mathbf{5 6}$ & $\mathbf{6 1}$ & $\boldsymbol{\Sigma}$ \\
\hline $\mathbf{1}$ & 0 & 1277 & 0 & 126 & 267 & 92 & 347 & 68 & 178 & 8 & 2363 \\
\hline $\mathbf{4}$ & 615 & 0 & 577 & 75 & 75 & 98 & 276 & 18 & 278 & 17 & 2029 \\
\hline $\mathbf{8}$ & 194 & 282 & 0 & 1217 & 209 & 73 & 103 & 4 & 98 & 0 & 2180 \\
\hline $\mathbf{1 0}$ & 355 & 870 & 0 & 0 & 443 & 0 & 85 & 96 & 463 & 136 & 2448 \\
\hline $\mathbf{2 5}$ & 0 & 55 & 507 & 380 & 0 & 0 & 0 & 532 & 0 & 474 & 1947 \\
\hline $\mathbf{3 3}$ & 56 & 8 & 214 & 53 & 0 & 0 & 0 & 194 & 511 & 533 & 1569 \\
\hline $\mathbf{5 2}$ & 148 & 57 & 16 & 49 & 350 & 239 & 0 & 197 & 297 & 56 & 1409 \\
\hline $\mathbf{5 3}$ & 259 & 123 & 59 & 187 & 254 & 58 & 647 & 0 & 141 & 0 & 1728 \\
\hline $\mathbf{5 6}$ & 364 & 636 & 14 & 111 & 273 & 448 & 326 & 228 & 0 & 19 & 2417 \\
\hline $\mathbf{6 1}$ & 6 & 8 & 0 & 142 & 336 & 998 & 3 & 8 & 180 & 0 & 1680 \\
\hline $\mathbf{\Sigma}$ & 1997 & 3315 & 1387 & 2339 & 2205 & 2005 & 1787 & 1346 & 2146 & 1243 & $\mathbf{1 9 . 7 7 0}$ \\
\hline
\end{tabular}

Tabela 4. 13: Matriz O-D estimada pelo TransCAD, considerando o processo iterativo e a utilização de uma matriz semente equivalente a $70 \%$ da matriz "real"

\begin{tabular}{c|c|c|c|c|c|c|c|c|c|c|c}
\hline $\mathbf{0} D$ & $\mathbf{1}$ & $\mathbf{4}$ & $\mathbf{8}$ & $\mathbf{1 0}$ & $\mathbf{2 5}$ & $\mathbf{3 3}$ & $\mathbf{5 2}$ & $\mathbf{5 3}$ & $\mathbf{5 6}$ & $\mathbf{6 1}$ & $\boldsymbol{\Sigma}$ \\
\hline $\mathbf{1}$ & 0 & 534 & 0 & 408 & 71 & 139 & 546 & 78 & 428 & 17 & 2221 \\
\hline $\mathbf{4}$ & 206 & 0 & 214 & 161 & 15 & 131 & 468 & 21 & 600 & 32 & 1847 \\
\hline $\mathbf{8}$ & 186 & 695 & 0 & 220 & 753 & 332 & 58 & 2 & 8 & 0 & 2254 \\
\hline $\mathbf{1 0}$ & 245 & 872 & 0 & 0 & 715 & 0 & 36 & 32 & 36 & 560 & 2497 \\
\hline $\mathbf{2 5}$ & 0 & 54 & 653 & 441 & 0 & 0 & 0 & 669 & 5 & 377 & 2199 \\
\hline $\mathbf{3 3}$ & 113 & 20 & 639 & 151 & 0 & 0 & 0 & 739 & 68 & 47 & 1778 \\
\hline $\mathbf{5 2}$ & 249 & 105 & 7 & 23 & 103 & 517 & 0 & 5 & 253 & 413 & 1676 \\
\hline $\mathbf{5 3}$ & 633 & 374 & 35 & 118 & 137 & 348 & 85 & 0 & 422 & 0 & 2152 \\
\hline $\mathbf{5 6}$ & 446 & 823 & 3 & 64 & 0 & 109 & 832 & 264 & 0 & 6 & 2547 \\
\hline $\mathbf{6 1}$ & 22 & 35 & 0 & 783 & 135 & 381 & 263 & 305 & 63 & 0 & 1987 \\
\hline $\mathbf{\Sigma}$ & 2101 & 3512 & 1551 & 2370 & 1929 & 1956 & 2287 & 2116 & 1883 & 1452 & $\mathbf{2 1 . 1 5 7}$ \\
\hline
\end{tabular}

Considerando a utilização do QOD foram estimadas 19.770 viagens, ou seja, 127 viagens a menos que as observadas na situação "real” e ao utilizar o TransCAD 21.157 viagens foram estimadas representando um aumento de 1.260 viagens em relação a quantidade de viagens “real”.

A Tabela 4.14 apresenta os fluxos estimado pelo QOD e TransCAD. 


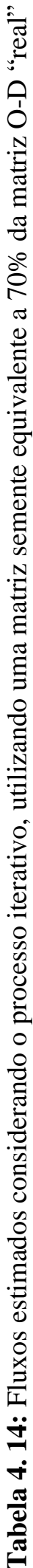

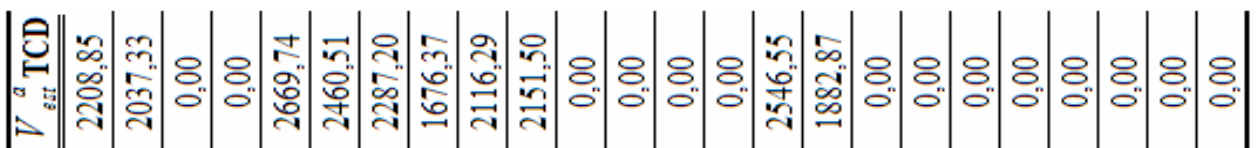

응.

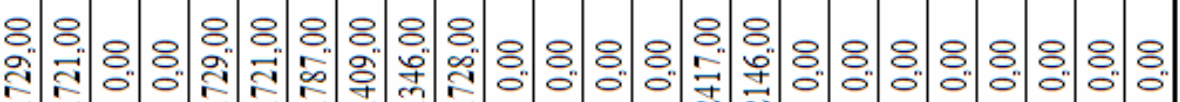
$\Delta=$

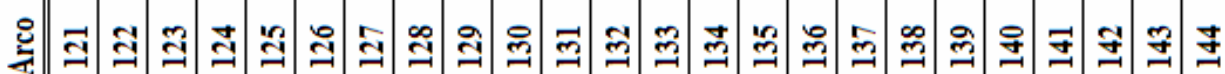

응

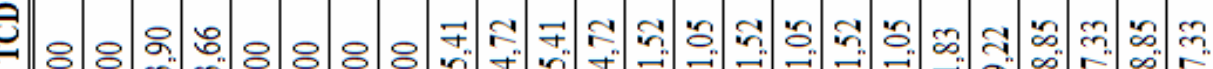
๘

응

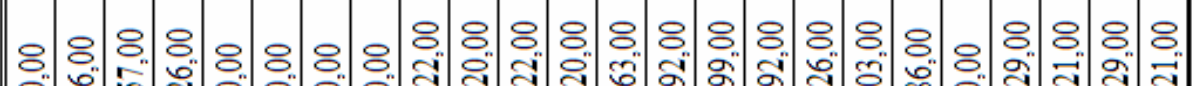

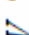

운 군

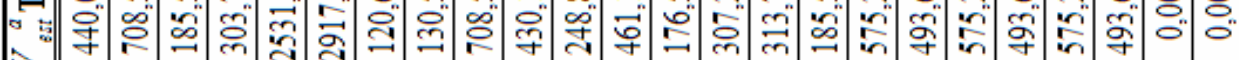

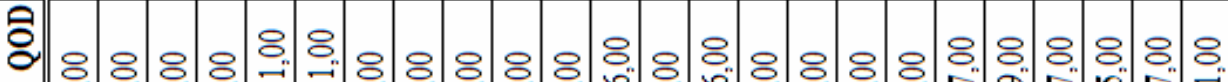
: 융응음 $\triangle$

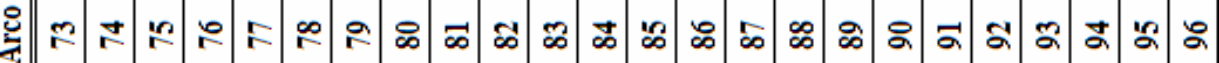

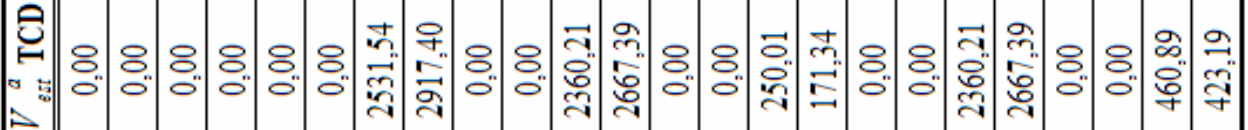

응

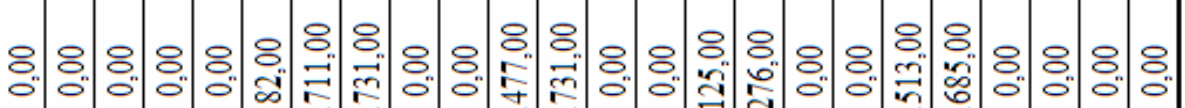

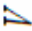

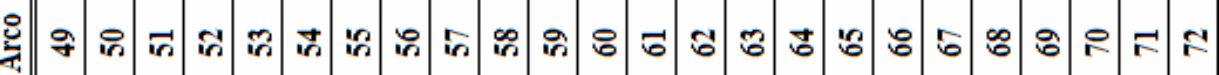

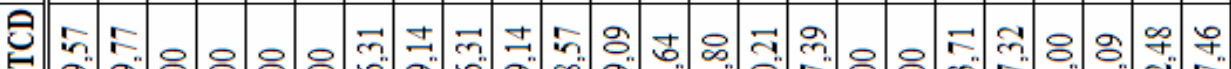
ڤ

ㅇํㅇ.

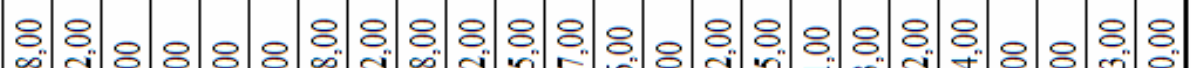

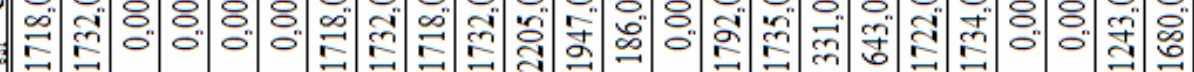
$\Delta$

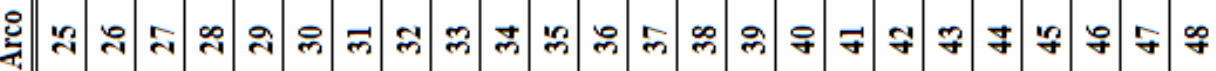

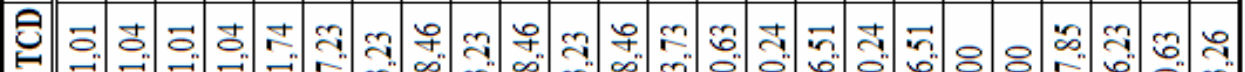

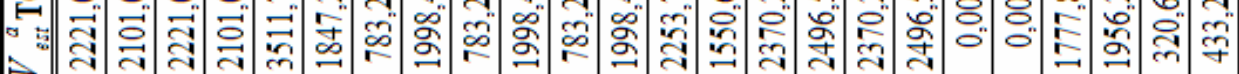

응

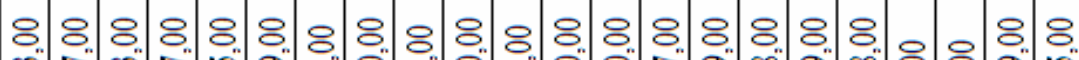
กิ

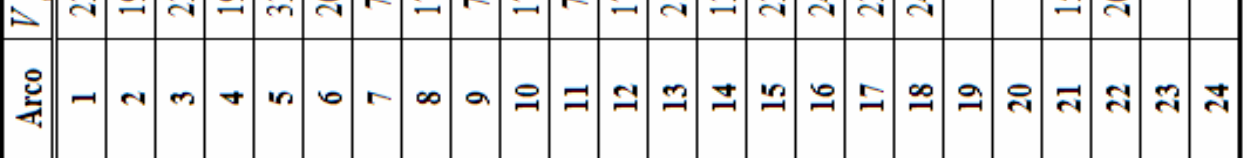


Possíveis diferenças entre valores estimados devem-se as considerações feitas por cada programa, conforme observado na Tabela 4.15. O modelo utilizado no QUEENSOD maximiza a entropia utilizando a equação proposta por Van Zuylen e Willumsen (1980) e como restrição uma função adaptada do modelo proposto por Cascetta (1984). Já o modelo utilizado no TransCAD considera a equação desenvolvida por Nielsen (1993) e a restrição fundamental do modelo sintético proposta por Willumsen (1978).

Tabela 4. 15: Modelos para cálculo de $Q_{i j}$ embutidos nos programas

\begin{tabular}{c|c|c}
\hline Programa & Equação utilizada para obtenção do $Q_{i j}$ & Restrição \\
\hline \hline QUEENSOD & $Z\left(Q_{i j}, s_{i j}\right)=\frac{Q !}{\prod_{i j}\left(Q_{i j} !\right.} \prod_{i j}\left(\frac{s_{i j}}{S}\right)^{Q_{i j}}$ & $E=\sum_{a}\left(V_{o b s}^{a}-p_{i j}^{a} Q_{i j}\right)^{2} w^{a}$ \\
\hline TransCAD & $Q_{i j}=\frac{N_{a}}{\sum_{a} \frac{1}{Q_{(E) i j}^{a}} ; \operatorname{sendo~} Q_{(E) i j}^{a}=\frac{V_{o b s}^{a}}{V_{a l o c}^{a}} S_{i j}}$ & $V_{o b s}^{a}=p_{i j}^{a} \cdot Q_{i j}$ \\
\hline
\end{tabular}

O próximo capítulo irá apresentar as análises destes resultados obtidos e pretende-se verificar o desempenho da matriz O-D estimada incrementalmente em relação à matriz "real” e em relação à matriz estimada através do método iterativo, de forma a verificar se existe vantagens em utilizar o método que está sendo proposto. 


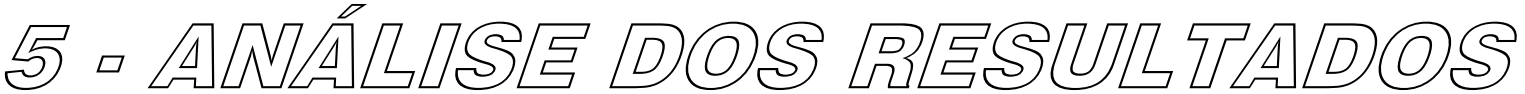

No Capítulo 4 foram realizados os testes experimentais para verificar o desempenho do método proposto. As matrizes O-D foram estimadas utilizando os programas QUEENSOD e TransCAD, e três situações distintas foram estudadas:

$\Rightarrow$ Caso A: aplicação do método incremental, em que cada parcela dos fluxos de tráfego observados foi carregada aos caminhos de custo mínimo resultantes dos carregamentos anteriores;

$\Rightarrow$ Caso B: aplicação dos métodos iterativos embutidos no QUEENSOD e no TransCAD, utilizando uma matriz semente do tipo binário; e

$\Rightarrow$ Caso C: aplicação dos métodos iterativos embutidos no QuEENSOD e no TransCAD, utilizando uma matriz semente equivalente a 70\% da matriz "real".

Neste capítulo serão analisados os resultados obtidos, de forma que os objetivos propostos para esta pesquisa sejam contemplados. Em primeiro lugar, os resultados da matriz O-D estimada com base no carregamento incremental dos fluxos observados aos caminhos mínimos serão comparados com os valores "reais". Posteriormente será verificado o desempenho do método proposto em relação aos métodos iterativos.

Para tal, este capítulo será dividido em três itens: 
$\Rightarrow$ Análise comparativa das diferenças dos valores da matriz O-D estimada incrementalmente em relação à matriz O-D “real”;

$\Rightarrow$ Análise comparativa das diferenças dos valores da matriz O-D estimada através do método incremental em relação às diferenças dos valores da matriz O-D estimada através dos métodos iterativos; e

$\Rightarrow$ Considerações finais sobre as análises dos resultados.

\section{1 - ANÁLISE COMPARATIVA DAS DIFERENÇAS DOS VALORES DA MATRIZ O-D ESTIMADA INCREMENTALMENTE EM RELAÇÃO À MATRIZ O-D "REAL"}

Este item é proposto a fim de verificar o desempenho dos valores de viagens estimadas pelo método proposto em relação aos valores de viagens "reais". Na situação "real" o número total de viagens geradas entre as 10 zonas de tráfego é de 19.897 viagens. Ao considerar os valores estimados pelo QUEENSOD o número total de viagens geradas foi 19.528, ou seja, uma redução de $2 \%$ em relação ao total de viagens "observadas". Ao considerar os valores estimados utilizando o TransCAD 19.050 viagens foram estimadas entre as zonas de tráfego, o que implica uma redução de 4\% em relação a quantidade "real" de viagens.

Em relação ao total de viagens geradas os resultados do método incremental foram satisfatórios. Porém, mais do que o total de viagens é importante analisar as diferenças entre o número de viagens "reais" e estimadas para cada par O-D, para que se possa ter uma melhor avaliação sobre o desempenho do método proposto. A seguir serão apresentadas estas análises em termos de diferenças absolutas, quadráticas e relativas, entre os valores das viagens "reais" e estimadas entre os pares O-D.

\subsection{1 - Verificação das diferenças absolutas entre as viagens “reais” e as estimadas pelo método incremental}


Neste item são inicialmente apresentados os valores das diferenças absolutas entre as viagens "reais" e as estimadas incrementalmente. Com esses elementos será possível realizar uma análise global do desempenho do método incremental.

A Tabela 5.1 apresenta as diferenças dos números de viagens reais em relação aos valores estimados utilizando o QUEENSOD.

Tabela 5. 1: Diferença absoluta entre as viagens "reais" e as estimadas pelo método incremental, utilizando o QUEENSOD

\begin{tabular}{c|c|c|c|c|c|c|c|c|c|c|c}
\hline $\mathbf{0 \backslash D}$ & $\mathbf{1}$ & $\mathbf{4}$ & $\mathbf{8}$ & $\mathbf{1 0}$ & $\mathbf{2 5}$ & $\mathbf{3 3}$ & $\mathbf{5 2}$ & $\mathbf{5 3}$ & $\mathbf{5 6}$ & $\mathbf{6 1}$ & $\mathbf{\Sigma}$ \\
\hline $\mathbf{1}$ & 0 & 330 & 0 & 156 & 548 & 187 & 11 & 218 & 137 & 101 & 1688 \\
\hline $\mathbf{4}$ & 45 & 0 & 190 & 8 & 69 & 256 & 22 & 230 & 10 & 13 & 842 \\
\hline $\mathbf{8}$ & 40 & 364 & 0 & 190 & 17 & 231 & 236 & 117 & 90 & 0 & 1284 \\
\hline $\mathbf{1 0}$ & 71 & 401 & 0 & 0 & 67 & 0 & 26 & 45 & 27 & 80 & 716 \\
\hline $\mathbf{2 5}$ & 0 & 155 & 77 & 181 & 0 & 0 & 0 & 280 & 158 & 124 & 975 \\
\hline $\mathbf{3 3}$ & 73 & 207 & 35 & 332 & 0 & 0 & 0 & 76 & 158 & 27 & 907 \\
\hline $\mathbf{5 2}$ & 9 & 134 & 40 & 18 & 67 & 305 & 0 & 15 & 25 & 4 & 617 \\
\hline $\mathbf{5 3}$ & 205 & 18 & 107 & 391 & 46 & 715 & 71 & 0 & 17 & 0 & 1569 \\
\hline $\mathbf{5 6}$ & 42 & 192 & 118 & 202 & 151 & 215 & 169 & 71 & 0 & 70 & 1230 \\
\hline $\mathbf{6 1}$ & 159 & 152 & 0 & 13 & 324 & 314 & 320 & 82 & 184 & 0 & 1546 \\
\hline $\mathbf{\Sigma}$ & 643 & 1953 & 566 & 1491 & 1289 & 2224 & 855 & 1132 & 805 & 418 & $\mathbf{1 1 . 3 7 4}$ \\
\hline
\end{tabular}

Pode-se perceber que a somatória dos erros absolutos neste caso apresentou valor de 11.374, ou seja, aproximadamente $57 \%$ do total de viagens geradas. Cerca de $52 \%$ desses erros foram devido à subestimação e 48\% devido à superestimação. O par O-D 53-33 foi o que apresentou a maior diferença (715), onde foram observadas 57 viagens e estimadas 772 viagens.

Procedendo a mesma análise para os resultados estimados utilizando o TransCAD, observa-se que a soma das diferenças absolutas neste caso apresentou valor de 10.450, o que equivale a aproximadamente $52 \%$ do total de viagens geradas. Cerca de $54 \%$ desses erros são provenientes de uma subestimação e $46 \%$ devido a uma superestimação.

A Tabela 5.2 apresenta as diferenças absolutas para cada um dos 100 pares O-D. 
Tabela 5. 2: Diferença absoluta entre as viagens "reais" e as estimadas pelo método incremental, utilizando o TransCAD

\begin{tabular}{c|c|c|c|c|c|c|c|c|c|c|c}
\hline $\mathbf{0} \backslash \mathrm{D}$ & $\mathbf{1}$ & $\mathbf{4}$ & $\mathbf{8}$ & $\mathbf{1 0}$ & $\mathbf{2 5}$ & $\mathbf{3 3}$ & $\mathbf{5 2}$ & $\mathbf{5 3}$ & $\mathbf{5 6}$ & $\mathbf{6 1}$ & $\mathbf{\Sigma}$ \\
\hline $\mathbf{1}$ & 0 & 67 & 0 & 67 & 553 & 207 & 37 & 247 & 114 & 86 & 1377 \\
\hline $\mathbf{4}$ & 36 & 0 & 63 & 87 & 65 & 269 & 53 & 263 & 5 & 5 & 846 \\
\hline $\mathbf{8}$ & 167 & 246 & 0 & 160 & 50 & 269 & 251 & 106 & 40 & 0 & 1289 \\
\hline $\mathbf{1 0}$ & 156 & 347 & 0 & 0 & 10 & 0 & 54 & 67 & 44 & 79 & 757 \\
\hline $\mathbf{2 5}$ & 0 & 163 & 104 & 122 & 0 & 0 & 0 & 195 & 141 & 147 & 872 \\
\hline $\mathbf{3 3}$ & 162 & 81 & 20 & 294 & 0 & 0 & 0 & 153 & 208 & 66 & 983 \\
\hline $\mathbf{5 2}$ & 96 & 232 & 73 & 9 & 9 & 61 & 0 & 72 & 94 & 143 & 791 \\
\hline $\mathbf{5 3}$ & 93 & 120 & 72 & 364 & 27 & 294 & 80 & 0 & 113 & 0 & 1163 \\
\hline $\mathbf{5 6}$ & 37 & 255 & 55 & 278 & 162 & 204 & 169 & 81 & 0 & 81 & 1322 \\
\hline $\mathbf{6 1}$ & 73 & 33 & 0 & 45 & 257 & 187 & 210 & 28 & 217 & 0 & 1051 \\
\hline $\mathbf{\Sigma}$ & 820 & 1545 & 387 & 1425 & 1133 & 1492 & 853 & 1213 & 975 & 607 & $\mathbf{1 0 . 4 5 0}$ \\
\hline
\end{tabular}

A maior diferença absoluta observada apresentou valor de 553 viagens e corresponde ao par O-D 1-25. Neste par foram observadas 696 viagens e o total estimado pelo método incremental foi 143 viagens, apresentando uma subestimação. Ao carregar o primeiro incremento de fluxo, foram estimadas 61 viagens. Do $2^{\circ}$ até o $5^{\circ}$ incremento foram estimadas 18 viagens, nos demais, o valor estimado ficou oscilando na faixa de 1 a 5 viagens.

Em termos de somatória total das diferenças absolutas os valores nas duas situações foram bastante elevados.

\subsection{2 - Verificação da diferença quadrática entre as viagens “reais” e as estimadas pelo método incremental}

Este item foi proposto para verificar as diferenças quadráticas entre as viagens "reais" e as estimadas. A principal razão para incluir a diferença quadrática nas análises é que ela complementa as informações do módulo das diferenças, acentuando a magnitude absoluta dos erros.

A Tabela 5.3 apresenta os valores das diferenças quadráticas entre os valores reais e os estimados utilizando o QOD. 
Tabela 5. 3: Diferença quadrática entre as viagens "reais" e as estimadas pelo método incremental, utilizando o QUEENSOD

\begin{tabular}{c|c|c|c|c|c|c|c|c|c|c|c}
\hline $\mathbf{0} \backslash \mathrm{D}$ & $\mathbf{1}$ & $\mathbf{4}$ & $\mathbf{8}$ & $\mathbf{1 0}$ & $\mathbf{2 5}$ & $\mathbf{3 3}$ & $\mathbf{5 2}$ & $\mathbf{5 3}$ & $\mathbf{5 6}$ & $\mathbf{6 1}$ & $\mathbf{\Sigma}$ \\
\hline $\mathbf{1}$ & 0 & 109164 & 0 & 24336 & 299975 & 34857 & 128 & 47350 & 18851 & 10221 & 544882 \\
\hline $\mathbf{4}$ & 2061 & 0 & 35910 & 66 & 4775 & 65587 & 493 & 52670 & 92 & 166 & 161821 \\
\hline $\mathbf{8}$ & 1624 & 132350 & 0 & 35986 & 286 & 53453 & 55460 & 13596 & 8082 & 0 & 300837 \\
\hline $\mathbf{1 0}$ & 4998 & 160480 & 0 & 0 & 4516 & 0 & 697 & 2007 & 702 & 6368 & 179769 \\
\hline $\mathbf{2 5}$ & 0 & 24025 & 5944 & 32652 & 0 & 0 & 0 & 78344 & 25059 & 15326 & 181351 \\
\hline $\mathbf{3 3}$ & 5256 & 43015 & 1190 & 110091 & 0 & 0 & 0 & 5776 & 24869 & 718 & 190916 \\
\hline $\mathbf{5 2}$ & 79 & 18010 & 1576 & 331 & 4529 & 92720 & 0 & 219 & 645 & 13 & 118123 \\
\hline $\mathbf{5 3}$ & 41820 & 324 & 11385 & 153233 & 2079 & 511654 & 5027 & 0 & 286 & 0 & 725808 \\
\hline $\mathbf{5 6}$ & 1756 & 36672 & 13971 & 40885 & 22922 & 46397 & 28561 & 5027 & 0 & 4844 & 201035 \\
\hline $\mathbf{6 1}$ & 25186 & 22983 & 0 & 174 & 104846 & 98784 & 102080 & 6642 & 33672 & 0 & 394368 \\
\hline $\mathbf{\Sigma}$ & 82781 & 547023 & 69977 & 397755 & 443929 & 903454 & 192446 & 211631 & 112259 & 37657 & $\mathbf{2 . 9 9 8 . 9 1 1}$ \\
\hline
\end{tabular}

Pode-se observar que a somatória total das diferenças quadráticas, apresentou um valor bastante elevado, 2.998.911.

Os valores das diferenças quadráticas entre as viagens "reais" e as estimadas pelo método incremental, utilizando o TransCAD, são apresentados na Tabela 5.4.

Tabela 5. 4: Diferença quadrática entre as viagens "reais" e as estimadas pelo método incremental, utilizando o TransCAD

\begin{tabular}{c|c|c|c|c|c|c|c|c|c|c|c}
\hline $\mathbf{0} \backslash \mathrm{D}$ & $\mathbf{1}$ & $\mathbf{4}$ & $\mathbf{8}$ & $\mathbf{1 0}$ & $\mathbf{2 5}$ & $\mathbf{3 3}$ & $\mathbf{5 2}$ & $\mathbf{5 3}$ & $\mathbf{5 6}$ & $\mathbf{6 1}$ & $\mathbf{\Sigma}$ \\
\hline $\mathbf{l}$ & 0 & 4490 & 0 & 4428 & 305997 & 42816 & 1385 & 60989 & 12896 & 7339 & 440340 \\
\hline $\mathbf{4}$ & 1319 & 0 & 3923 & 7600 & 4220 & 72496 & 2768 & 69301 & 23 & 24 & 161673 \\
\hline $\mathbf{8}$ & 27779 & 60516 & 0 & 25597 & 2478 & 72582 & 62876 & 11257 & 1621 & 0 & 264705 \\
\hline $\mathbf{1 0}$ & 24264 & 120069 & 0 & 0 & 107 & 0 & 2884 & 4535 & 1931 & 6238 & 160027 \\
\hline $\mathbf{2 5}$ & 0 & 26618 & 10837 & 14862 & 0 & 0 & 0 & 38091 & 19940 & 21536 & 131884 \\
\hline $\mathbf{3 3}$ & 26118 & 6608 & 397 & 86213 & 0 & 0 & 0 & 23299 & 43098 & 4392 & 190124 \\
\hline $\mathbf{5 2}$ & 9228 & 53875 & 5401 & 74 & 83 & 3747 & 0 & 5249 & 8864 & 20566 & 107087 \\
\hline $\mathbf{5 3}$ & 8603 & 14518 & 5217 & 132751 & 724 & 86189 & 6330 & 0 & 12708 & 0 & 267040 \\
\hline $\mathbf{5 6}$ & 1403 & 65071 & 3023 & 77145 & 26286 & 41640 & 28446 & 6563 & 0 & 6613 & 256190 \\
\hline $\mathbf{6 1}$ & 5388 & 1099 & 0 & 2022 & 66003 & 35044 & 44163 & 800 & 46881 & 0 & 201399 \\
\hline $\mathbf{\Sigma}$ & 104101 & 352864 & 28797 & 350692 & 405898 & 354513 & 148851 & 220083 & 147962 & 66708 & 2.180 .469 \\
\hline
\end{tabular}

Assim, como havia sido observado com a somatória dos erros absolutos, a somatória total das diferenças quadráticas apresentou um valor bastante elevado, 2.180.469, ao utilizar o TransCAD. 
Se o desempenho do método incremental fosse verificado apenas pela somatória das diferenças absolutas e quadráticas, poder-se-ia afirmar que o desempenho apresentado pelo método incremental não foi bom. Porém, é necessário que seja realizada uma verificação em termos dos erros entre cada uma das viagens estimadas e observadas. O próximo item irá apresentar a distribuição dos erros relativos entre as viagens "reais" e as estimadas.

\subsection{3 - Verificação da distribuição dos erros relativos entre os valores das viagens “reais" e estimadas pelo processo incremental}

Além da análise comparativa anteriormente apresentada, fez-se a opção de calcular os erros relativos entre os elementos da matriz O-D "real" e os da estimada pelo processo incremental, e distribuí-los segundo uma faixa de erros. Desta forma, foi possível verificar intuitivamente o desempenho do método. Nesta análise, os 21 pares O-D que não apresentaram viagens observadas e estimadas foram desconsiderados, ou seja, dos 100 pares O-D considerou-se apenas 79.

As seguintes faixas de erros relativos foram adotadas arbitrariamente por melhor representar a distribuição dos erros: $e_{r} \leq 10 \%, \quad 10 \%<e_{r} \leq 30 \%, 30 \%<e_{r} \leq 50 \%$, $50 \%<e_{r} \leq 70 \%, 70 \%<e_{r} \leq 90 \%, e_{r}>90 \%$.

A Figura 5.1 representa as freqüências absolutas considerando os erros relativos, considerando os resultados obtidos com o QueensOD e com o TransCAD. Um melhor detalhamento desta distribuição dos erros relativos, considerando os 79 elementos não nulos da matriz O-D, encontram-se na Tabela 5.5. 


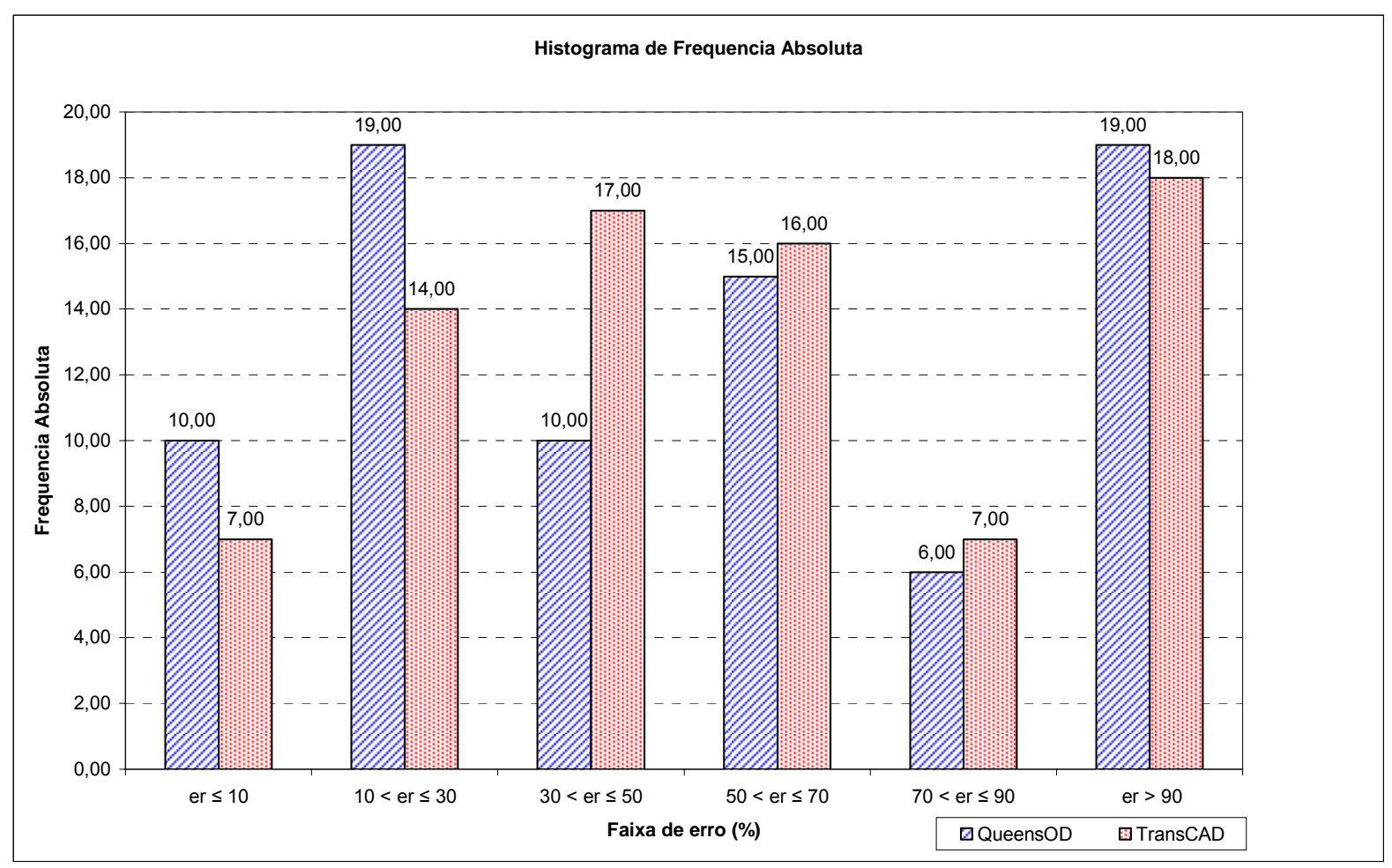

Figura 5. 1: Distribuição das freqüências absolutas em função do erro relativo considerando o carregamento incremental dos fluxos

Tabela 5. 5: Distribuição do valor absoluto dos erros relativos entre a matriz O-D "real" e a matriz OD estimada pelo método incremental

\begin{tabular}{|c|c|c|c|c|c|c|c|c|c|}
\hline Situaçãa & Programa & Intervalo do Erro $(\%)$ & $0, \leq 10$ & $10<\theta_{\gamma} \leq 3$ & $30<0_{\gamma} \leq 5$ & $50<\theta_{y} \leq 7$ & $70<\theta_{0} \leq 00$ & $\theta_{\gamma}>90$ & Total de O-D \\
\hline \multirow{6}{*}{ Caso A } & \multirow{3}{*}{ Queens (0D } & Frequencia ubsoluta & 1000 & 1900 & 10,00 & 15,00 & 6,00 & 19000 & \multirow{3}{*}{79,00} \\
\hline & & Frequencia Relatima & $12,66 \%$ & $24,05 \%$ & $12,66 \%$ & $18,90 \%$ & $7,50 \%$ & $24,0,5 \%$ & \\
\hline & & Frequencia Acumulada & 0,1266 & 0,3671 & 0,4937 & 0,6835 & 0,7595 & 1,0000 & \\
\hline & \multirow{3}{*}{ Trans $C A D$} & Frequencia sbosuta & 7,00 & 14,00 & 17,00 & 16,00 & 7,00 & 18,010 & \multirow{3}{*}{79,00} \\
\hline & & Frequencia Relativa & $8,86 \%$ & $17,7 \% \%$ & $21,52 \%$ & $20,20 \%$ & $8,86 \%$ & $22,78 \%$ & \\
\hline & & Erequencia Acumulada & 0,0886 & 0,2658 & 0,4810 & 0,685 & 0,7722 & 1,0000 & \\
\hline
\end{tabular}

A interpretação desta tabela será dividida em duas etapas: (i) serão analisadas as diferenças relativas entre as viagens da matriz O-D "real" e as estimadas incrementalmente usando o QUEENSOD e (ii) serão analisadas as diferenças relativas entre as viagens da matriz O-D "real" e as estimadas incrementalmente usando o TransCAD.

- Análise das diferenças relativas entre as viagens "reais" e as estimadas incrementalmente utilizando o QUEENSOD: 
Observando os resultados apresentados na Tabela 5.5, verifica-se que $13 \%$ dos erros gerados ao utilizar o processo incremental apresentaram valores de no máximo $10 \%$. Ou seja, em 10 dos 79 pares O-D considerados o erro causado por uma subestimação ou uma superestimação das viagens foi menor ou igual a 10\% em relação ao valor "real".

Ainda observando a Tabela 5.5, verifica-se que 13\% dos erros encontram-se acumulados na faixa de $30 \%<e_{r}^{Q_{i j}} \leq 50 \%$, sendo que $49 \%$ dos erros totais apresentam valores que variam de 0 a 50\%. Além disso, 19 pares O-D apresentam erro relativo com valor superior a $90 \%$, destes, 18 possuem erro relativo com valor superior a $100 \%$.

Dos 18 pares O-D com valores de erro superiores a 100\%, 4 apresentaram valores superiores a $500 \%$. O maior dos erros possui valor de $1.765 \%$, ocasionado por uma superestimação de viagens no par O-D 4-53.

Neste par foram observadas 13 viagens e estimadas 243 viagens. Em termos absolutos, a diferença entre o valor observado e o estimado foi 230 viagens, que corresponde a $15 \%$ do total de viagens "reais" atraídas para esta zona, em termos relativos acaba sendo elevado, devido ao pequeno número de viagens observadas.

Os demais pares que apresentaram valor de erro relativo acima de 500\% foram: $8-53$ $\left(Q_{i j}^{o b s}=15\right.$ e $\left.Q_{i j}^{e s t}=131\right) ; 53-33\left(Q_{i j}^{o b s}=57\right.$ e $\left.Q_{i j}^{\text {est }}=772\right)$, e; $61-25\left(Q_{i j}^{o b s}=57\right.$ e $\left.Q_{i j}^{\text {est }}=381\right)$. Estes quatro pares O-D também apresentaram os menores valores de viagens observadas e, também, devido a isso, seus erros relativos ficaram elevados.

As possíveis causas destes erros podem ser: (i) por se tratar de um valor observado muito pequeno em relação aos demais valores, o erro relativo tende a ser maior; (ii) a indeterminação nos fluxos em alguns nós, como por exemplo, o nó 35 , que concentra a maioria das viagens destinadas a esta região da rede viária, pode ter contribuído para possíveis 
erros das viagens entre 4-53, 8-53 e 53-33, assim como a indeterminação no nó 23 pode ter contribuído para os possíveis erros das viagens entre 61-25; porém, esta é uma deficiência do modelo sintético.

- Análise dos resultados obtidos utilizando o TransCAD:

Pela análise da Tabela 5.2 dos 79 pares O-D, 7 apresentaram erros com valor menor ou igual a $10 \%$.

Em 41 pares O-D os erros relativos foram superiores a $50 \%$ e, destes, 18 apresentaram valores maiores do que 90\%, sendo, 14 observações distribuídas na faixa de 100 a $455 \%$ e 4 apresentaram valores acima de $500 \%$. Os pares O-D que apresentaram valores superiores a $500 \%$ foram: $1-53\left(Q_{i j}^{o b s}=45\right.$ e $\left.Q_{i j}^{\text {est }}=292\right) ; 4-53\left(Q_{i j}^{\text {obs }}=13\right.$ e $\left.Q_{i j}^{\text {est }}=276\right) ; 8-53$ $\left(Q_{i j}^{o b s}=15\right.$ e $\left.Q_{i j}^{e s t}=121\right)$, e; 53-33 $\left(Q_{i j}^{o b s}=67\right.$ e $\left.Q_{i j}^{\text {est }}=350\right)$. Todos possuem valores baixos de viagens observadas, o que leva à obtenção de erros relativos maiores. O maior erro relativo, em módulo, foi $2.025 \%$, apresentado pelo par 4-53, com 13 viagens observadas e 276 viagens estimadas, em termos de diferenças absolutas esta superestimação de viagens não foi muito grande. A diferença entre a quantidade de viagens observada e estimada para este par O-D representa aproximadamente $18 \%$ do total de viagens atraídas pela zona 53 .

De forma geral, o desempenho do método incremental não foi satisfatório, pois apresentou uma quantidade alta de erros relativos com valor acima de 50\%.

Independentemente desta constatação, os objetivos principais deste trabalho foram atendidos, pois, foi proposto um método com o qual uma matriz O-D foi estimada sem necessidade de iterações. Assim com intuito de verificar a sua utilidade como um método alternativo, o próximo passo será a verificação do desempenho dos métodos iterativos e compará-los com o desempenho do método incremental. 


\section{2 - COMPARAÇÃO DAS DIFERENÇAS DOS VALORES DA MATRIZ O-D ESTIMADA ATRAVÉS DO MÉTODO INCREMENTAL EM RELAÇÃO ÀS DIFERENÇAS DAS MATRIZES O-D ESTIMADAS ATRAVÉS DOS MÉTODOS ITERATIVOS}

Utilizando os programas QUEENSOD e TransCAD, considerando o método iterativo, foram estimadas duas matrizes $\mathrm{O}-\mathrm{D}$, cada qual com um tipo de matriz semente: (i) matriz semente binária (Caso B), que representa a forma mais simples de uma matriz semente, e (ii) matriz semente equivalente a 70\% da matriz O-D "real" (Caso C).

A matriz O-D estimada no Caso B utilizando o QOD apresentou um total de 20.431 viagens geradas, aproximadamente $3 \%$ a mais de viagens do que a situação "real". Ao utilizar o TransCAD, o total gerado, para este mesmo caso, foi 20.811 viagens, aproximadamente $5 \%$ de viagens a mais do que a situação "real".

No Caso C, utilizando o QOD foram estimadas $19.770,1 \%$ a menos do que o total de viagens "reais". Ao utilizar TransCAD foram estimadas 21.157 viagens, $6 \%$ a mais do que o total "real".

Em termos do número total de viagens, a diferença não foi significativa. Portanto, há necessidade de aprofundar a análise dos erros de forma a verificar o desempenho dos métodos iterativos e compará-los ao desempenho obtido com a aplicação do método incremental.

Para avaliar o desempenho do método incremental em relação ao iterativo este item foi dividido em três etapas: (i) comparação da somatória total das diferenças absolutas obtidas entre as viagens "reais" e as estimadas por cada um dos métodos (incremental e iterativo); (ii) comparação da somatória total das diferenças quadráticas entre as viagens "reais" e as estimadas por ambos os métodos; e, (iii) verificação da distribuição dos erros relativos entre as viagens "reais" e as estimadas. 


\subsection{1 - Comparação da somatória total das diferenças absolutas obtidas entre as viagens "reais" $\mathrm{e}$ as estimadas}

Este item apresenta o comparativo entre a somatória das diferenças absolutas entre a matriz O-D "real" e a estimada pelos métodos iterativos. Este comparativo servirá apenas para que se tenha uma noção global sobre os resultados estimados.

Pelos resultados apresentados na Tabela 5.6, observa-se que a somatória das diferenças absolutas entre as viagens "reais" e as estimadas, apresentou um valor de 15.177 , ou seja, aproximadamente $76 \%$ do total de viagens geradas. Cerca de $48 \%$ dos erros foram causados pela subestimação de viagens e 52\% pela superestimação. O par 8-10 foi o que apresentou o maior valor desta diferença, sendo que neste foram observadas 146 viagens e estimadas 1.410 viagens, este par O-D possui apenas um caminho possível para a realização das viagens.

Tabela 5. 6: Diferença absoluta entre as viagens "reais" e estimadas pelo QUEENSOD, utilizando o método iterativo e matriz semente binária

\begin{tabular}{c|c|c|c|c|c|c|c|c|c|c|c}
\hline $\mathbf{0} \mathrm{DD}$ & $\mathbf{1}$ & $\mathbf{4}$ & $\mathbf{8}$ & $\mathbf{1 0}$ & $\mathbf{2 5}$ & $\mathbf{3 3}$ & $\mathbf{5 2}$ & $\mathbf{5 3}$ & $\mathbf{5 6}$ & $\mathbf{6 1}$ & $\boldsymbol{\Sigma}$ \\
\hline $\mathbf{1}$ & 0 & 1045 & 0 & 212 & 523 & 285 & 21 & 170 & 42 & 19 & 2316 \\
\hline $\mathbf{4}$ & 306 & 0 & 249 & 17 & 31 & 346 & 4 & 156 & 74 & 95 & 1278 \\
\hline $\mathbf{8}$ & 61 & 633 & 0 & 1264 & 340 & 75 & 331 & 17 & 60 & 0 & 2781 \\
\hline $\mathbf{1 0}$ & 248 & 303 & 0 & 0 & 11 & 0 & 56 & 106 & 123 & 228 & 1076 \\
\hline $\mathbf{2 5}$ & 0 & 203 & 60 & 146 & 0 & 0 & 0 & 30 & 144 & 205 & 788 \\
\hline $\mathbf{3 3}$ & 243 & 2 & 194 & 77 & 0 & 0 & 0 & 87 & 227 & 398 & 1228 \\
\hline $\mathbf{5 2}$ & 34 & 92 & 26 & 44 & 201 & 200 & 0 & 62 & 152 & 303 & 1114 \\
\hline $\mathbf{5 3}$ & 293 & 110 & 144 & 439 & 164 & 141 & 596 & 0 & 26 & 0 & 1913 \\
\hline $\mathbf{5 6}$ & 97 & 84 & 245 & 233 & 102 & 35 & 156 & 18 & 0 & 82 & 1051 \\
\hline $\mathbf{6 1}$ & 30 & 73 & 0 & 327 & 333 & 538 & 8 & 174 & 149 & 0 & 1633 \\
\hline $\mathbf{\Sigma}$ & 1311 & 2547 & 918 & 2760 & 1705 & 1619 & 1172 & 820 & 996 & 1330 & $\mathbf{1 5 . 1 7 7}$ \\
\hline
\end{tabular}

A Tabela 5.7 apresenta os valores das diferenças absolutas entre as viagens "reais" e as estimadas utilizando o QOD considerando o Caso C. 
Tabela 5. 7: Diferença absoluta entre as viagens "reais" e estimadas pelo QUEENSOD, utilizando o método iterativo e matriz semente equivalente a $70 \%$ da matriz "real"

\begin{tabular}{c|c|c|c|c|c|c|c|c|c|c|c}
\hline $\mathbf{0} \mathrm{D}$ & $\mathbf{1}$ & $\mathbf{4}$ & $\mathbf{8}$ & $\mathbf{1 0}$ & $\mathbf{2 5}$ & $\mathbf{3 3}$ & $\mathbf{5 2}$ & $\mathbf{5 3}$ & $\mathbf{5 6}$ & $\mathbf{6 1}$ & $\mathbf{\Sigma}$ \\
\hline $\mathbf{1}$ & 0 & 929 & 0 & 209 & 429 & 265 & 65 & 23 & 23 & 45 & 1988 \\
\hline $\mathbf{4}$ & 394 & 0 & 285 & 78 & 118 & 308 & 25 & 5 & 18 & 105 & 1336 \\
\hline $\mathbf{8}$ & 13 & 444 & 0 & 1071 & 225 & 62 & 278 & 10 & 66 & 0 & 2170 \\
\hline $\mathbf{1 0}$ & 93 & 5 & 0 & 0 & 11 & 0 & 113 & 105 & 337 & 167 & 831 \\
\hline $\mathbf{2 5}$ & 0 & 283 & 25 & 92 & 0 & 0 & 0 & 170 & 201 & 272 & 1042 \\
\hline $\mathbf{3 3}$ & 242 & 48 & 141 & 21 & 0 & 0 & 0 & 211 & 179 & 408 & 1249 \\
\hline $\mathbf{5 2}$ & 43 & 19 & 32 & 72 & 238 & 53 & 0 & 146 & 155 & 270 & 1028 \\
\hline $\mathbf{5 3}$ & 148 & 98 & 145 & 316 & 154 & 1 & 445 & 0 & 24 & 0 & 1331 \\
\hline $\mathbf{5 6}$ & 33 & 40 & 12 & 255 & 66 & 114 & 181 & 27 & 0 & 13 & 740 \\
\hline $\mathbf{6 1}$ & 54 & 94 & 0 & 259 & 279 & 536 & 106 & 192 & 166 & 0 & 1686 \\
\hline $\mathbf{\Sigma}$ & 1020 & 1960 & 639 & 2373 & 1519 & 1339 & 1211 & 890 & 1168 & 1280 & $\mathbf{1 3 . 4 0 0}$ \\
\hline
\end{tabular}

Nota-se que a somatória total das diferenças absolutas apresentou um valor elevado (13.400) que equivale a $67 \%$ do número total de viagens "observadas". A maior diferença também ocorreu no par 8-10, em que 146 viagens foram observadas e 1.217 viagens foram estimadas.

Nas Tabelas 5.8 e 5.9 encontram-se os valores das diferenças absolutas entre as viagens "reais" e as viagens estimadas, utilizando o TransCAD. A Tabela 5.8 apresenta esta diferença considerando a matriz estimada do Caso B e a Tabela 5.9 apresenta as diferenças absolutas considerando os resultados estimados no Caso C.

Tabela 5. 8: Diferença absoluta entre as viagens "reais" e estimadas pelo TransCAD, utilizando o método iterativo e matriz semente binária

\begin{tabular}{c|c|c|c|c|c|c|c|c|c|c|c}
\hline $\mathbf{0} \mathbf{D}$ & $\mathbf{1}$ & $\mathbf{4}$ & $\mathbf{8}$ & $\mathbf{1 0}$ & $\mathbf{2 5}$ & $\mathbf{3 3}$ & $\mathbf{5 2}$ & $\mathbf{5 3}$ & $\mathbf{5 6}$ & $\mathbf{6 1}$ & $\mathbf{\Sigma}$ \\
\hline $\mathbf{1}$ & 0 & 211 & 0 & 95 & 509 & 245 & 105 & 259 & 193 & 40 & 1658 \\
\hline $\mathbf{4}$ & 29 & 0 & 112 & 46 & 34 & 313 & 108 & 265 & 57 & 44 & 1008 \\
\hline $\mathbf{8}$ & 129 & 194 & 0 & 173 & 46 & 386 & 342 & 17 & 7 & 0 & 1293 \\
\hline $\mathbf{1 0}$ & 186 & 173 & 0 & 0 & 160 & 0 & 144 & 158 & 74 & 180 & 1075 \\
\hline $\mathbf{2 5}$ & 0 & 286 & 76 & 284 & 0 & 0 & 0 & 190 & 198 & 198 & 1231 \\
\hline $\mathbf{3 3}$ & 239 & 5 & 151 & 418 & 0 & 0 & 0 & 61 & 259 & 9 & 1141 \\
\hline $\mathbf{5 2}$ & 100 & 274 & 3 & 67 & 31 & 162 & 0 & 29 & 108 & 153 & 928 \\
\hline $\mathbf{5 3}$ & 59 & 208 & 151 & 441 & 16 & 683 & 47 & 0 & 189 & 0 & 1793 \\
\hline $\mathbf{5 6}$ & 70 & 13 & 3 & 330 & 206 & 279 & 32 & 128 & 0 & 7 & 1068 \\
\hline $\mathbf{6 1}$ & 6 & 46 & 0 & 43 & 297 & 230 & 530 & 42 & 287 & 0 & 1480 \\
\hline $\mathbf{\Sigma}$ & 817 & 1409 & 496 & 1898 & 1299 & 2297 & 1308 & 1148 & 1373 & 631 & $\mathbf{1 2 . 6 7 5}$ \\
\hline
\end{tabular}


Os valores contidos na Tabela 5.8 mostram que a soma de todas as diferenças absolutas para esta situação apresentou um valor de 12.675 , erro equivalente a $64 \%$ do total de viagens "observadas". A maior diferença ocorreu no par 53-33, em que 57 viagens foram observadas e 740 viagens estimadas.

Tabela 5. 9: Diferença absoluta entre as viagens "reais" e estimadas pelo TransCAD, utilizando o método iterativo e matriz semente equivalente a $70 \%$ da matriz "real"

\begin{tabular}{c|c|c|c|c|c|c|c|c|c|c|c}
\hline $\mathbf{0} \mathrm{D}$ & $\mathbf{1}$ & $\mathbf{4}$ & $\mathbf{8}$ & $\mathbf{1 0}$ & $\mathbf{2 5}$ & $\mathbf{3 3}$ & $\mathbf{5 2}$ & $\mathbf{5 3}$ & $\mathbf{5 6}$ & $\mathbf{6 1}$ & $\mathbf{\Sigma}$ \\
\hline $\mathbf{1}$ & 0 & 185 & 0 & $\mathbf{7 3}$ & 625 & 217 & 264 & 33 & 227 & 36 & 1661 \\
\hline $\mathbf{4}$ & 16 & 0 & $\mathbf{7 8}$ & 9 & 178 & 275 & 217 & 8 & 304 & 90 & 1176 \\
\hline $\mathbf{8}$ & 21 & 31 & 0 & 74 & 318 & 197 & 323 & 13 & 24 & 0 & 1002 \\
\hline $\mathbf{1 0}$ & 16 & 3 & 0 & 0 & 283 & 0 & 162 & 169 & 91 & 257 & 982 \\
\hline $\mathbf{2 5}$ & 0 & 285 & 121 & 153 & 0 & 0 & 0 & 308 & 195 & 176 & 1237 \\
\hline $\mathbf{3 3}$ & 185 & 36 & 285 & 78 & 0 & 0 & 0 & 334 & 264 & 79 & 1260 \\
\hline $\mathbf{5 2}$ & 59 & 30 & 42 & 97 & 10 & 331 & 0 & 46 & 111 & 87 & 811 \\
\hline $\mathbf{5 3}$ & 226 & 153 & 170 & 386 & 37 & 291 & 118 & 0 & 257 & 0 & 1638 \\
\hline $\mathbf{5 6}$ & 50 & 147 & 22 & 302 & 207 & 225 & 325 & 63 & 0 & 26 & 1367 \\
\hline $\mathbf{6 1}$ & 39 & 67 & 0 & 382 & 78 & 81 & 155 & 105 & 283 & 0 & 1189 \\
\hline $\mathbf{\Sigma}$ & 611 & 936 & 718 & 1553 & 1737 & 1617 & 1564 & 1078 & 1757 & 751 & $\mathbf{1 2 . 3 2 3}$ \\
\hline
\end{tabular}

Os valores contidos na Tabela 5.9 mostram que a soma de todas as diferenças absolutas para o Caso C, utilizando o TransCAD, apresentou um valor de 12.323 , um erro que corresponde a $61 \%$ do total de viagens "observadas". A maior diferença ocorreu no par 1-25, em que 696 viagens foram observadas e 71 viagens estimadas.

Os valores da somatória total das diferenças absolutas em cada um dos casos (A, B, C) e para cada programa utilizado, estão apresentados na Figura 5.2. Pode-se observar que os valores destas somatórias foram bastante elevados em todas as situações. 


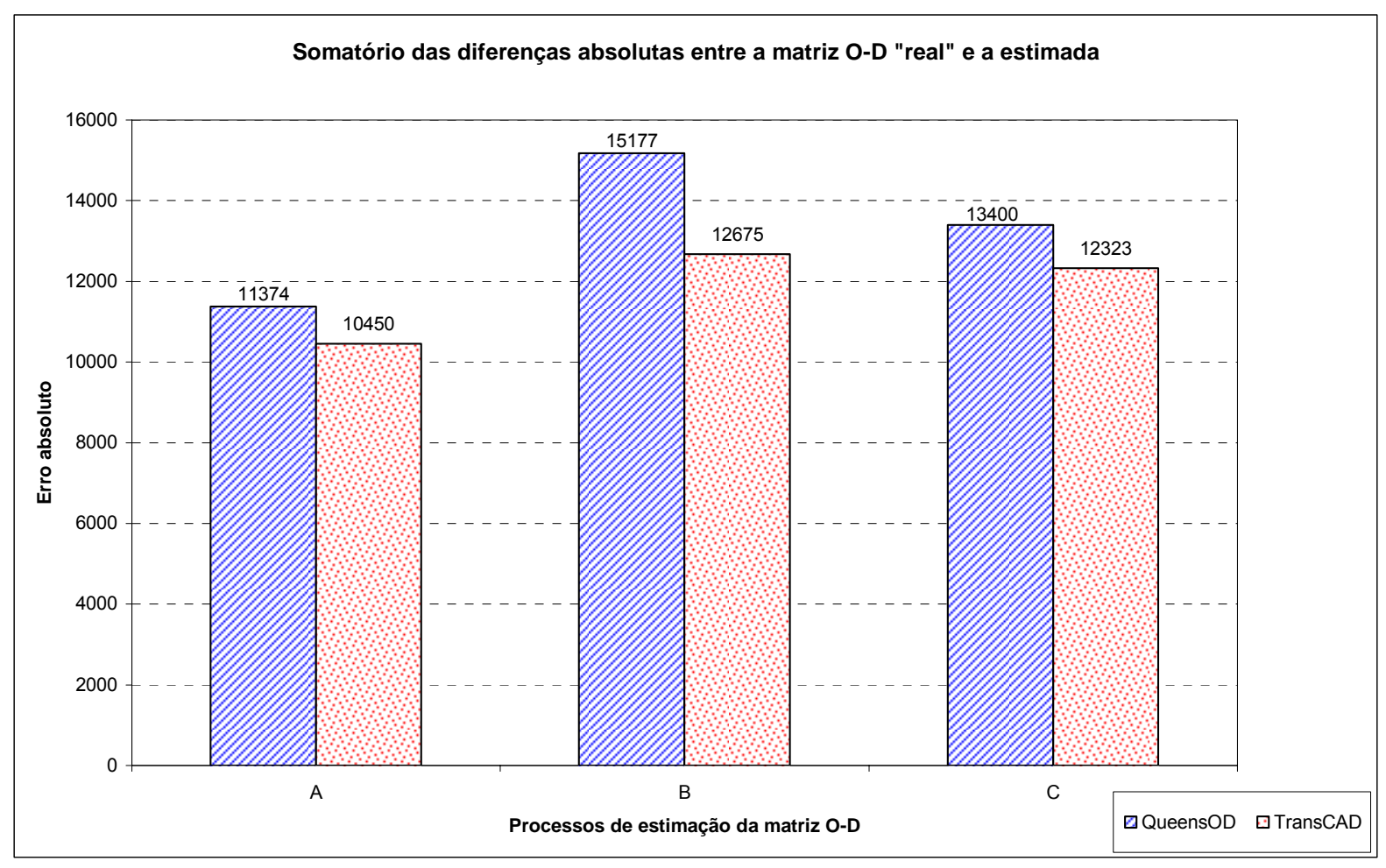

Figura 5. 2: Somatório das diferenças absolutas entre a matriz O-D "real" e a estimada em função dos casos analisados e dos programas utilizados

A seguir será apresentada uma discussão dos resultados obtidos considerando cada um dos programas e métodos utilizados.

- Comparativo dos resultados obtidos utilizando o QUEENSOD:

A soma total das diferenças absolutas entre a matriz "real" e a estimada considerando o carregamento incremental foi 11.374, considerando o Caso B o valor foi 15.177 e ao considerar o caso $\mathrm{C}$ este valor foi 13.400. Apesar de estes valores terem sido bastante elevados é possível perceber que dentre os três, o menor foi obtido considerando o carregamento incremental.

O erro considerando o carregamento incremental é aproximadamente $25 \%$ menor que o obtido ao considerar o método iterativo proposto no Caso B. Também percebe-se que o erro ao considerar o carregamento incremental é $15 \%$ menor que o obtido ao utilizar o método iterativo com matriz semente equivalente a $70 \%$ da matriz "real". 
- Comparativo dos resultados obtidos utilizando o TransCAD:

A somatória das diferenças absolutas entre a matriz "real" e a estimada, apresentou valor de 10.450 ao considerar o carregamento incremental, quando se considerou utilização de uma semente binária o valor desta diferença foi 12.675 e ao utilizar uma matriz semente equivalente a $70 \%$ da matriz "real" proporcional a matriz "real" esse valor passou a ser 12.323.

Isto significa que a consideração de um carregamento incremental dos fluxos de tráfego teve um erro de aproximadamente $18 \%$ menor do que o obtido ao utilizar o método iterativo com matriz semente binária; e a utilização de um processo de carregamento incremental dos fluxos proporcionou a redução dos erros em $15 \%$ em relação aos resultados do método iterativo utilizando uma matriz semente equivalente a $70 \%$ da matriz "real".

Apesar de elevados, o método incremental foi o que apresentou os menores valores para a somatória das diferenças absolutas.

\subsection{2 - Comparação da somatória total das diferenças quadráticas obtidas entre as viagens "reais" e as estimadas}

Nas Tabelas 5.10 e 5.11 é possível observar os valores da diferença quadrática entre as viagens observadas e a estimadas para os Casos B e C, utilizando o QUEENSOD. 
Tabela 5. 10: Diferença quadrática entre a matriz "real" e a matriz estimada pelo QUEENSOD, método iterativo e uma matriz semente binária

\begin{tabular}{c|c|c|c|c|c|c|c|c|c|c|c}
\hline $\mathbf{0} \backslash \mathrm{D}$ & $\mathbf{1}$ & $\mathbf{4}$ & $\mathbf{8}$ & $\mathbf{1 0}$ & $\mathbf{2 5}$ & $\mathbf{3 3}$ & $\mathbf{5 2}$ & $\mathbf{5 3}$ & $\mathbf{5 6}$ & $\mathbf{6 1}$ & $\mathbf{\Sigma}$ \\
\hline $\mathbf{l}$ & 0 & 1091607 & 0 & 44859 & 273843 & 81453 & 420 & 28764 & 1747 & 357 & 1523051 \\
\hline $\mathbf{4}$ & 93391 & 0 & 62101 & 303 & 930 & 119647 & 18 & 24398 & 5506 & 8968 & 315262 \\
\hline $\mathbf{8}$ & 3733 & 400436 & 0 & 1597190 & 115872 & 5580 & 109495 & 292 & 3600 & 0 & 2236199 \\
\hline $\mathbf{1 0}$ & 61653 & 92052 & 0 & 0 & 125 & 0 & 3114 & 11236 & 15031 & 52075 & 235286 \\
\hline $\mathbf{2 5}$ & 0 & 41372 & 3588 & 21228 & 0 & 0 & 0 & 918 & 20592 & 41943 & 129641 \\
\hline $\mathbf{3 3}$ & 58806 & 5 & 37791 & 5898 & 0 & 0 & 0 & 7482 & 51620 & 158643 & 320246 \\
\hline $\mathbf{5 2}$ & 1142 & 8519 & 692 & 1962 & 40280 & 39880 & 0 & 3856 & 22983 & 91809 & 211124 \\
\hline $\mathbf{5 3}$ & 85790 & 12100 & 20765 & 193028 & 26994 & 19740 & 355216 & 0 & 671 & 0 & 714305 \\
\hline $\mathbf{5 6}$ & 9428 & 7123 & 59780 & 54476 & 10302 & 1225 & 24398 & 310 & 0 & 6675 & 173718 \\
\hline $\mathbf{6 1}$ & 900 & 5388 & 0 & 106929 & 110889 & 289659 & 71 & 30311 & 22141 & 0 & 566288 \\
\hline $\mathbf{\Sigma}$ & 314845 & 1658601 & 184717 & 2025875 & 579237 & 557185 & 492732 & 107568 & 143891 & 360470 & $\mathbf{6 . 4 2 5 . 1 2 0}$ \\
\hline
\end{tabular}

Os valores contidos na Tabela 5.10 mostram que a soma de todas as diferenças quadráticas para o Caso B, utilizando o QOD, apresentou um valor de 6.425.120, sendo que a maior diferença ocorreu no par 53-33, em que 57 viagens foram observadas e 740 viagens foram estimadas.

Tabela 5. 11: Diferença quadrática entre a matriz "real" e a matriz estimada iterativamente pelo QUEENSOD, utilizando uma matriz semente equivalente a 70\% da matriz "real"

\begin{tabular}{c|c|c|c|c|c|c|c|c|c|c|c}
\hline $\mathbf{0} \backslash \mathrm{D}$ & $\mathbf{1}$ & $\mathbf{4}$ & $\mathbf{8}$ & $\mathbf{1 0}$ & $\mathbf{2 5}$ & $\mathbf{3 3}$ & $\mathbf{5 2}$ & $\mathbf{5 3}$ & $\mathbf{5 6}$ & $\mathbf{6 1}$ & $\mathbf{\Sigma}$ \\
\hline $\mathbf{1}$ & 0 & 862298 & 0 & 43723 & 184213 & 69960 & 4173 & 548 & 529 & 2043 & 1167486 \\
\hline $\mathbf{4}$ & 154921 & 0 & 81168 & 6084 & 13995 & 94802 & 610 & 27 & 313 & 11088 & 363009 \\
\hline $\mathbf{8}$ & 164 & 197491 & 0 & 1146398 & 50760 & 3881 & 77228 & 104 & 4369 & 0 & 1480397 \\
\hline $\mathbf{1 0}$ & 8705 & 28 & 0 & 0 & 119 & 0 & 12679 & 11046 & 113232 & 27922 & 173731 \\
\hline $\mathbf{2 5}$ & 0 & 80316 & 600 & 8427 & 0 & 0 & 0 & 28934 & 40240 & 73875 & 232393 \\
\hline $\mathbf{3 3}$ & 58516 & 2266 & 19796 & 420 & 0 & 0 & 0 & 44563 & 32148 & 166382 & 324092 \\
\hline $\mathbf{5 2}$ & 1815 & 357 & 1037 & 5170 & 56596 & 2841 & 0 & 21374 & 23963 & 73008 & 186161 \\
\hline $\mathbf{5 3}$ & 21934 & 9584 & 21112 & 100141 & 23593 & 1 & 198025 & 0 & 571 & 0 & 374961 \\
\hline $\mathbf{5 6}$ & 1076 & 1616 & 132 & 65178 & 4316 & 13064 & 32689 & 713 & 0 & 159 & 118943 \\
\hline $\mathbf{6 1}$ & 2959 & 8761 & 0 & 67236 & 77562 & 287296 & 11172 & 36941 & 27589 & 0 & 519518 \\
\hline $\mathbf{\Sigma}$ & 250089 & 1162717 & 123846 & 1442778 & 411155 & 471846 & 336577 & 144250 & 242956 & 354478 & $\mathbf{4 . 9 4 0 . 6 9 1}$ \\
\hline
\end{tabular}

A soma de todas as diferenças quadráticas para o Caso C, utilizando o QOD, apresentou um valor de 4.940.691, sendo que a maior diferença ocorreu no par 1-25, em que 696 viagens foram observadas e apenas 71 viagens foram estimadas. 
Os valores das diferenças quadráticas entre a matriz O-D "real" e a estimada, considerando os resultados obtidos utilizando o TransCAD, encontram-se apresentados nas Tabelas 5.12 e 5.13. Na Tabela 5.12 é apresentado o valor das diferenças quadráticas quando foi considerado o Caso B e o valor desta mesma diferença considerando o Caso C, encontrase apresentado na Tabela 5.13.

Tabela 5. 12: Diferença quadrática entre a matriz "real" e a matriz estimada pelo TransCAD, o método iterativo e uma matriz semente binária

\begin{tabular}{c|c|c|c|c|c|c|c|c|c|c|c}
\hline $\mathbf{0} \mathrm{D}$ & $\mathbf{1}$ & $\mathbf{4}$ & $\mathbf{8}$ & $\mathbf{1 0}$ & $\mathbf{2 5}$ & $\mathbf{3 3}$ & $\mathbf{5 2}$ & $\mathbf{5 3}$ & $\mathbf{5 6}$ & $\mathbf{6 1}$ & $\mathbf{\Sigma}$ \\
\hline $\mathbf{l}$ & 0 & 44711 & 0 & 9038 & 259091 & 59912 & 10939 & 67231 & 37311 & 1621 & 489855 \\
\hline $\mathbf{4}$ & 820 & 0 & 12526 & 2150 & 1155 & 97656 & 11679 & 70066 & 3304 & 1969 & 201326 \\
\hline $\mathbf{8}$ & 16577 & 37593 & 0 & 29905 & 2128 & 148811 & 116759 & 284 & 49 & 0 & 352106 \\
\hline $\mathbf{1 0}$ & 34689 & 29849 & 0 & 0 & 25530 & 0 & 20805 & 24980 & 5525 & 32224 & 173602 \\
\hline $\mathbf{2 5}$ & 0 & 81659 & 5752 & 80804 & 0 & 0 & 0 & 35918 & 39343 & 39077 & 282552 \\
\hline $\mathbf{3 3}$ & 56963 & 26 & 22852 & 174716 & 0 & 0 & 0 & 3670 & 66869 & 85 & 325181 \\
\hline $\mathbf{5 2}$ & 9934 & 75202 & 11 & 4509 & 973 & 26309 & 0 & 862 & 11606 & 23482 & 152888 \\
\hline $\mathbf{5 3}$ & 3486 & 43069 & 22701 & 194269 & 254 & 466544 & 2243 & 0 & 35649 & 0 & 768215 \\
\hline $\mathbf{5 6}$ & 4890 & 156 & 11 & 109177 & 42617 & 77635 & 1041 & 16318 & 0 & 43 & 251889 \\
\hline $\mathbf{6 1}$ & 35 & 2094 & 0 & 1823 & 88132 & 52964 & 280688 & 1737 & 82467 & 0 & 509941 \\
\hline $\mathbf{\Sigma}$ & 127395 & 314359 & 63854 & 606392 & 419880 & 929831 & 444155 & 221066 & 282122 & 98501 & $\mathbf{3 . 5 0 7 . 5 5 4}$ \\
\hline
\end{tabular}

Os valores contidos na Tabela 5.12 mostram que a soma de todas as diferenças absolutas para esta situação apresentou um valor de 3.507.554, sendo que a maior diferença ocorreu no par 53-33, em que 57 viagens foram observadas e 740 viagens foram estimadas. 
Tabela 5. 13: Diferença quadrática entre a matriz "real" e a matriz estimada iterativamente pelo TransCAD, utilizando uma matriz semente equivalente a $70 \%$ da matriz "real"

\begin{tabular}{c|c|c|c|c|c|c|c|c|c|c|c}
\hline $\mathbf{0} \backslash \mathrm{D}$ & $\mathbf{1}$ & $\mathbf{4}$ & $\mathbf{8}$ & $\mathbf{1 0}$ & $\mathbf{2 5}$ & $\mathbf{3 3}$ & $\mathbf{5 2}$ & $\mathbf{5 3}$ & $\mathbf{5 6}$ & $\mathbf{6 1}$ & $\mathbf{\Sigma}$ \\
\hline $\mathbf{1}$ & 0 & 34369 & 0 & 5330 & 391150 & 47033 & 69775 & 1067 & 51697 & 1316 & 601737 \\
\hline $\mathbf{4}$ & 249 & 0 & 6093 & 75 & 31816 & 75895 & 47024 & 70 & 92550 & 8187 & 261959 \\
\hline $\mathbf{8}$ & 439 & 977 & 0 & 5454 & 101404 & 38915 & 104562 & 160 & 576 & 0 & 252487 \\
\hline $\mathbf{1 0}$ & 256 & 9 & 0 & 0 & 80287 & 0 & 26338 & 28568 & 8328 & 66275 & 210061 \\
\hline $\mathbf{2 5}$ & 0 & 81111 & 14668 & 23311 & 0 & 0 & 0 & 94562 & 38177 & 30902 & 282732 \\
\hline $\mathbf{3 3}$ & 34236 & 1272 & 81219 & 6025 & 0 & 0 & 0 & 111810 & 69527 & 6187 & 310277 \\
\hline $\mathbf{5 2}$ & 3425 & 893 & 1731 & 9393 & 93 & 109455 & 0 & 2070 & 12294 & 7569 & 146924 \\
\hline $\mathbf{5 3}$ & 51266 & 23326 & 28771 & 148826 & 1390 & 84611 & 13844 & 0 & 66203 & 0 & 418238 \\
\hline $\mathbf{5 6}$ & 2469 & 21612 & 501 & 91355 & 42770 & 50531 & 105846 & 3929 & 0 & 652 & 319666 \\
\hline $\mathbf{6 1}$ & 1507 & 4452 & 0 & 146230 & 6104 & 6530 & 23923 & 10977 & 80180 & 0 & 279902 \\
\hline $\mathbf{\Sigma}$ & 93847 & 168022 & 132983 & 436000 & 655015 & 412970 & 391312 & 253213 & 419532 & 121088 & $\mathbf{3 . 0 8 3 . 9 8 2}$ \\
\hline
\end{tabular}

Os valores contidos na Tabela 5.13 mostram que a soma de todas as diferenças absolutas para esta situação apresentou um valor de 3.083.982, sendo que a maior diferença ocorreu no par 1-25, em que 696 viagens foram observadas e 71 viagens foram estimadas.

Na Figura 5.3 é possível visualizar a evolução da somatória total das diferenças quadráticas para cada uma das situações estudadas.

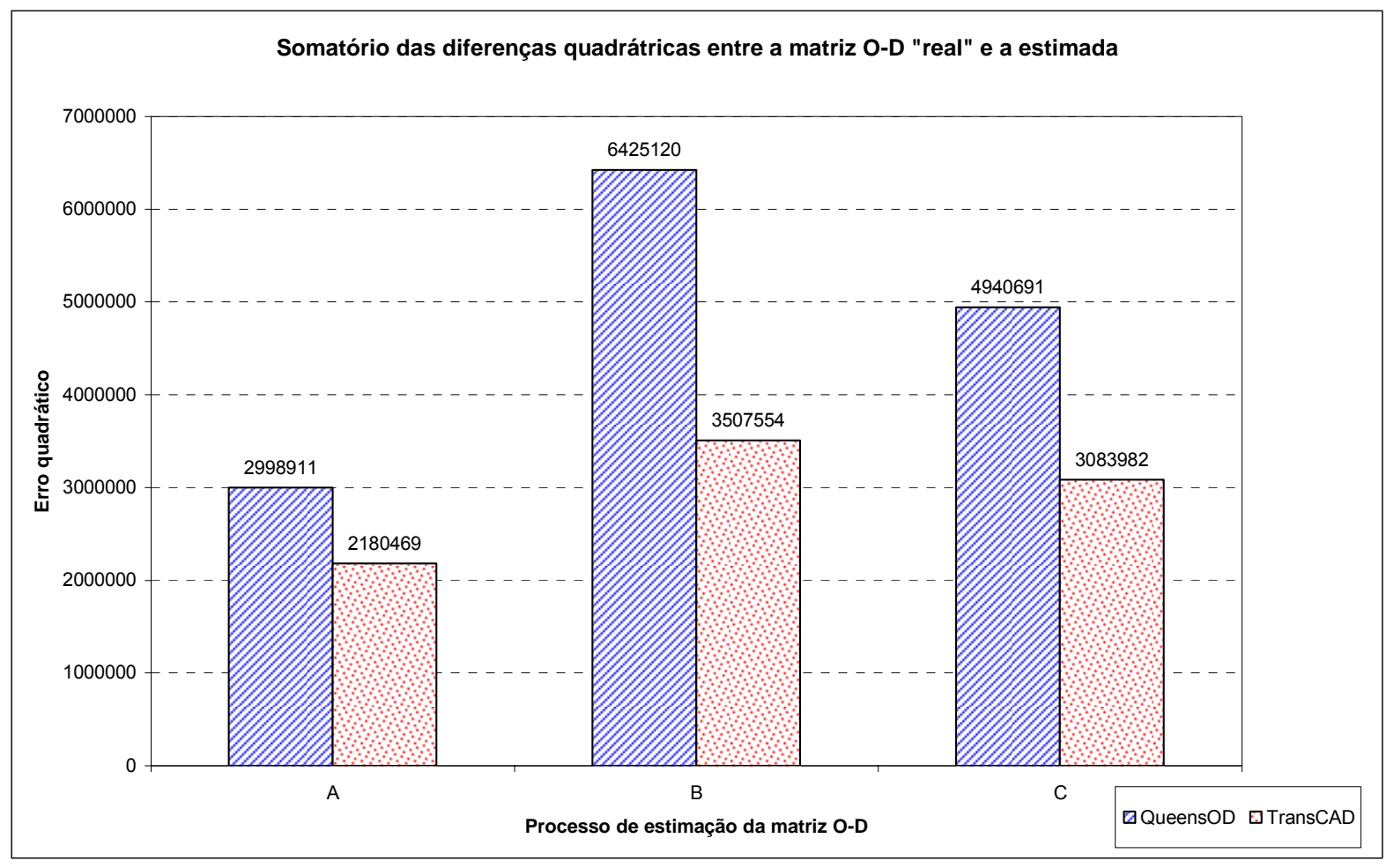

Figura 5. 3: Somatório das diferenças quadráticas entre a matriz O-D "real" e a estimada em função dos casos analisados e dos programas utilizados 
Note que os valores considerando a somatória das diferenças quadráticas nas três situações foram elevados e que, novamente, o Caso A apresentou os menores valores dentre os três.

- Comparativo dos resultados obtidos utilizando o QUEENSOD:

O valor total das diferenças quadráticas foi 2.998 .911 ao considerar o carregamento incremental dos fluxos, este valor foi 6.425 .120 ao considerar o Caso B e de 4.940.691 ao considerar o Caso C.

O processo de carregamento incremental fez com que a somatória das diferenças quadráticas fosse $53 \%$ menor do que a obtida para o Caso B e $39 \%$ menor do que a obtida no Caso C.

- Comparativo dos resultados obtidos utilizando o TransCAD:

A somatória do erro quadrático para o Caso A foi 2.180 .469 , para o Caso B foi 3.507.554 e para o Caso C foi 3.083.982, o que implica uma redução de $38 \%$ ao considerar o Caso A em relação ao B e uma redução de $29 \%$ do erro ao considerar o Caso A em relação ao Caso C.

Porém não é possível tecer uma análise sobre o desempenho dos métodos levando em consideração apenas a somatória das diferenças absolutas ou quadráticas. Para que uma análise mais detalhada possa ser realizada, sobre os resultados estimados por cada um dos métodos, fez-se a opção de distribuir os erros relativos, entre as viagens "reais" e estimadas, em freqüências, assim como foi feito com os erros relativos considerando o método incremental. O próximo subitem pretende apresentar estes comparativos e suas respectivas análises. 


\subsection{3 - Verificação da distribuição dos valores absolutos dos erros relativos entre as viagens "reais" $\mathrm{e}$ as estimadas}

Os erros relativos entre as viagens "reais" e as estimadas foram calculados e distribuídos em faixas de erros relativos, conforme mencionado no item 5.2. Estas análises serão realizadas em duas partes, uma considerando o QUEENSOD e outra o TransCAD.

- Análise dos resultados considerando os valores estimados pelo QUEENSOD:

Os valores da distribuição de freqüências absolutas considerando o erro relativo entre as viagens "reais" e estimadas, utilizando o QOD, encontram-se apresentados na Figura 5.4. Na Tabela 5.14 pode-se observar um melhor detalhamento desta distribuição em cada um dos três casos estudados (A, B e C).

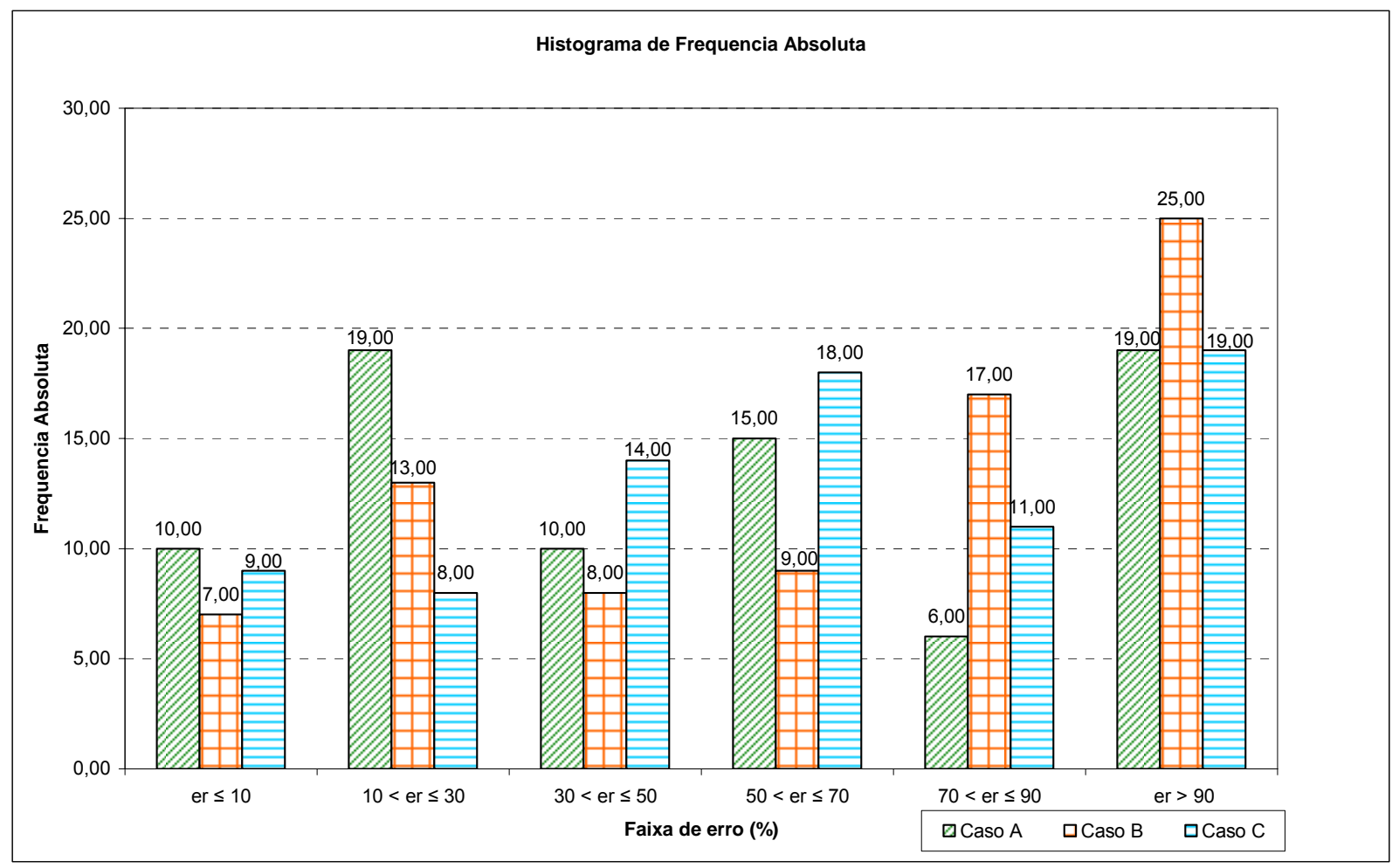

Figura 5. 4: Distribuição das freqüências absolutas em função do erro relativo. Viagens estimadas pelo QUEENSOD 
Tabela 5. 14: Distribuição dos erros relativos entre a matriz "real" e a estimada, obtida com a utilização do QUEENSOD

\begin{tabular}{|c|c|c|c|c|c|c|c|c|c|}
\hline Sittuação & Programa & Intervalo do Erro $(\%)$ & $\theta_{\gamma} \leq 10$ & $10<0, \leq 30$ & $30<\theta_{0} \leq 50$ & $50<0, \leq 70$ & $70<\theta_{1} \leq 90$ & $0,>90$ & Total de O-D \\
\hline \multirow{3}{*}{ Caso A } & \multirow{3}{*}{ Oueens(0D } & Frequencia Mbsoluta & 10,00 & 19,00 & 10,00 & 15,000 & 6,00 & 19,00 & \multirow{3}{*}{79,00} \\
\hline & & Frequencia Relatria & $12,66 \%$ & $24,05 \%$ & $12,60 \%$ & $18,99 \%$ & $7,59 \%$ & $24,05 \%$ & \\
\hline & & Frequencia Acumilada & 0,1266 & 0,3671 & 0,4937 & 0,6035 & 0,7595 & 1,00000 & \\
\hline \multirow{3}{*}{ Caso B } & \multirow{3}{*}{ Oueens(0D } & Erequencia Mbsoluta & 7,00 & 13,00 & 8,000 & 9,00 & 17,00 & 25,00 & \multirow{3}{*}{79000} \\
\hline & & Frequencia Relatira & $8,86 \%$ & $16,46 \%$ & $10,13 \%$ & $11,3 \% \%$ & $21,52 \%$ & $31,60 \%$ & \\
\hline & & Frequencia Acumada & 0,0886 & 0,2532 & 0,3544 & 0,4684 & 0,6835 & 1,00000 & \\
\hline \multirow{3}{*}{ Caso C } & \multirow{3}{*}{ Oueens (0D } & Erequencicia Abouluta & 9,000 & 8,00 & 14,00 & 18,000 & 11,00 & 19,00 & \multirow{3}{*}{79,00} \\
\hline & & Frequencia Relatria & $11,30 \%$ & $10,13 \%$ & $17,7 \%$ & $22,70 \%$ & $139 \%$ & $24,05 \%$ & \\
\hline & & Frequencia Acumulada & 0,1139 & 0,2152 & 0,3924 & 0,003 & 0,7595 & 1,0000 & \\
\hline
\end{tabular}

A análise da distribuição dos erros relativos do Caso A foi apresentada no subitem 5.1.3.

Ao considerar o método iterativo descrito como Caso B, os valores apresentados na Tabela 5.14 mostram que $9 \%$ dos erros possuem valor menor ou igual a $10 \%$, o que equivale a 7 pares O-D dos 79 que apresentaram viagens "observadas" e estimadas.

Ainda considerando o Caso B, observa-se que 35\% dos erros estão acumulados na faixa $0 \%<e_{r}^{Q_{i j}} \leq 50 \%$, e; $65 \%$ dos erros apresentaram valores superiores a $50 \%$. Em 25 pares O-D os erros relativos apresentaram valores acima de 90\%, destes, 18 possuem erros cujos valores são superiores a $100 \%$, sendo que em 4 pares O-D os valores foram superiores a $500 \%$ $\left[4-53\left(Q_{i j}^{o b s}=13\right.\right.$ e $\left.Q_{i j}^{\text {est }}=169\right) ; 8-10\left(Q_{i j}^{o b s}=146\right.$ e $\left.Q_{i j}^{e s t}=1410\right) ; 56-8\left(Q_{i j}^{o b s}=26\right.$ e $Q_{i j}^{e s t}=$ 270), e; 61-25 $\left(Q_{i j}^{o b s}=57\right.$ e $\left.\left.Q_{i j}^{e s t}=390\right)\right]$. Para o Caso A, 4 pares também apresentaram erros relativos com valor maior do que 500\%, sendo que os pares 4-53 e 61-25 apresentaram erros elevados tanto no Caso A quanto no Caso B.

Considerando o Caso B, o maior erro relativo ocorreu no par O-D 4-53 que teve magnitude de $1.202 \%$, causado por uma superestimação de viagens. Duas possibilidades 
podem ter levado a obtenção desses valores elevados de erros: (i) o processo iterativo não conseguiu atingir o ponto de máximo global da função; e, (ii) é possível que devido alguma indeterminação no sistema de equações fez com que o equilíbrio não tenha sido dado de maneira correta.

Observando a Tabela 5.14, o Caso C possui 9 pares O-D com erros cujo valor é menor ou igual a $10 \%$. Pode-se constatar que $39 \%$ dos erros possuem valor na faixa de $0 \%<e_{r}^{Q_{i j}} \leq$ $50 \%$ e $61 \%$ dos erros possuem valor superior a 50\%. Destes, em 19 pares O-D os erros foram superiores a $90 \%$.

Em um par O-D, 25-56, o valor do erro relativo foi $100 \%$, pois nenhuma viagem foi estimada, apesar de terem sido observadas 201 viagens. Possivelmente isto ocorreu para satisfazer as condições de equilíbrio, conforme afirmam Yang (1995) e Nielsen (1998).

O maior valor de erro relativo, para o Caso C, refere-se ao par O-D 8-10, que teve 146 viagens observadas e 1217 estimadas, resultando em um erro relativo de $731 \%$, devido a uma superestimação de viagens. O erro máximo apresentado no Caso $\mathrm{C}$ foi menor do que os dos $\operatorname{casos} \mathrm{A}$ e B.

Aparentemente os casos A e C apresentam desempenhos similares, sendo que o Caso A concentra $68 \%$ dos erros com valor de no máximo $70 \%$ e possui $13 \%$ dos erros com valor abaixo de $10 \%$, porém, em contrapartida em 4 pares O-D os erros foram superiores a $500 \%$. Ainda assim, o desempenho do Caso A em relação aos demais possui uma ligeira vantagem, principalmente por não depender de iterações para alcançar o equilíbrio da rede de tráfego. Além disso, o Caso C procurou refletir uma situação idealizada e favorável à aplicação do método iterativo, em que a matriz semente equivale a $70 \%$ da matriz real e os fluxos de tráfego se encontravam equilibrados. 
- Análise dos resultados considerando os valores estimados pelo TransCAD:

Os valores da distribuição de freqüências absolutas considerando o erro relativo entre as viagens "reais" e estimadas, utilizando o TransCAD, encontram-se apresentados na Figura 5.5, já na Tabela 5.15 é possível visualizar um melhor detalhamento destas frequencias.

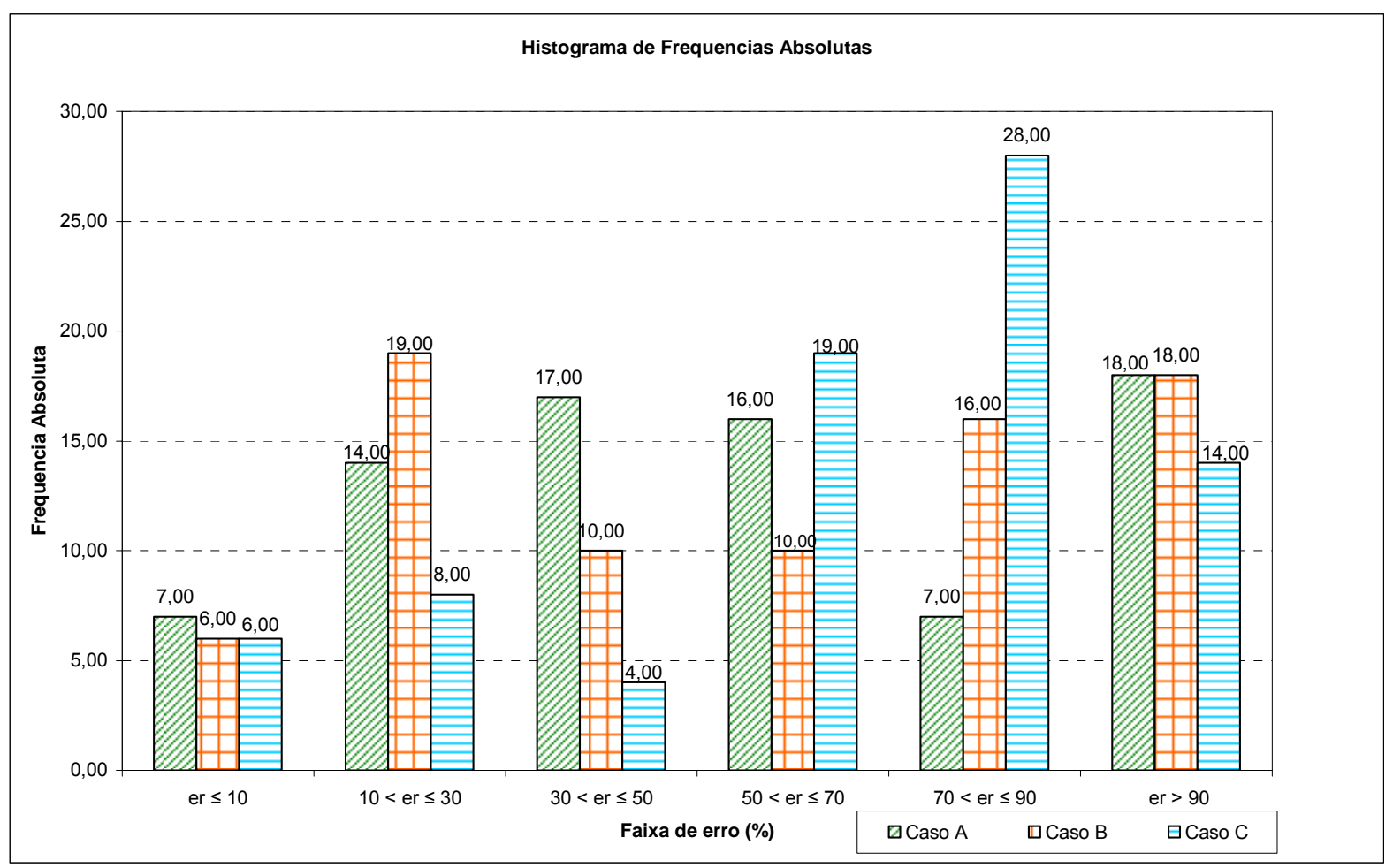

Figura 5. 5: Distribuição das freqüências absolutas em função do erro relativo. Viagens estimadas pelo TransCAD

Tabela 5. 15: Distribuição dos erros relativos entre matriz "real" e estimada, obtida com a utilização do TransCAD

\begin{tabular}{|c|c|c|c|c|c|c|c|c|c|}
\hline Situaçãa & Programa & Intervalo do Erro $(\%)$ & $0, \leq 10$ & $10<\theta_{\gamma} \leq 30$ & $30<\theta_{\gamma} \leq 50$ & $50<\theta_{y} \leq 70$ & $70<\theta_{r} \leq 90$ & $e_{\gamma}>90$ & Total de O-D \\
\hline \multirow{3}{*}{ Caso $A$} & \multirow{3}{*}{ Trans $C A D$} & Frequencia Abroluta & 7,000 & 14,000 & 17,00 & 16,00 & 7,00 & 18,00 & \multirow{3}{*}{79,00} \\
\hline & & Frequencia Relatira & $8,86 \%$ & $17,7 \% \%$ & $21,52 \%$ & $20,25 \%$ & $8,86 \%$ & $22,70 \%$ & \\
\hline & & Frequencia Acumulada & 0,0886 & 0,2658 & 0,4810 & 0,6855 & 0,7722 & 1,0000 & \\
\hline \multirow{3}{*}{ Caso B } & \multirow{3}{*}{ Trans $C A D$} & Frequencia sbosoluta & 6,00 & 19,00 & 10,00 & 10,00 & 16,000 & 18,00 & \multirow{3}{*}{79,00} \\
\hline & & Freguencia Relatio & $7,9 \% \%$ & $24,05 \%$ & $12,66 \%$ & $12,66 \%$ & $20,25 \%$ & $22,78 \%$ & \\
\hline & & Frequeficia Acumulada & 0,0759 & 0,3165 & 0,4430 & 0,5666 & 0,7722 & 1,0000 & \\
\hline \multirow{3}{*}{ Caso C } & \multirow{3}{*}{ TransCAD } & Frequencia Absoluta & 6,00 & 8,000 & 4,00 & 19,00 & 28,00 & 14,00 & \multirow{3}{*}{79,00} \\
\hline & & Frequencia Relationa & $7,59 \%$ & $10,13 \%$ & $5,06 \%$ & $24,05 \%$ & $35,44 \%$ & $17,72 \%$ & \\
\hline & & Frequencia Acumulada & 0,0759 & 0,1772 & 0,278 & 0,4684 & 0,8228 & 1,0000 & \\
\hline
\end{tabular}


O Caso B, apresenta 44\% dos erros relativos com valor menor ou igual a 50\%. Em 6 pares O-D o valor do erro relativo não ultrapassou $10 \%$.

Em 18 pares O-D, os erros relativos apresentaram valor superior a 90\%. O par O-D 56-25 apresentou um erro de praticamente $100 \%$ ao estimar 0,56 viagens, enquanto o observado havia sido 207. Em 5 pares O-D os erros apresentaram valor superior a 500\%, são eles: $1-53\left(Q_{i j}^{o b s}=45\right.$ e $\left.Q_{i j}^{e s t}=304\right) ; 4-53\left(Q_{i j}^{o b s}=13\right.$ e $\left.Q_{i j}^{e s t}=278\right) ; 33-10\left(Q_{i j}^{o b s}=74\right.$ e $Q_{i j}^{e s t}=$ 492); 53-33 ( $Q_{i j}^{o b s}=57$ e $\left.Q_{i j}^{e s t}=740\right)$, e; 61-25 $\left(Q_{i j}^{o b s}=57\right.$ e $\left.Q_{i j}^{e s t}=354\right)$.

O par O-D 4-53 foi, novamente, o que apresentou o maior erro relativo, $2.036 \%$, devido a uma superestimação de viagens. Acredita-se que as razões de tal erro foram as mesmas anteriormente apresentadas, ao analisar os resultados do QOD.

O Caso C, que possuía as melhores condições para aplicação do método iterativo, apresenta $8 \%$ dos erros relativos com valor menor ou igual a $10 \%$.

Apenas 23\% dos erros, ou seja, 18 pares O-D, apresentam erros de no máximo 50\%. Em contrapartida, ao contrário dos demais casos, apenas 18\% dos erros possuem valor acima de $90 \%$. O par 56-25 apresentou um erro de $100 \%$ ao estimar 0,19 viagens, quando eram esperadas 207.

O maior erro relativo no Caso C possui valor de 513\%, por sinal é o único acima de $500 \%$, e corresponde ao par 53-33. Neste par foram observadas 57 viagens e foram estimadas 348 viagens.

Apesar de não ter apresentado um desempenho satisfatório, o método proposto foi capaz de gerar erros menores que os apresentados pelos métodos iterativos, pois sempre 
estimou demandas entre os pares que as apresentou e não precisou realizar processos iterativos.

O subitem a seguir irá apresentar uma verificação do erro relativo em função da distância, em tempo, para cada um dos três casos estudados.

\subsection{4 - Verificação da distribuição dos erros relativos em função da distância}

A proposta deste subitem é avaliar qual a relação entre os erros relativos e a distância, em termos de tempo, entre os pares O-D. Acredita-se que os maiores valores de erro relativo devem estar relacionados com as maiores distâncias.

Foram considerados nestas análises os 79 pares O-D que apresentaram viagens observadas e também estimadas. Em relação ao tempo, este seria representado pelo tempo de percurso considerando o caminho de custo mínimo entre o par O-D.

Nas Tabelas 5.16 e 5.17 é possível verificar os erros relativos para cada um dos três casos estudados, agrupados em ordem decrescente de tempo de viagem. Na primeira tabela os valores são referentes ao QUEENSOD, já na segunda os valores são os do TransCAD. 


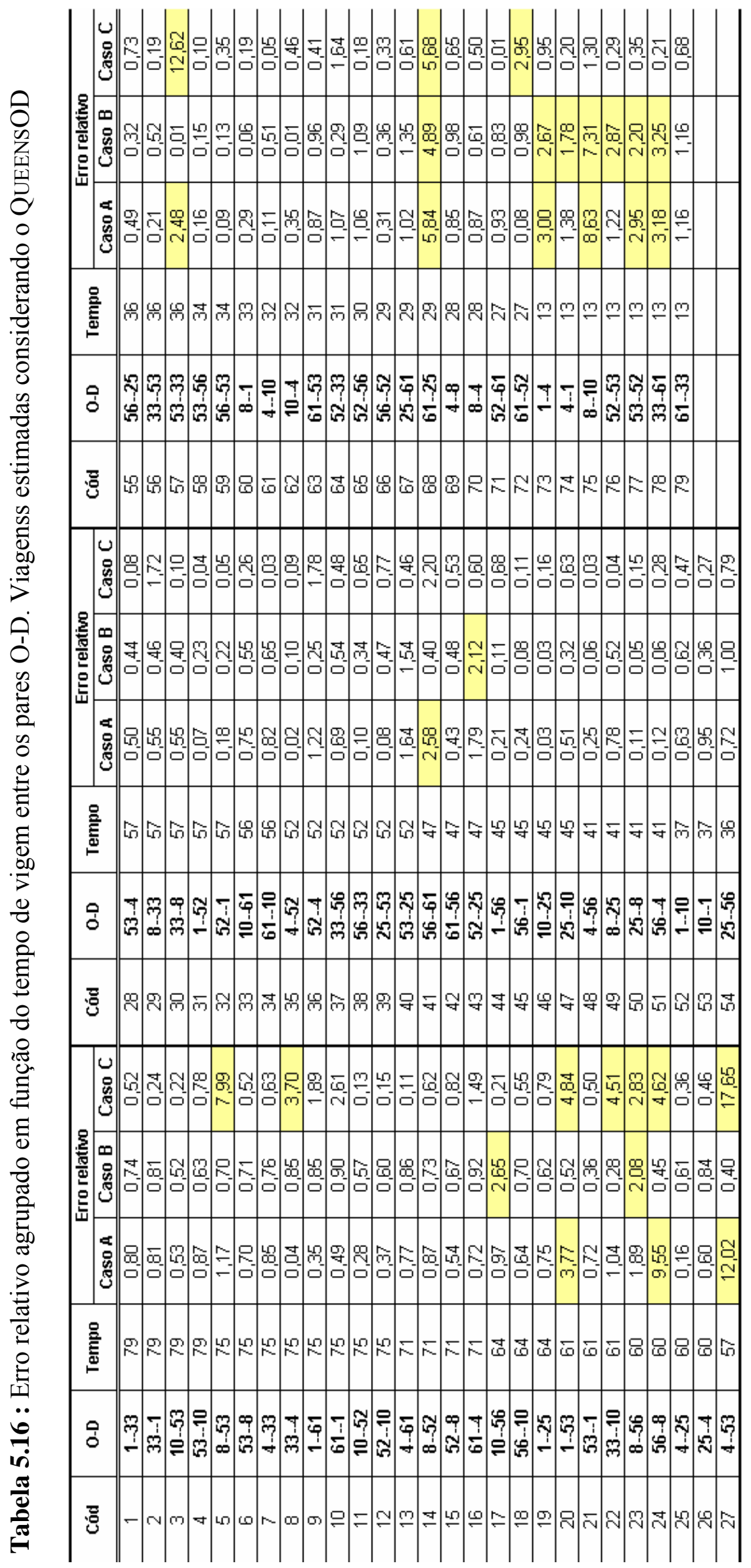




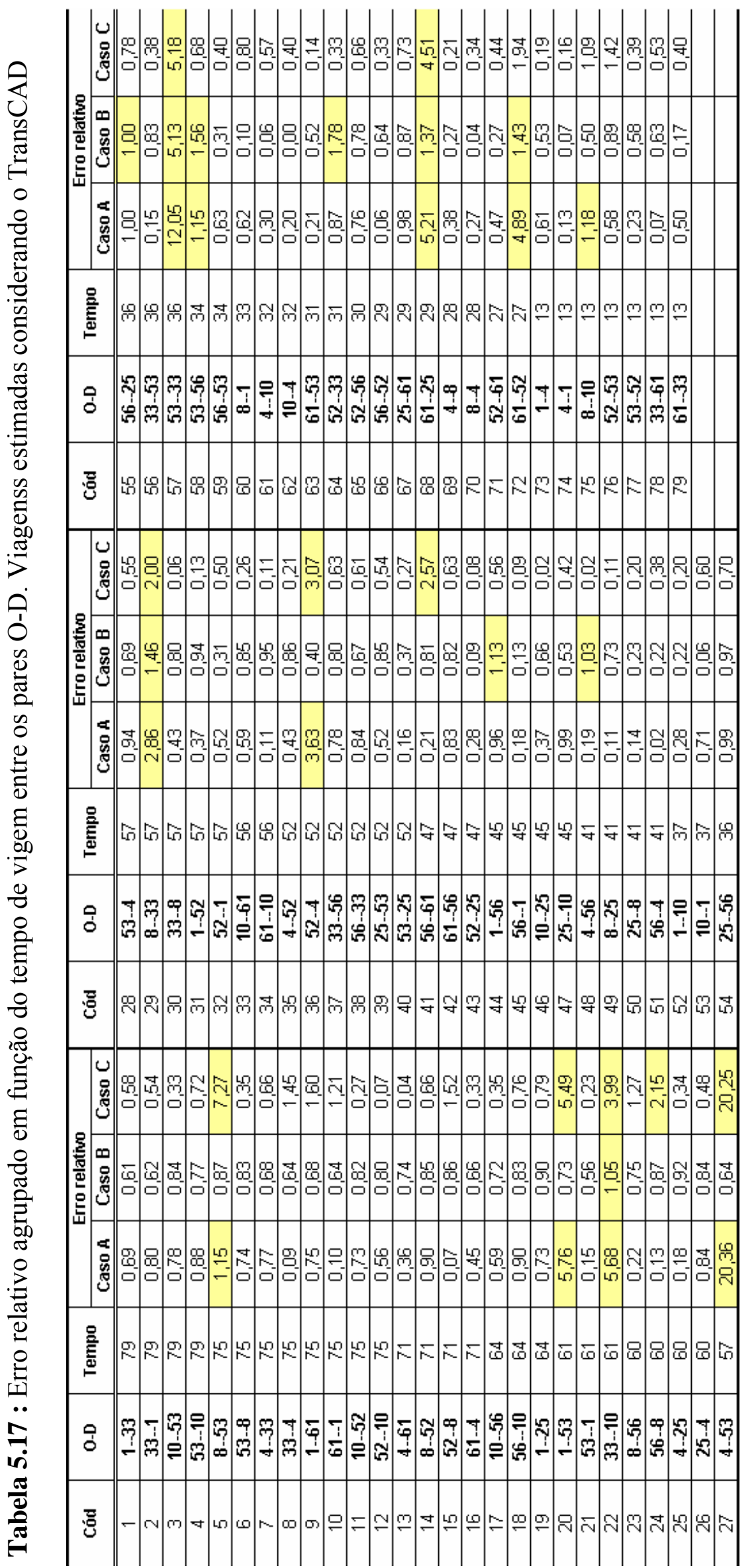


Pode-se observar nas tabelas anteriormente apresentadas que existem algumas células em destaque, no total são 10 células por caso, que representam os maiores valores de erros relativos.

Ordenando estes 10 valores e agrupando-os em função dos intervalos de tempo, pôdese construir a Figura 5.6 que informa a quantidade de erros em cada intervalo de tempo, considerando os valores estimados utilizando o QOD.

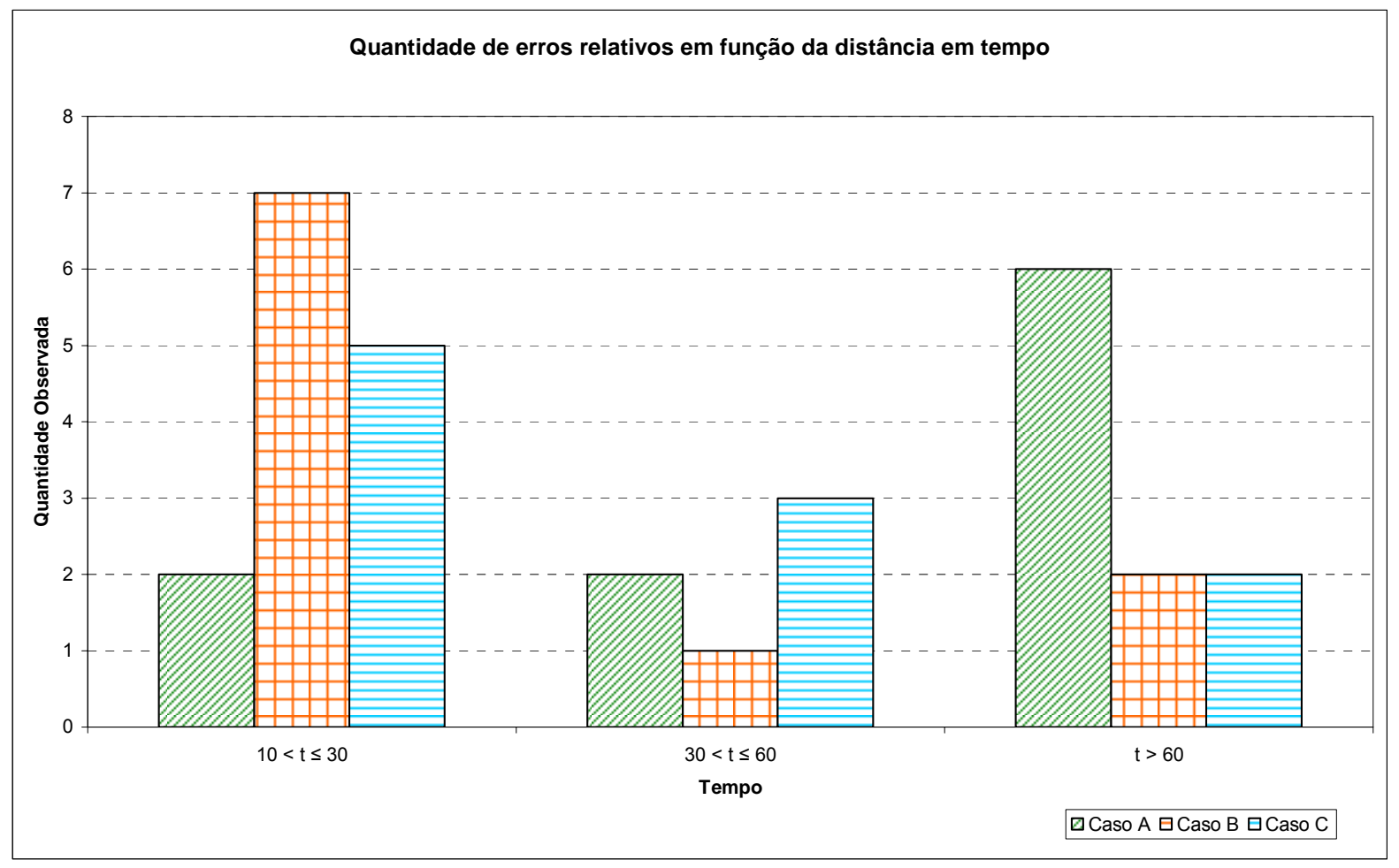

Figura 5. 6: Distribuição dos 10 maiores valores de erros relativos em função da distância (considerando o QUEENSOD)

Dos valores apresentados na Figura 5.6 é possível visualizar que dos 10 maiores erros relativos, seis encontram-se no intervalo de tempo de $t>60$ ao considerar o Caso A, ou seja, assim como era esperado os maiores valores de erros relativos estão vinculados as maiores distâncias, devido as dificuldades existentes na definição dos caminhos. Em termos de valor numérico os dois maiores valores de erros relativos $(17,65$ e 12,62) estão relacionados aos tempos 57 ut e 36 ut. 
Ao analisar o Caso B o desempenho apresentado foi pior já que sete dos 10 maiores erros relativos estão compreendidos no intervalo de $10<t \leq 30$, o maior erro $(7,31)$ ocorreu entre um par O-D cujo tempo mínimo de percurso é 13 ut. O Caso C apresentou uma quantidade alta de erros na faixa entre $10<t \leq 30$, porém o maior erro $(12,02)$ está relacionado a um caminho cujo tempo de percurso é de 57 ut.

Fazendo o mesmo procedimento, só que considerando os resultados do TransCAD, foi construída o histograma apresentado na Figura 5.7.

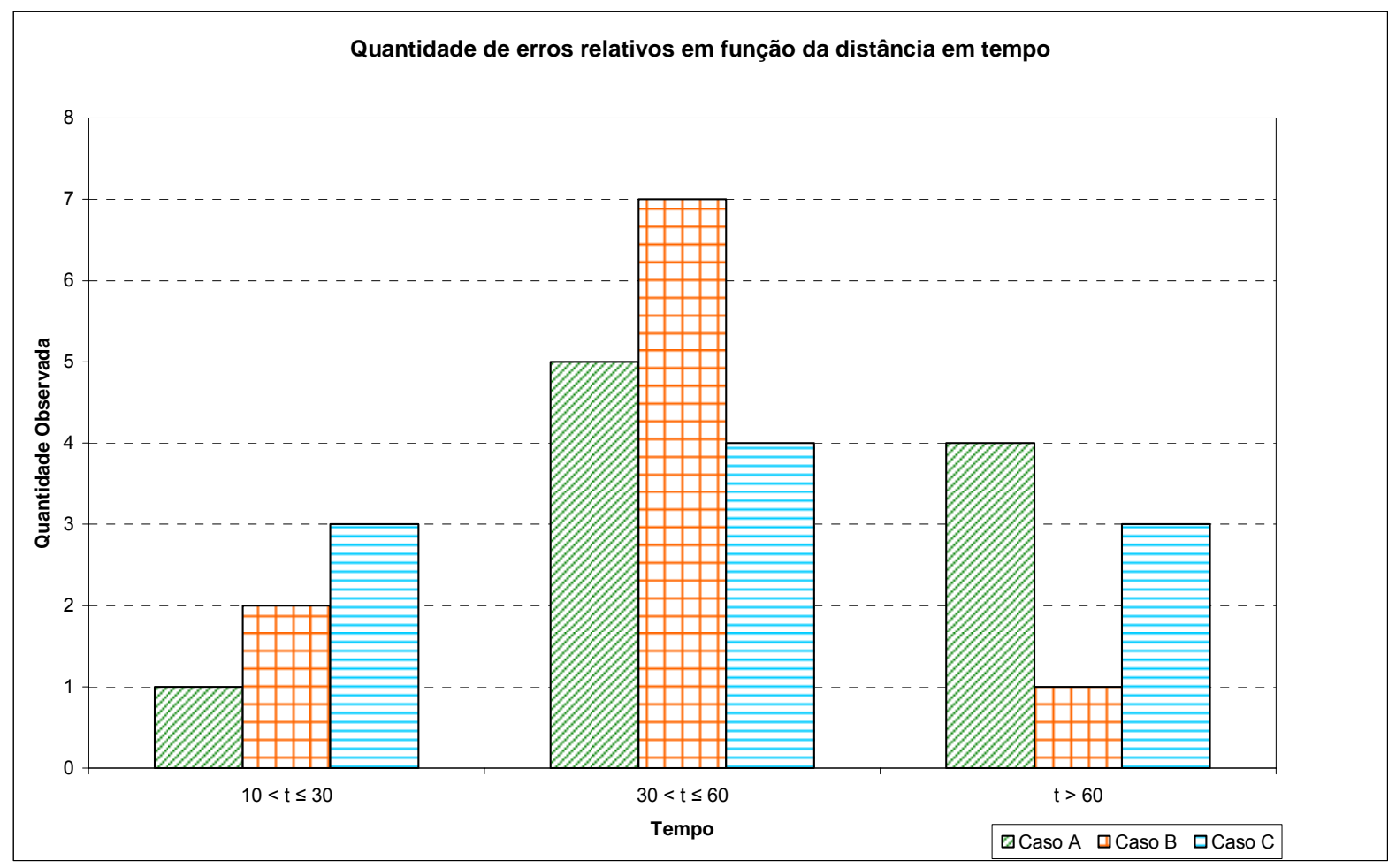

Figura 5. 7: Distribuição dos 10 maiores valores de erros relativos em função da distância (considerando o TransCAD)

A análise da Figura 5.7, permite observar que a maior quantidade de erros encontra-se acumulada em uma faixa intermediária de tempo ao considerar o TransCAD. O Caso A, dentre os três, apresentou uma maior quantidade de erros acumulados na faixa de $t>60$, sendo que o maior valor $(20,25)$ está relacionado ao tempo 57 ut. 
O que pôde ser verificado é que, de uma maneira geral, os valores mais elevados de erros estão relacionados aos pares O-D que apresentam tempo de percurso, de certa forma, elevado. Isto era esperado já que, via de regra, estes caminhos são compartilhados por outras viagens, aumento assim a complexidade e a indeterminação no sistema de equações.

\section{3 - CONSIDERAÇÕES FINAIS SOBRE AS ANÁLISES DOS RESULTADOS}

Os resultados obtidos indicaram que os dois métodos, incremental e iterativo, não foram capazes de estimar matrizes O-D da forma como era esperado, já que os dados de entrada eram favoráveis (fluxos observados refletiam as condições de equilíbrio e continuidade, e no caso dos métodos iterativos as matrizes favoreciam a aplicação do método) a um bom desempenho dos métodos. De fato, os valores totais de viagens estimadas foram próximos aos "reais".

Porém, a distribuição das viagens nem sempre foi dada de maneira correta, principalmente nos pares O-D cujas viagens passam pelos trechos da rede em que há indeterminação, isto é, impossibilidade de estabelecer conexão entre os fluxos nos arcos e os fluxos entre os pares O-D.

Procedendo a uma análise em função dos erros, pôde-se verificar que os dois métodos, incremental e iterativo, apresentaram valores elevados em termos de somatória dos erros absolutos e quadráticos.

O erro absoluto obtido ao considerar o Caso A, utilizando o QOD, foi aproximadamente $57 \%$ do total de viagens geradas, sendo que, cerca de metade dos erros foi devido à subestimação e a outra metade devido à superestimação.

Ao considerar o Caso B a somatória das diferenças absolutas apresentou valor de 15.177, equivale a aproximadamente a $76 \%$ do total de viagens geradas. Quando foi utilizada 
uma matriz semente equivalente a $70 \%$ da matriz "real", a somatória dos erros absolutos foi 13.400 , o que equivale a $67 \%$ do total de viagens reais.

Pode-se perceber que o erro absoluto ao considerar o método incremental apresentou um resultado mais satisfatório do que os obtidos considerando o método iterativo do QOD.

Este desempenho também foi observado ao estimar a matriz O-D utilizando o TransCAD. A somatória de erro absoluto considerando o Caso A apresentou um valor equivalente a $52 \%$ do total de viagens geradas, já o Caso B apresentou um valor equivalente a $64 \%$ do total de viagens geradas e o Caso $\mathrm{C}$ apresentou um valor equivalente a $61 \%$ do total de viagens geradas. Assim, o erro obtido ao considerar o Caso A foi menor do que o cometido ao utilizar o método iterativo do TransCAD.

Pode-se perceber que os erros absolutos causados pelo método incremental foram menores que os obtidos ao considerar os métodos iterativos. Porém estas análises não são suficientes para a verificação do desempenho do método e devido a isso fez-se a opção de distribuir os erro relativos em faixas de acordo com a freqüência de ocorrência.

Os Casos A e B tiveram um desempenho parecido ao comparar a quantidade de erros com valores acima de $90 \%$. Os erros apresentados ao utilizar o Caso C foram menores do que ao utilizar o Caso B; no entanto, seu desempenho foi parecido, porém pior, com o obtido ao utilizar o Caso A, que não dependeu de nenhum processo iterativo complexo para estimar as demandas.

O Caso $\mathrm{C}$ representa uma situação favorável à aplicação dos métodos iterativos conforme sugerem Yang et al (1992) e Nielsen (1998). Neste, os fluxos observados refletiram as condições de equilíbrio e continuidade e a matriz semente foi equivalente a $70 \%$ da matriz real. 
Além disso, nos dois casos do método iterativo, para garantir o equilíbrio da rede, estimaram zero viagens entre alguns pares O-D que tinham viagens observadas. Este fato já havia sido verificado por pesquisadores como Yang (1995) e Nielsen (1998). Este tipo de problema não ocorreu ao utilizar o método incremental.

Foi possível observar que os maiores valores de erros estão relacionados aos pares OD mais distantes. Uma possível explicação é que à medida que a distância entre um par O-D aumenta, as dificuldades na obtenção da solução também tendem a aumentar, pois geralmente o caminho é compartilhado por outras viagens, implicando em possíveis erros.

Pode-se perceber que a proposta de carregamento incremental, mesmo apresentando valores elevados de erros, foi capaz de apresentar resultados mais satisfatórios do que os apresentados pelos métodos iterativos. 


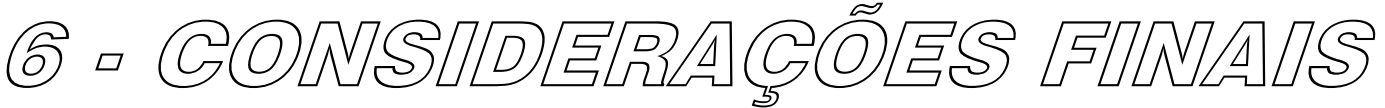

O objetivo principal deste trabalho foi propor e verificar um método para a estimação de matriz O-D a partir do carregamento incremental dos fluxos observados nos arcos. Uma das principais vantagens do referido método é que ele não requer utilização de um processo iterativo complexo (atualmente em uso), para se atingir o equilíbrio do usuário na rede de tráfego ao estimar a matriz O-D.

O procedimento em uso foi desenvolvido de forma a solucionar os problemas apresentados em redes viárias congestionadas. É baseado no processo iterativo de forma a atingir o equilíbrio do usuário na rede de tráfego. Esse processo, além de complexo, nem sempre garante um bom resultado, conforme foi apresentado no Capítulo 2 deste trabalho.

O método ora proposto consiste em dividir os fluxos em incrementos e, para cada um dos incrementos, estimar uma matriz O-D parcial ou sub-matriz. A soma de todas as submatrizes irá resultar na matriz O-D final. O procedimento proposto parte do pressuposto de que as viagens sempre irão utilizar aos caminhos de custo mínimo entre os pares O-D. Com isso, as rotas entre os pares O-D ficam definidas de uma maneira mais fácil, bastando uma simples alocação do tipo tudo-ou-nada. Possíveis erros provenientes de um incremento inicial relativamente grande serão corrigidos ao longo dos carregamentos.

De forma a verificar desempenho do método proposto foi desenvolvido um experimento onde foi alocada uma matriz O-D a uma rede de tráfego hipotética, considerando 
a técnica de equilíbrio do usuário, de forma a obter os fluxos nos arcos. A partir de tais fluxos, foi estimada a matriz O-D considerando o carregamento incremental. A matriz O-D foi estimada utilizando os programas QUEENSOD e TransCAD de uma forma adaptada.

\section{1 - CONCLUSÕES}

A principal conclusão do presente trabalho é que o método proposto foi capaz de estimar uma matriz O-D sintética sem a necessidade de iterações e também sem fazer qualquer tipo de simplificação quanto à escolha da rota, conforme era feito nos primeiros métodos para estimação de matrizes sintéticas, atingindo assim o objetivo principal deste trabalho.

O método apresentado neste trabalho tem como vantagem o fato de reduzir o esforço computacional para obtenção da resposta, o inconveniente até então está na formatação dos arquivos de entrada, caso opte por utilizar o QUEENSOD ou o TransCAD como ferramenta de estimação da demanda.

Neste trabalho supôs-se que a relação que rege tanto a alocação de viagens à rede, como a obtenção dos caminhos de custo mínimo para a estimação da matriz O-D sintética é dada pela equação proposta pelo BPR (BPR, 1964). Portanto, indiretamente está se supondo que não há diferença entre a forma como o tempo de percurso aumenta quando o fluxo no arco cresce e a sua representação matemática. No entanto, na prática não há nenhuma garantia de que a equação do BPR representa satisfatoriamente essa relação. Porém, quanto melhor esta relação estiver representada pelo modelo mais precisa será a matriz O-D resultante.

As análises realizadas a fim de verificar o desempenho do método proposto indicaram que os resultados estimados não foram satisfatórios ao serem comparados com os valores “reais” das viagens, talvez um reflexo da afirmação feita no parágrafo anterior. 
Um desempenho satisfatório só foi verificado em termos de quantidade total de viagens. A distribuição das viagens nem sempre foi dada de maneira correta, principalmente nos pares O-D cujas viagens passam pelos trechos da rede em que há indeterminação, isto é, impossibilidade de estabelecer conexão entre os fluxos nos arcos e os fluxos entre os pares OD.

Em relação à quantidade total de viagens estimadas, o método conseguiu aproximar dos valores “reais”. Em média, houve um erro de 3\% no total "real”.

Porém, ao analisar as viagens em função dos pares O-D, pode-se perceber que houve erros altos, reforçando a idéia de que a distribuição das viagens não se deu de maneira correta. A soma dos erros absolutos equivale em média a 55\% do total de viagens "reais” da rede, o que pode ser considerado elevado. Além disso, mais da metade dos erros relativos entre as viagens “reais" e as estimadas apresentaram valor de erro superior a $50 \%$.

Pode-se justificar os altos valores de erros relativos através de dois pontos principais: (i) pequenos números de viagens "reais" tendem a aumentar os valores de erros relativos; e (ii) a indeterminação da distribuição das viagens em partes da rede.

Apesar de os resultados obtidos não terem sido suficientemente satisfatórios, pode-se afirmar que o objetivo principal deste trabalho foi atingido.

Com o intuito de verificar a sua utilidade como um método alternativo, os mesmos dados foram processados através de dois métodos iterativos. Os métodos iterativos utilizados foram os dos programas QuEEnsOD e TransCAD. Além disso, duas situações distintas em relação à matriz semente, verificando assim a interferência que esta pode ter sobre os resultados, foram avaliadas: (i) matriz semente binária; e (ii) matriz semente equivalente a $70 \%$ da matriz real. 
Posteriormente foi feita uma verificação comparativa dos desempenhos dos métodos iterativo e incremental, conforme foi previsto nos objetivos secundários deste trabalho.

No método iterativo a quantidade total de viagens estimadas também se aproximou da “real”. Todavia, a distribuição das viagens contém erros relativamente elevados. Neste caso, além da indeterminação que ocorre em partes da rede, as iterações para alcançar o equilíbrio do usuário contribuíram para este erro na distribuição, pois às vezes viagens deixam de ser estimadas.

Os resultados mostraram que em termos de diferenças absolutas ao utilizar uma matriz semente binária os erros em média equivalem a 70\% do total de viagens “reais”, ou seja, maior que ao considerar o método incremental. Este resultado era, de certa forma, esperado, pois autores como Yang (1995) têm afirmado que o método iterativo nem sempre fornece bons resultados quando se utiliza uma matriz semente deste tipo (YANG, 1995).

Ao utilizar uma matriz semente equivalente a 70\% da matriz "real” a soma dos erros, em média, equivale a 66\% das viagens “reais”. Apesar de continuarem elevados, inclusive superiores aos valores de erro obtidos com o método proposto, a consideração de uma matriz semente mais próxima a matriz "real”, fez com que os resultados fossem um pouco melhores.

Em relação à utilização de uma matriz semente equivalente a 70\% da “real”, pode-se dizer que ela representa uma situação bastante favorável à aplicação do método atualmente em uso, mas é, de certa forma, improvável que uma matriz semente deste tipo esteja disponível. Pesquisadores como Yang et al (1992) e Nielsen (1998), têm afirmado que o uso de uma matriz semente semelhante à real melhora o desempenho do método iterativo, pois auxilia na redução da indeterminação do sistema de equações, o que de fato isto ocorreu. Mas mesmo com todas estas vantagens, os resultados apresentados pelo método iterativo foram piores do que os do método proposto neste trabalho. 
Ao comparar os erros relativos obtidos entre as viagens "reais" e estimadas, pôde-se perceber que, de maneira geral, os três casos estudados apresentaram uma distribuição de erros similar. Os Casos A e B tiveram um desempenho parecido ao comparar a quantidade de erros com valores acima de 90\%. No entanto, a distribuição dos erros obtidos com o método incremental, no geral, foi mais próxima da distribuição dos erros obtidos com o método iterativo considerando uma matriz semente equivalente a 70\% da "real”.

Foi possível também verificar que o método iterativo, para garantir o equilíbrio da rede, estimou zero viagens entre alguns pares O-D em que viagens tinham sido “observadas”, corroborando a observação de outros pesquisadores como, por exemplo, Nielsen (1998), que já tinham constatado tais erros. Este tipo de erro não foi apresentado pelo método incremental.

As matrizes estimadas por ambos os métodos iterativos, apresentaram erros elevados em relação à matriz “real”, não refletindo as condições favoráveis (fluxos equilibrados e com continuidade, matriz semente binária preenchendo com zero os pares O-D em que não foi observada nenhuma viagem e matriz semente proporcional à matriz real) definidas no experimento proposto. É possível que as informações referentes a fluxo nos arcos e utilização de uma matriz semente não sejam suficientes para resolver as indeterminações do modelo sintético.

Verificou-se também que os maiores valores de erro, no caso do método incremental, estavam relacionados com os pares O-D que apresentam uma maior distância.. Uma possível explicação é que à medida que a distância entre um par O-D aumenta, pois, o caminho utilizado pode ser compartilhado por outras viagens, aumenta-se as dificuldades na obtenção da solução implicando em possíveis erros.

De um lado os resultados mostram que nem o método iterativo e nem o incremental fornecem resultados satisfatórios, indicando que é preciso prosseguir e aprofundar a pesquisa 
sobre matriz O-D sintética. De outro lado, os resultados indicam que o método incremental aqui proposto é uma alternativa interessante para a obtenção de matriz O-D sintética.

Por fim, cabe ressaltar que o estudo apresentado nesta dissertação aborda apenas um estudo de caso. Muito mais casos deverão ser analisados antes de generalizar qualquer conclusão.

\section{2 - RECOMENDAÇÕES PARA TRABALHOS FUTUROS}

Na tentativa de trazer melhorias ao método proposto, seria interessante que trabalhos futuros estudassem alguns pontos:

$\Rightarrow$ Um problema apresentado pelo modelo sintético é em relação as indeterminações. Assim, recomenda-se que seja estudada uma forma de reduzir a quantidade de indeterminações dos sistemas de equações.

$\Rightarrow$ Sugere-se que sejam analisadas as diferentes formas de reduzir a quantidade de incrementos a ser utilizado, sem com isso aumentar o valor do erro máximo. Com isto haverá uma redução significativa no tempo de processamento.

$\Rightarrow$ Considerando-se que quanto melhor representada pelo modelo estiver a relação entre tempo de percurso em um arco e a relação V/C mais precisa será a matriz O-D resultante, sugere-se que a relação tempo x V/C seja bem estudada.

$\Rightarrow$ Por fim, poderia ser verificado se viajantes se comportam conforme preconiza o paradigma da maximização da entropia. 
BELL, M. G. H. (1983) The estimation of an origin-destination matrix from traffic counts. Transportation Science, n. 1, p. 198-217.

BELL M. G. H. (1991) The estimation of origin-destination matrices by constrained generalized least squares. Transportation Research Part B, n. 25, p. 13-22.

BRILLOUIN, L. (1956) Science and Information Theory. Academic Press, New York.

BUREAU OF PUBLIC ROADS - BPR (1964) Traffic Assignment Manual, Washington, DC, USA

CALIPER (1996) Travel Demand Modeling with TransCAD 3.0. Caliper Corporation, Newton, USA

CAREY, M.; REVELLI, R. (1986) Constrained estimation of direct demand functions and trip matrices. Transportation Science, n. 3, p. 143-152.

CASCETTA, E. (1984) Estimation of Trip Matrices from Traffic Counts and Survey Data: a Generalized Least Squares Estimator. Transportation Research Part B, v. 16, n. 4-5, p. 289299.

DEMARCHI, S. H.; BERTONCINI, B. V. (2003a) Análise de Métodos para Determinação de Demandas Veiculares. In: IV ENCONTRO TECNOLÓGICO DE ENGENHARIA E ARQUITETURA DE MARINGÁ (ENTECA), 2. 2003, Maringá. Maringá, PR. Maringá, PR. Anais do IV ENTECA. Maringá, PR. Departamento de Engenharia Civil, UEM. p.461-472 
DEMARCHI, S. H.; BERTONCINI, B. V.; LIMA, E. P. (2004) Estimativa de uma Matriz O-

D Sintética para a Região Central de Maringá utilizando o QuEENsOD. In: XVIII CONGRESSO DE PESQUISA E ENSINO EM TRANSPORTES, Florianópolis, SC. Anais do XVIII ANPET. Rio de Janeiro, RJ: Lagoa, 2004. v. 2, p. 844-855.

DONALD, A. M. (1976) Statistical Mechanics. Harper Collins, New York.

FISK, C. S. (1984) Game theory and transportation systems modeling. Transportation Research Part B, n. 18, p. 301-313.

FISK, C. S. (1988) On combining maximum entropy trip matrix estimation with user optimal assignmenr. Transportation Research Part B, n.22 p. 66-79.

GUR, Y. et al. (1978). Determining an origin-destination trip table based on observed volumes. ORSA-TIMS Annual Meeting, New York, May 1978.

HELLINGA, B.R. (1994) Estimating Dynamic Origin - Destination Demands from Link and Probe Counts. Ph.D. Dissertation, Department of Civil Engineering, Queen's University, Kingston, Ontario, Canada.

HOGBERG, P. (1976). Estimation of parameters in models for traffic prediction: a non-linear approach. Transportation Research Part B, n 10, pp. 263-265.

HOLM, J. et al. (1976). Calibrating traffic models on traffic census results only. Traffic Engineering and Control, n 17, pp. 137-140.

IIDA, Y.; TAKAYAMA, J.; KANEKO, N. (1987) Traffic Demand Estimation Model by Observed Link Flows Considering Trend of Secular Change. Proceedings of JSCE, n. 383/IV10, p. 83-91.

INOUE, H. (1977) Test of accuracy of OD survey and its correction by screen line survey. Traffic Engineering. 12(6), 11-19. 
INOUE, H. (1983) Statistical Estimation of Traffic Demand Using Traffic Census Results. Proceedings of JSCE, n.332, p. 85-94

KANAFANI, A. (1983) Transportation Demand Analysis. McGraw-Hill Book Company, New York.

LOW, D. (1972). A new approach to transportation systems modelling. Traffic Quart., n 26, pp. 391-404.

MAHER, M. J. (1983) Inferences on Trip Matrices from Observations on Link Volumes: A Bayesian Statistical Approach. Transportation Research Part B, n. 17, p. 435-447.

MCNEIL, S.; HENDERICKSON, C. (1985) A Regression Formulation of the Matrix Estimation Problem, Transportation Science, 19, p.278-292

NANDA, D. (1997) A Method to Enhance the Performance of Synthetic Origin-Destination (O-D) Trip Table Estimation Models. Dissertation (Master of Science), Department of Civil and Enviromental Engineering, Virginia Polytechnic Institute and State University, Blacksburg, VA. 99 p.

NGUYEN S. (1977) Estimating an OD matrix from network data: A network equilibrium approach. Publication 87. Centre de Recherche sur les Transports, Université de Montreal.

NIELSEN, O. A.(1993) A New Method for Estimating Trip Matrices from Traffic Counts. Institute of Roads, Traffic, and Town Planning. The Technical University of Denmark, Paper 1993-3.

NIELSEN, O. A.(1998) Two New Methods for Estimating Trip Matrices from Traffic Counts. Travel Behaviour Research: Updating the State of Play. Ed. Elsevier.

NOBLE, B. (1969) Applied Linear Algebra. Prentice-Hall, Englewoodd Cliffs, New Jersey. 
ORTÚZAR, J. D.; WILLUMSEN, L. G. (1994) Modelling Transport. John Wiley \& Sons, Chichester.

PARAMAHAMSAN, H. (1999) Fundamental Properties of Synthetic O-D Generation Formulations and Solutions. Dissertation (Master of Science), Department of Civil and Enviromental Engineering, Virginia Polytechnic Institute and State University, Blacksburg, VA. 133 p.

RAKHA, H. (2001) INTEGRATION Release 2.30 for Windows: User's Guide-Volumes 1 e 2, Michel Van Aerde \& Associates, Ltd, Blacksburg, VA, USA.

RAKHA, H.; VAN AERDE, M.; BLOOMBERG, L.; HUANG, X. (1998) Construction and Calibration of a Large-Scale Microsimulation Model of the Salt Lake Area. Transportation Research Record 1644, p. 93-102.

ROBILLARD, P. (1975) Estimating the O-D Matrix from Observed Link Volumes Transportation Research Part B, n. 9, p. 123-128.

SPIESS, H. (1987) A Maximum Likelihood Model for Estimating Origin-Destination Matrices. Transportation Research Part B, n. 2l, pp 395-412.

SYMONS, J. et al. (1976). A model of inter-city motor travel estimated by link volumes. ARRB Proc.8, pp. 53-65.

VAN AERDE, M. (1998) QUEENSOD - Release 2.10 - User's Guide: Estimating Origin Destination Traffic Demands from Link Flow Counts. Michel Van Aerde \& Associates, Ltd, Blacksburg, VA, USA.

VAN AERDE, M.; RAKHA, H.; PARAMAHAMSAN, H. (2003) Estimation of O-D Matrices: the Relationship between Practical and Theoretical Considerations. Transportation Research Record, 1831, p. 122-130. 
VAN ZUYLEN, H. (1978). The information minimizing method: validity and applicability to transport planning. In. New Developments in Modeling Travel Demand and Urban Systems. Edited by G. R. M. Jansen et al.). Saxon, Farnborough.

VAN ZUYLEN, H. J. (1981) Some improvements in the estimation of an OD matrix from traffic counts. Proc. $8^{\text {th }}$ International Symposiums on Transportation and Traffic Theory, Toronto.

VAN ZUYLEN, H. J.; BRANSTON, D. M. (1982) Consistent Link Flow Estimation From Counts. Transportation Research, n 148, pp 28 I-293.

VAN ZUYLEN, H. J.; WILLUMSEN, L. G. (1980) The Most Likely Trip Matrix Estimated from Traffic Counts. Transportation Research Part B, n. 14, p. 281-293.

WARDROP, J. G. (1952) Some Theoretical Aspects of road Traffic Research. Proc. Inst, Civil Engineers, Part 2, pgs 325-378

WILLUMSEN, L. (1978a) Estimation of an O-D matrix from traffic counts: a review. Institute for Transport Studies. Working paper 99, Leeds University.

WILLUMSEN, L. (1978b) O-D matrices from network data: a comparasion of alternative methods for their estimation. Proc. of PTRC Summer Annual Meeting 1978 Seminar in Transport Models, PTRC Education Research Services Ltd., London.

WILLUMSEN, L. (1979) Estimating the most likely O-D matrix from traffic counts. $11^{\text {th }}$ Annual Conference of Universities Transport Studies Group, University of Southampton, January 1979.

WILLUMSEN, L. G. (1978) Estimation of an O-D matrix from traffic counts: a review. Working Paper 99, Institute for Transport Studies, University of Leeds. 
WILLUMSEN, L. G. (1984) Estimating Time-Dependent Trip Matrices from Traffic Counts. Proceedings of the $9^{\text {th }}$ International Symposium on Transportation and Traffic Theory, The Netherlands, Delft University, July, pp. 397-41 I.

WILSON, A. G.(1970) Entropy in Urban and Regional Modelling. Pion, London.

YANG, H.; SASAKI, T. (1991) An Analysis on the Equilibrium-Based Estimation of OriginDestination Matrices from Traffic Counts. Infrastructure Planning Review 9, n 9. pp 29-36.

YANG, H.; SASAKI, T.; IIDA, Y.; ASAKURA, Y. (1992). Estimation of Origin-Destination Matrices from Link Traffic Counts on Congested Networks. Transportation Research Part B, n 26, pp 417-434.

YANG, H.; IIDA, Y.; SASAKI, T. (1994). The Equilibrium-Based Origin-Destination Matrix Estimation Problem. Transportation Research Part B, n 28, pp. 23-33.

YANG, H. (1995) Heuristic algorithms for the bilevel origin-destination matrix estimation problem. Transportation Research Part B, n 29, p 231-242. 